\section{CATÁlOGO dA BIBLIOTECA dA RAINHA D. CARLOTA JOAQUINA}

The catalogue of Queen Carlota Joaquina's library
Moizeis Sobreira de

\section{SOUSA}

(D) moyses_jesus@hotmail.com

Universidade Estadual

de Campinas

Campinas, SP, Brasil

\section{RESUMO}

Este artigo tem por objetivo apresentar a biblioteca da rainha Carlota Joaquina. Para tanto, tomaremos como base o catálogo dessa biblioteca, documento ainda inédito, que foi escrito em 1831 na Biblioteca da Ajuda, onde permanece intocado desde então. Esse catálogo revela a existência de um acervo incomum para a época. Ele contabiliza 2.366 volumes, número bastante diferente das cifras encontradas em livrarias coetâneas, cuja média girava em torno de 25 unidades.

Palavras-chave: Bibliotecas particulares, História da leitura, Catálogo, Biblioteca da Ajuda, D. Carlota Joaquina

\begin{abstract}
ABSTRAC
This article presents the library of the Queen Carlota Joaquina (1775-1830). In order to do so, the catologue of that library has been used as a basis to our work. That document was written in 1831 at the Biblioteca da Ajuda and have remained untouched ever since. This paper show records of an unusual collection. It contains 2,366 books, which is quite a different amount from contemporany libraries, whose averege was close to 25 books.
\end{abstract}

Keywords: Private libraries, History of reading, Catalogue, The Ajuda Library, D. Carlota Joaquina 


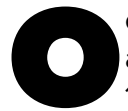
códice manuscrito 51-XIII-7 da Biblioteca da Ajuda, ainda inédito, corresponde ao catálogo da biblioteca que pertenceu à rainha D. Carlota Joaquina (17751830). Intitulado Catálogo da livraria que foi de Sua Majestade a Senhora Dona Carlota Joaquina de Bourbon, esse documento registra um fato quase completamente ignorado pela história até o momento: D. Carlota Joaquina formou uma biblioteca para uso particular ${ }^{1}$, ato que pode ser traduzido como manifestação de interesse pelo universo dos livros, e reflexo da formação intelectual privilegiada que recebeu desde os primeiros anos de idade ${ }^{2}$, o que sem dúvida contribuiu para que ela se transformasse em uma mulher bastante culta e instruída ${ }^{3}$.

O Catálogo da livraria que foi de Dona Carlota Joaquina data de 1831. Embora ele não ofereça indicações conclusivas sobre o local e as circunstâncias em que foi redigido, é razoável supor que esse processo tenha se dado na Biblioteca da Ajuda (então Real Biblioteca da Ajuda), instituição que o mantém guardado desde então e para onde foram enviadas as obras referidas nele, fato este ocorrido provavelmente na sequência da morte da rainha, que se deu um ano antes, em $1830^{4}$.

Por ser de natureza post-mortem, esse catálogo dirige o olhar para uma representação global e definitiva da biblioteca, pretensão aliás expressa no título, que se afirma como Catálogo da livraria que foi de Sua Majestade, deixando entrever a imagem de um documento que se propõe a condensar a totalidade desse acervo. De fato, ele se credencia como via para se chegar até essa biblioteca, na impossibilidade de acessá-la em sua dimensão física, já que foi desmembrada em outro acervo (de natureza familiar e patrimonial), o que a fez perder seu desenho original e caráter particular.

Sem perder de vista que o catálogo da biblioteca de D. Carlota Joaquina não garante o registro de todas as obras que ela terá possuído em vida - podendo ter sido resultado das escolhas de quem o redigiu e/ou de testamenteiros ${ }^{5}-$, ainda assim permanece como fonte para se conhecer essa biblioteca, pois disponibiliza informações sobre um conjunto de livros/escritos que, a despeito de corresponder ou não à totalidade do acervo, seguramente compõe a maior parte dele, o que abre caminho para se mapear suas características e reconstituir seu processo de formação. Além disso, oferece subsídios para identificar virtuais preferências de leitura ou a simples posse de livros por parte da rainha, permitindo estabelecer pontos de convergência entre sua biblioteca e os papéis sociais que lhe foram reservados, de maneira a verificar o quanto essa coleção buscou (ou não) responder ao desejo de fornecer à sua proprietária patrimônio simbólico-material para o desempenho desses papéis.

A análise global desse catálogo revela um acervo extenso em quantidade de obras e plural em conteúdos. Ao todo, ele registra 2366 volumes, o que equivale a aproximadamente 1241 entradas. Desse montante, 2298 volumes correspondem a impressos (livros, em sua grande maioria, folhetos, periódicos e um incunábulo), e 68 são manuscritos. A título de ilustração, essas dimensões ultrapassam consideravelmente o tamanho das bibliotecas femininas (conhecidas) das últimas décadas do século $X V I I I$, e as três primeiras do século $X X^{6}$, que, mesmo em situações excepcionais, não excediam 600 volumes, levando a pensar que o acervo da rainha Carlota Joaquina 
pode ter sido um dos maiores, talvez o maior, em posse de uma mulher nesse período, destancando-se inclusive entre coleções que perteceram a mulheres da nobreza e família real.

Nos termos desse extenso volume de entradas, cabe destacar um repertório de obras inequivocamente heterogêneo, assinalado pela diversidade de autores, textos e categorias. A escritora inglesa Mary Wollstonecraft (1759-1797), assumida como precursora do feminismo, aparece aí ao lado da freira portuguesa Sóror Madalena da Glória (1672-1760), autora de textos de edificação; os clássicos Aristóteles e Santo Agostinho coexistem com contemporâneos a D. Carlota Joaquina, como Jane Austen (1775-1817), Chateaubriand (1768-1848) e José Daniel Rodrigues da Costa (1757-1832); obras de cunho iluminista, como Del Contrato Social: o principios del derecho político $(1810)^{7}$, de Rousseau, convivem com o pensamento absolutista de José Agostinho de Macedo (1761-1831), Jacques-Bénigne Bossuet (1627-1704) e José Acúrsio das Neves (1766-1834); Oeuvres complètes (1795), de Gabriel Mably (1709-1785), conhecido por constestar o poder régio, dividem espaço com Oeuvres (1799), de Maquiavel, e algumas dezenas de panegíricos que enaltecem as casas reais de Bragança e Bourbon; inúmeros textos de devoção (novenas, hagiografias e cartas pastorais) contemporizam com romances e livros de natureza científica.

Ao procedermos à ordenação dessas entradas por áreas temáticas, identificamos estas categorias: romance, religião, política, história, ciências, panegírico, poesia, jurisprudência, teatro, biografia, imprensa periódica, gramática, correspondência, história/crítica literária e música.

Essa variedade de temas constrasta com o que se conhece até o momento sobre as bibliotecas femininas setecencistas, cuja lógica de composição tendia para a orientação canônica, em que a predominância ou mesmo exlusividade de textos ligados à religião parecia corresponder "à realidade da posse de livros pela maioria das mulheres” (ANASTÁCIO, 2013, p. 53). A predileção por obras de natureza religiosa era comum a mulheres tanto da elite quanto das camadas inferiores, como salienta Ana Cristina Duarte Pereira (2008). Embora seja recorrente no catálogo da biblioteca da rainha Carlota Joaquina - aparecendo como o tema que concentra o segundo maior número de obras -, esse segmento não consegue ser hegemônico. Ele divide espaço aí com obras sobre política, história, geografia, ciências e filosofia, áreas temáticas que também têm relevância, além de indicarem o alargamento dos conteúdos na direção de uma cultura escrita secularizada e, no caso específico das duas últimas categorias, de uma mentalidade que parece ecoar o pensamento iluminista. Aliás, não deixa de causar surpresa que uma mulher, que ficou guardada no imaginário intelectual como devassa e conspiradora, tenha possuído uma quantidade significativa de textos religiosos.

A categoria que reúne a maior quantidade de títulos/entradas no catálogo é o romance ${ }^{8}$, gênero que, no contexto dos séculos XVIII e XIX, foi considerado com frequência um antagonista ideológico e editorial da religião, a ponto de protagonizar uma mudança sensível no panorama cultural da época ${ }^{9}$. Mudança essa perceptível na tendência que combinou o decréscimo de edições de textos religiosos e a ascensão 
do romance na preferência do público em geral, movimento que a biblioteca da rainha Carlota Joaquina parece captar.

O romance responde por aproximadamente 17\% desse acervo, proporção que, além de indicar o peso expressivo que esse gênero possui, garante-lhe a possibilidade de marcar presença de variadas formas, englobando romances antológicos, como $O$ engenhoso fidalgo Dom Quixote de la Mancha (1794) e Pamela (1799); best-sellers, como Les aventures de Télémaque (1810) e Aventuras de Gil Blas de Santillana (1805); picarescos, como Vida, e acçoens celebres, e graciosas de Gusmão de Alfarache (1792) e Le diable boiteux (1775); licenciosos, como Le comte de Valmont, ou les Égaremens de la raison (1784): didáticos, como Brados do Desegano contra o Profundo Sono do Esquecimento (1736); góticos - L’Abbaye de Lussington (1807) e Angelo Guicciardini, ou le Bandit des Alpes (1817); pastoris - Estelle Partorale (1812); e contemporâneos Os martyres (1810) e Le Parc de Mansfield (1816).

Entre esses romances, há dois que ainda são inéditos. Trata-se de dois manuscritos que foram descobertos recentemente no âmbito da pesquisa que desenvolvi no acervo da Biblioteca da Ajuda, com o objetivo de localizar os livros que pertenceram à rainha D. Carlota Joaquina. São eles Deolinda e Deonel, de Maria do Livramento Spencer, e Novela familiar instructiva, de José Joaquim Carneiro de Miranda e Costa, escritos no Brasil entre o final do século XVIII e começo do século XIX, em data anterior aos textos que são considerados precursores do romance no país, o que confere a esses dois inéditos bastante relevância histórica, pois torna possível ampliar o que se sabe atualmente sobre a história desse gênero no Brasil.

A afluência de romances na biblioteca da rainha Carlota Joaquina também pode ser traduzida como uma extrapolação ao perfil especializado da biblioteca principesca, que em tese era voltado à realidade institucional dos príncipes, configurando-se como espaço de promoção da cultura erudita e de exibição de poder, em que o romance, gênero desprovido de capital político e ascedência nobre à época, parecia não ter lugar garantido ${ }^{10}$. Nesse sentido, a coleção supramencionada não se limitou a subsididar a ilustração de alguém que integrava a elite política e intelectual; era também permeável a objetos impressos não especializados, isto é, voltados a um público geral, como parecia ser o caso do romance ${ }^{11}$. Resta saber se esse gênero também tinha penetração equivalente em outras coleções coetâneas e com características semelhantes, demostrando que sua circulação já era fluida o bastante para estender seu lastro por diversos segmentos, ou se era apenas um dado que diferenciava a biblioteca em questão.

Dos temas que integram a ilustração principesca, a política é um dos que mais se destacam no catálogo dessa biblioteca. Essa constante repercute certamente na atuação da rainha $\mathrm{D}$. Carlota Joaquina no campo do poder, espaço em que ela foi uma das protagonistas mais destacadas, tendo sido a mulher mais poderosa, ou que mais disputou poder político, no mundo luso-brasileiro que vai do final do século XVIII até as três primeiras décadas do século seguinte. Entre os textos relacionados à política, constam inúmeros manifestos - Dictamen proponiendo para regenta del reyno a la serenísima señora D. Carlota Joaquina de Borbón -, circulares - Carta 
circular del Excmo. Sr. Obispo de Orense -, representações - Representacion de Don Josef Fernandez de Castro al soberano Congreso de las Cortes Nacionales -, discursos - Discurso pronunciado por el Sr. D. Francisco Rodríguez de Ledesma, presidente de las Cortes generales ordinarias, folhetos - Sentinela contra franceses -, tratados - Tratado de amizade, e aliança entre o Príncipe Regente de Portugal, e El-Rey da Gram-Bretanha -, periódicos - Diários das Cortes - e exemplares da Constituição Política da Monarquia Portuguesa (1822) e da Constitución de Cádiz (1812). Esses escritos põem em evidência o trânsito da rainha Carlota Joaquina pelo universo da política, em especial a sua atuação para se tornar regente da Espanha (1808-1812), e a luta antiliberal travada a partir de 1821.

Os textos dessa seção recobrem um amplo espectro ideológio, ecoando desde o pensamento iluminista, como em Esquisse d'un tableau historique des progrès de l'esprit humain, de Condorcet, passando pelas ideias liberais em Observaciones sobre la probable disolución del Estado, de Juan Romero Alpuente, até chegar à reação absolutista, presente em escritos como Mémoires pour servir à l'histoire du Jacobinisme, de Augustin de Barruel, o que, uma vez mais, comprova o caráter plural dessa biblioteca.

As obras que compõem a biblioteca de D. Carlota Joaquina foram editadas em 15 países e/ou territórios, todos eles compreendidos no espaço transatlântico situado entre os continentes europeu e americano. São eles Portugal, França, Espanha, Inglaterra, Bélgica, Itália, Alemanha, Suiça, Malta, Holanda, Áustria, Brasil, Argentina, Colômbia e Cuba (Gráfico 1).

Desses países, Portugal, França, Espanha, Brasil são respectivamente os locais em que se concentram a maior parte das edições. Em primeiro lugar, esses dados mostram

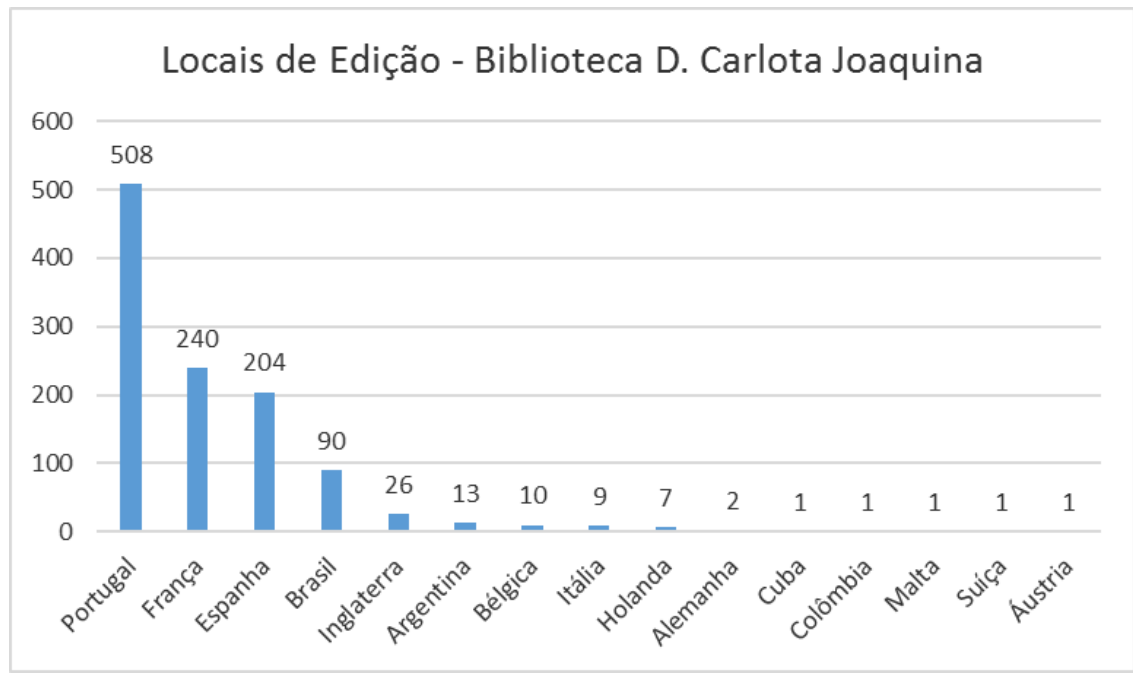

Gráfico 1: Distribuição dos locais de edição - Biblioteca Carlota Joaquina 
Portugal como polo dominante nesse aspecto, proporção que está em consonância com a tendência verificada nas bibliotecas femininas portuguesas do século XVIII. Além disso, mostram um trânsito de livros e impressos entre Portugal e diversas outras praças europeias e americanas, o que, em alguma medida, contribui para afastar a ideia de que o país era fechado ao contato com outras nações, sobretudo com as do Velho Continente. Em segundo lugar, detectam a presença ascendente da França, frequência que se intensificará no século XIX, e da Espanha, não muito comum nas bibliotecas femininas portuguesas do período, mas que pode aqui ser explicada pelo fato de a Espanha ser o país de origem de D. Carlota Joaquina, o qual permaneceu como alvo dos seus interesses mesmo após sua ida para Portugal. Em último lugar, chama atenção o fato de o Brasil surgir em quarto lugar nessa lista, o que parece ser um dado bastante significativo, porque demonstra o quanto essa biblioteca abarca áreas situadas além das fronteiras europeias, atingindo a América, com a presença do Brasil e de outros terrirórios, Argentina, Colômbia e Cuba, o que assegura a interface transatlântica dessa cartografia. Com isso, na biblioteca da rainha Carlota Joaquina detecta-se a circulação/produção dos impressos em uma geografia que já não é mais exclusivamente europeia, mas em deslocamento global, traço que a singulariza.

A importância que a presença do Brasil tem nesse cenário não é certamente apenas quantitativa. Acima de tudo, o que está em jogo é o fato de esses livros estarem entre os primeiros impressos publicadas no Brasil pela via legal, consequência da implantação da Impressão Régia do Rio de Janeiro em 1808, por ordem do princípe regente $\mathrm{D}$. João. A implantação da Impressão Régia está intimamente ligada à chegada da família real portuguesa ao Brasil em 1808, evento ao qual D. Carlota Joaquina esteve diretamente ligada. Esse acontecimento inverte a lógica do pacto colonial que prendia Portugal e Brasil até aquela data e, ato contínuo, a direção do fluxo livresco, que, antes compreendido apenas no sentido Lisboa-Rio de Janeiro, passa então a incluir o outro lado do caminho, a rota Rio de Janeiro/Lisboa.

A biblioteca da rainha Carlota Joaquina, nesse sentido, assume a condição de testemunha dos desdobramentos históricos decorrentes da transferência da família real portuguesa para o Brasil, além de repercuti-los em sua formação. Os livros que integram esse acervo e têm o Brasil como local de edição, em especial os romances, fazem parte da história desse gênero no Brasil, espaço em que ajudam a formar uma rede de produção e circulação local, da qual também findam por se alimentar, absorvendo obras como O diabo coxo (1810), Paulo e Virgínia (1806), Cartas de huma peruviana (1812) e Aventuras pasmozas do célebre Barão Munkausen (1814), romances que estão entre as primeiras obras de ficção publicadas no Brasil pela via legal.

Tendo em vista a importância do catálogo da biblioteca da rainha D. Carlota Joaquina como fonte documental para o estudo da história da leitura no Brasil e em Portugal, bem como para lançar luz sobre a trajetória dessa rainha, que ainda tem sua imagem associada a uma série de distorções cristalizadas na historiografia e no imaginário intelectual luso-brasileiro, propomo-nos aqui a disponibilizar uma edição deste documento, sobre o qual cabe referir antes algumas de suas características materiais e os critérios adotados para editá-lo. 
Ele é composto por 78 fólios encadernados (figuras 1a, b) e organizados em duas seções, uma contendo obras impressas, e outra manuscritos. Na primeira, as informações estão dispostas em tabelas com seis colunas, nas quais aparecem respectivamente o nome do autor, título das obras, volume (quantidade por cada obra), estante, casinha (subdivisão da estante) e número de obras por fólio (figura 2). $\mathrm{Na}$ segunda, além dessas colunas, foi acrescentada uma sétima, reservada para o código de identificação que as obras receberam ao serem catalogadas na Biblioteca da Ajuda (figura 3).

Nem todas as colunas foram utilizadas por quem elaborou o catálogo, como se pode observar nas imagens que seguem. No caso da seção dos impressos, apenas as destinadas aos autores, títulos e volumes foram preenchidas. Já na seção de manuscritos foram utilizadadas as três primeiras e a última. Por essa razão, preferimos descartar as colunas que não contêm informação.

No catálogo, as entradas/títulos aparecem ordenadas com base em um critério alfabético, que se vale ora dos nomes dos autores, ora dos títulos (figura 3), lógica que foi seguida nesta edição. Ao efetuarmos a transcrição dos dados, buscamos preservar a ortografia dos títulos, dispondo-os tal como aparecem no documento, mesmo quando notamos a existência de termos grafados em desacordo com as normas atualmente em vigor. Em relação aos nomes dos autores, optamos por atualizar a ortografia. Nos casos em que os nomes dos autores não foram registrados no catálogo, preferimos deixar em branco o espaço reservado para essa informação, mesmo quando sabíamos quem era o autor ou autora da obra registrada.

Em caráter de exceção, as alterações realizadas na grafia dos títulos ocorreram nos casos em que havia abreviações, pois em algumas situações poderiam dificultar a identificação da obra por conter dados insuficientes - como o caso da entrada Académie des Jeux, que aparece na transcrição como Académie [Universelle] des Jeux -, ou poderiam confundir a obra registrada com outras edições do mesmo título, como foi o caso da entrada Elogio Historico do Serenissimo Senhor Infante Dom Pedro Carlos de Bourbon e Bragança, que foi acrescida do seguinte: [Almirante General da Armada Real Portugueza. Composto, e Dedicado ao Principe Nosso Senhor o Senhor Dom João, Principe Regente de Portugal e das Conquistas]. Também efetuamos mudanças nas situações em que ficou claro que a redação do catálogo discrepava em relação à ortografia dos títulos relacionados. Para tanto, fizemos o cotejo do catálogo com as edições correspondentes das obras, que foram consultadas diretamente na biblioteca da Ajuda ou por meio da base de dados da Biblioteca Nacional de Lisboa, Biblioteca Nacional do Rio de Janeiro, Bibliothèque Nationale de France e Biblioteca 


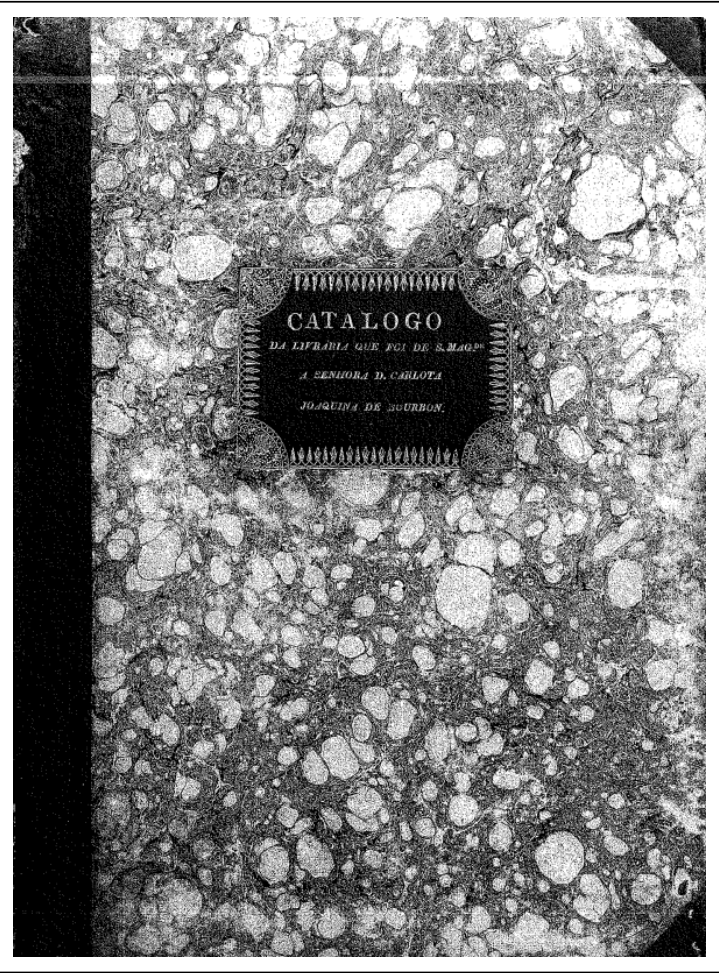

Figura 1a. Capa do catálogo da biblioteca da rainha D. Carlota Joaquina 


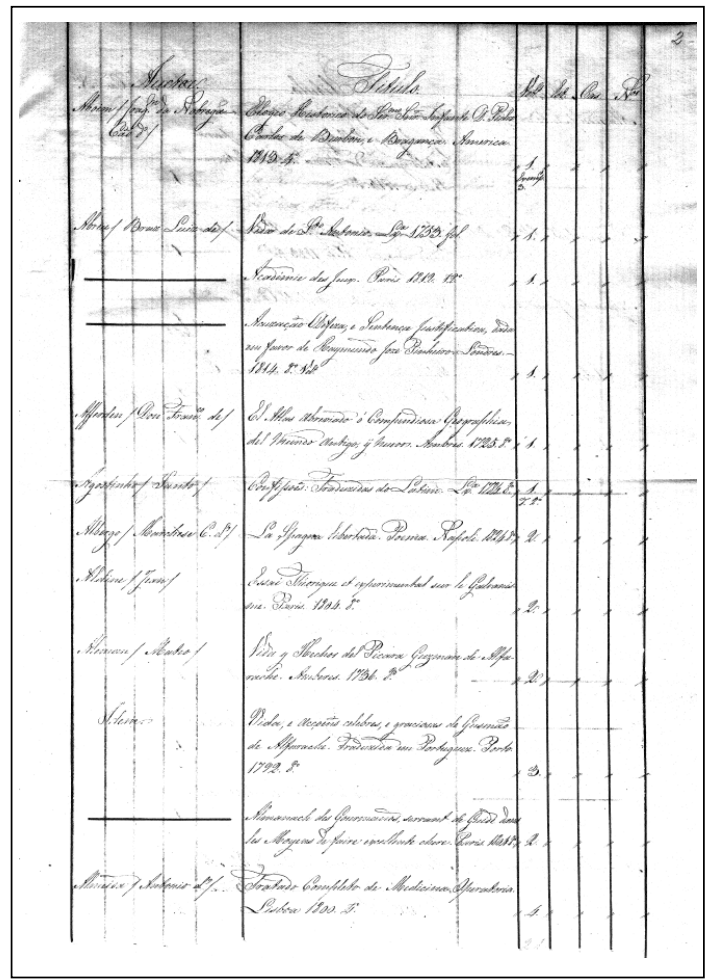

Figura 1b. Folha de rosto do catálogo da biblioteca da rainha D. Carlota Joaquina 


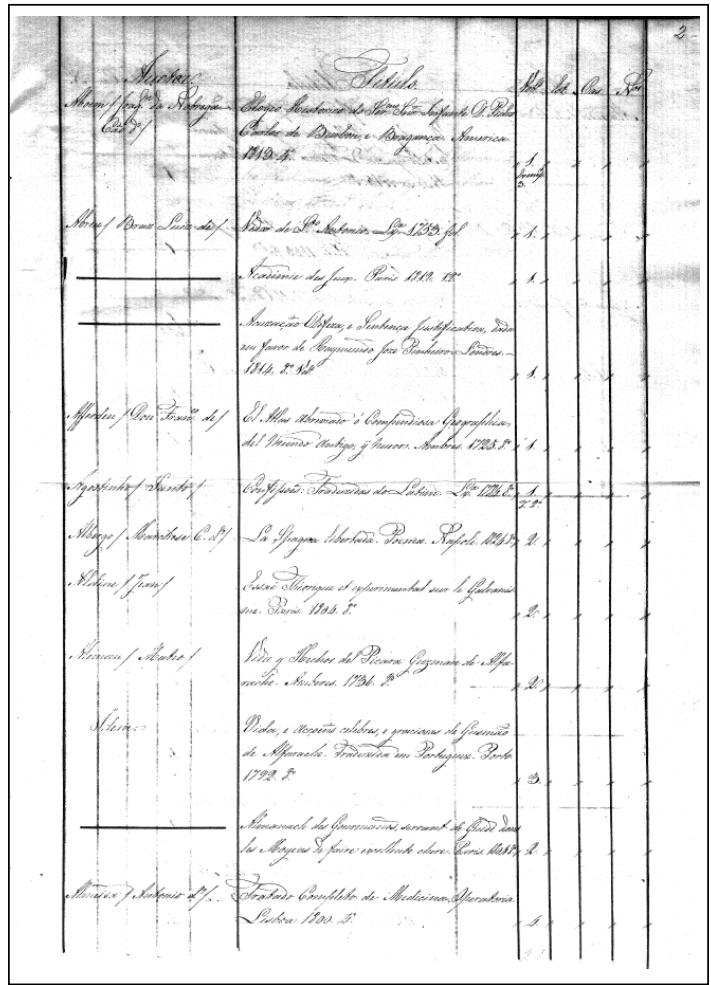

Figura 2. Fólio 2, Seção de impressos do catálogo da biblioteca da rainha D. Carlota Joaquina. 


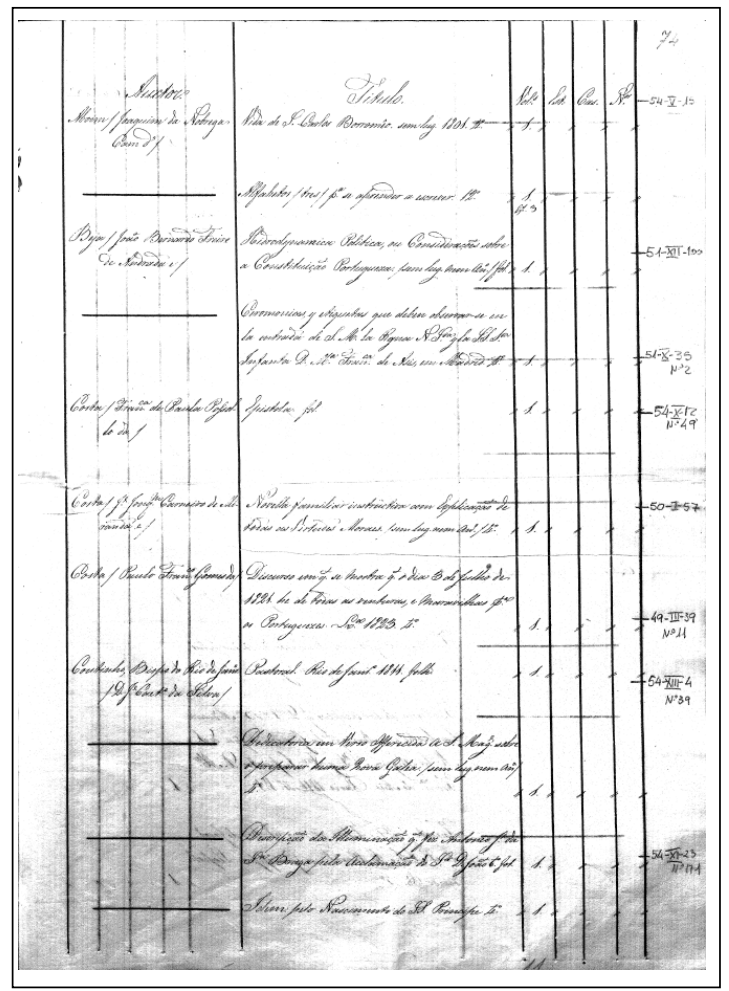

Figura 3. Fólio 74, Seção de manuscritos da biblioteca da rainha D. Carlota Joaquina. 
Nacional de España.

Catálogo da livraria que foi de Sua Majestade a Imperatriz Rainha a Senhora Dona Carlota Joaquina de Bourbon

\begin{tabular}{|c|c|c|}
\hline Autor & Título & Vol \\
\hline $\begin{array}{l}\text { Aboim/ Joaquim da } \\
\text { Nóbrega Cão de/ }\end{array}$ & $\begin{array}{l}\text { Elogio Historico do Serenissimo Senhor Infante Dom } \\
\text { Pedro Carlos de Bourbon e Bragança [Almirante } \\
\text { General da Armada Real Portugueza. Composto, e } \\
\text { Dedicado ao Principe Nosso Senhor o Senhor Dom } \\
\text { João, Principe Regente de Portugal e das Conquistas] } \\
\text { Rio de Janeiro. } 1813.4^{\circ} \text {. }\end{array}$ & 1 \\
\hline \multirow[t]{3}{*}{ Abreu/ Braz Luís de/ } & $\begin{array}{l}\text { Vida de Santo Antonio } \\
\text { Lisboa. 1753. Fol. }\end{array}$ & 1 \\
\hline & $\begin{array}{l}\text { Académie [Universelle] des Jeux } \\
\text { Paris. } 1812.12^{\circ} .\end{array}$ & 1 \\
\hline & $\begin{array}{l}\text { Acuzação, Defeza, e Sentença Justificativa, Dada } \\
\text { em Favor de Raymundo Joze Pinheiro } \\
\text { Londres. } 1814.8^{\circ} .\end{array}$ & 1 \\
\hline $\begin{array}{l}\text { Aefferden/ } \\
\text { Francisco de/ }\end{array}$ & $\begin{array}{l}\text { El Atlas Abreviado, ò Compendiosa Geographia } \\
\text { del Mundo Antigo, y Nuevo } \\
\text { Antuérpia. } 1725.8^{\circ} \text {. }\end{array}$ & 1 \\
\hline Agostinho/ Santo/ & $\begin{array}{l}\text { Confissões: Traduzidas do Latim } \\
\text { Lisboa. } 1784.8^{\circ} .\end{array}$ & $\begin{array}{c}1 \\
\text { Tomo } 2^{\circ}\end{array}$ \\
\hline $\begin{array}{l}\text { Albergo/ Marchese } \\
\text { C. D'/ }\end{array}$ & $\begin{array}{l}\text { La Spagna Liberata. Poema } \\
\text { Nápoles. } 1824.8^{\circ} .\end{array}$ & 2 \\
\hline Aldini/ Jean/ & $\begin{array}{l}\text { Essai Theórique et Expérimental sur le Galvanisme } \\
\text { Paris. } 1804.8^{\circ} .\end{array}$ & 2 \\
\hline Alemán/Mateo/ & $\begin{array}{l}\text { Vida y Hechos del Picaro Guzman de Alfarache } \\
\text { Antuérpia. 1736. } 8^{\circ} .\end{array}$ & 20 \\
\hline \multirow[t]{2}{*}{ Alemán/Mateo/ } & $\begin{array}{l}\text { Vida, e Acçoens Celebres, e Graciosas de Gusmão } \\
\text { de Alfarache. Traduzida em Portuguez } \\
\text { Porto. } 1792.8^{\circ} .\end{array}$ & 3 \\
\hline & $\begin{array}{l}\text { Almanach des Gourmands, Servant de Guide dans } \\
\text { les Moyens de Faire Excellente Chère } \\
\text { Paris. } 1804.8^{\circ} .\end{array}$ & 2 \\
\hline
\end{tabular}




\begin{tabular}{|c|c|c|}
\hline Autor & Título & Vol \\
\hline Almeida/ Antônio de/ & $\begin{array}{l}\text { Tratado Completo de Medicina Operatória } \\
\text { Lisboa. } 1800.4^{\circ} .\end{array}$ & 4 \\
\hline Almeida/ Antônio de/ & $\begin{array}{l}\text { Tratado da Inflammação Precedido da Physiologia, e } \\
\text { Pathologia Necessarias para Intelligencia da Theoria } \\
\text { desta Molestia } \\
\text { Londres. } 1814.8^{\circ} .\end{array}$ & 1 \\
\hline $\begin{array}{l}\text { Almeida/ Antônio } \\
\text { Pereira de/ }\end{array}$ & $\begin{array}{l}\text { Requerimento em que Pede Portaria } \\
\text { para Poder Advogar } \\
\text { Porto. 1822. Fol. }\end{array}$ & 1 \\
\hline $\begin{array}{l}\text { Alpuente/ Juan } \\
\text { Romero/ }\end{array}$ & $\begin{array}{l}\text { Observaciones sobre la Probable Disolucion del Estado } \\
\text { Madrid. 1823. } 4^{\circ} \text {. }\end{array}$ & 1 \\
\hline $\begin{array}{l}\text { Alpuente/ Juan } \\
\text { Romero/ }\end{array}$ & $\begin{array}{l}\text { Wellington en España y Ballesteros en Ceuta } \\
\text { Cádis. 1813. } 4^{\circ} \text {. }\end{array}$ & 1 \\
\hline \multirow[t]{2}{*}{$\begin{array}{l}\text { Alpuente/ Juan } \\
\text { Romero/ }\end{array}$} & $\begin{array}{l}\text { Wellington en España y Ballesteros en Ceuta } \\
\text { Cádis. 1813. } 4^{\circ} \text {. }\end{array}$ & 1 \\
\hline & $\begin{array}{l}\text { Alvará por que Sua Magestade Há por Bem Fazer } \\
\text { Mercê do Tratamento de Senhoria aos Brigadeiros etc } \\
\text { Rio de Janeiro. 1821. Fol. }\end{array}$ & 1 \\
\hline \multirow[t]{4}{*}{ Alvear/ Carlos/ } & $\begin{array}{l}\text { Exposicion que Hace [el Señor Brigadier Don Carlos } \\
\text { Alvear General en Xefe del Exercito Sitiador de } \\
\text { Montevideo,] de su Conducta en la Rendicion de } \\
\text { [esta Plaza] } \\
\text { Buenos Aires. 1814. Fol. }\end{array}$ & 1 \\
\hline & $\begin{array}{l}\text { Alzira. /Dramma/ } \\
\text { Lisboa. } 1803.8^{\circ} .\end{array}$ & 1 \\
\hline & $\begin{array}{l}\text { Amante /L'/ per Forza. /Dramma/ } \\
\text { Lisboa.1805. } 8^{\circ} .\end{array}$ & 1 \\
\hline & $\begin{array}{l}\text { Amante /EI/ de la Libertad Civil } \\
\text { Cadiz. } 1813.4^{\circ} .\end{array}$ & 2 \\
\hline $\begin{array}{l}\text { Amaral/ Antônio } \\
\text { Caetano do/ }\end{array}$ & $\begin{array}{l}\text { Memorias para a Historia da Vida do Veneravel } \\
\text { Arcebispo de Braga Dom Frei Caetano Brandão } \\
\text { Lisboa. } 1818.4^{\circ} .\end{array}$ & 2 \\
\hline Ambrósio/ Santo/ & $\begin{array}{l}\text { [Os Tres Livros das] Obrigaçoens Christans, e Civis } \\
\text { Lisboa. } 1768.8^{\circ} \text {. }\end{array}$ & 1 \\
\hline
\end{tabular}




\begin{tabular}{|c|c|c|}
\hline Autor & Título & Vol \\
\hline & $\begin{array}{l}\text { Ame /L/ Élevée a Dieu, par les Réflexions et les } \\
\text { Sentimens, pour chaque Jour du Mois } \\
\text { Toulouse. } 1804.8^{\circ} .\end{array}$ & 2 \\
\hline \multirow[t]{2}{*}{ Ambrósio/ Santo/ } & $\begin{array}{l}\text { Americani /Gli/. Dramma. } \\
\text { Lisboa. } 1803.8^{\circ} .\end{array}$ & 1 \\
\hline & $\begin{array}{l}\text { Amis /Les Deux/ } \\
\text { Londres. } 1802.8^{\circ} .\end{array}$ & $\begin{array}{c}1 \\
\text { Tomo } 1^{\circ}\end{array}$ \\
\hline $\begin{array}{l}\text { Andrade/ Joaquim } \\
\text { Navarro de/ }\end{array}$ & $\begin{array}{l}\text { Carta Apologetica, e Analytica ao Redator do Periodico } \\
\text { Intitulado o Portuguez, [Impresso em Londres] } \\
\text { Lisboa. } 1822.8^{\circ} \text {. }\end{array}$ & 1 \\
\hline $\begin{array}{l}\text { Andrade/ Joaquim } \\
\text { Navarro de/ }\end{array}$ & $\begin{array}{l}\text { Representação ás Côrtes Geraes, Extraordinarias, } \\
\text { e Constituintes da Nação Portugueza } \\
\text { Coimbra. 1822. Fol. }\end{array}$ & $\begin{array}{c}1 \\
\text { Exemplar } 2\end{array}$ \\
\hline \multirow[t]{2}{*}{$\begin{array}{l}\text { Ana/ Frei José Pereira } \\
\text { de Santa }\end{array}$} & $\begin{array}{l}\text { Vida da [Insigne Mestra de Espirito, a Virtuosa] Madre } \\
\text { Maria Perpetua da Luz, [Religiosa Carmelita Calçada } \\
\text { do Exemplarissimo Convento da Esperança, da Cidade } \\
\text { de Beja, onde acabou a Vida Temporal no dia } 6 \text { de } \\
\text { Agosto de 1736] } \\
\text { Lisboa. 1742. Fol. }\end{array}$ & 1 \\
\hline & $\begin{array}{l}\text { Anno /L'/ Cristiano Contenente I'Epistole, e I Vangeli. } \\
\text { Traduzione dal Francese del. Sig. Conte Gaspare Gozzi } \\
\text { Veneza. } 1761.8^{\circ} .\end{array}$ & 13 \\
\hline Anquetil & $\begin{array}{l}\text { Compendio de la Historia Universal ó Pintura Histórica } \\
\text { de Todas las Naciones. Traducida por el Padre Dom } \\
\text { Francisco Vazquez } \\
\text { Madrid.1801. } 8^{\circ} .\end{array}$ & 17 \\
\hline Anquetil & $\begin{array}{l}\text { Histoire de France depuis les Gaulois jusqu'à la Mort } \\
\text { de Louis XVI } \\
\text { Paris. } 1813.8^{\circ} .\end{array}$ & 16 \\
\hline Antoine/ A./ & $\begin{array}{l}\text { Le Chansonnier des Fêtes de Famille, ou Recueil } \\
\text { de Chanssons et Complimens pour Fêtes, Premier Jour } \\
\text { de L'An, Mariages, Baptêmes } \\
\text { Paris. Sem ano. } 12^{\circ} \text {. }\end{array}$ & 1 \\
\hline Antônio/ Dom Frei/ & $\begin{array}{l}\text { Historia de la Esclarecida Vida, y Milagros del } \\
\text { Bienaventurado, San Juan de Dios } \\
\text { Madrid. 1659. } 4^{\circ} \text {. }\end{array}$ & 1 \\
\hline $\begin{array}{l}\text { Antônio/ João } \\
\text { Bautista de Santo/ }\end{array}$ & $\begin{array}{l}\text { Paraiso Serafico } \\
\text { Lisboa. 1734. Fol. }\end{array}$ & 2 \\
\hline
\end{tabular}




\begin{tabular}{|c|c|c|}
\hline Autor & Título & Vol \\
\hline $\begin{array}{l}\text { Antônio/ José } \\
\text { de Santo/ }\end{array}$ & $\begin{array}{l}\text { Vitorias dos Impossiveis Conseguidas em Tres } \\
\text { Campanhas da Vida, Morte \& Bemaventurança da } \\
\text { Beata Rita de Cassia } \\
\text { Lisboa. } 1718.4^{\circ} .\end{array}$ & 1 \\
\hline \multirow[t]{3}{*}{ Antônio/ Manoel/ } & $\begin{array}{l}\text { Novena do Gloriozo Principe dos Apostolos São Pedro } \\
\text { Lisboa. } 1740.8^{\circ} \text {. }\end{array}$ & 1 \\
\hline & $\begin{array}{l}\text { Apéndice al Dictamen del Doctor Don Antonio José } \\
\text { Ruiz de Padron sobre el Tribunal de la Inquisicion } \\
\text { Cadiz. } 1813.4^{\circ} \text {. }\end{array}$ & $\begin{array}{c}1 \\
\text { Exemplar } 2\end{array}$ \\
\hline & $\begin{array}{l}\text { Apologia da Conducta de Joze Anselmo Correa contra } \\
\text { as Asserções Mentirozas do Correio Braziliense } \\
\text { Sem lugar e ano. } 8^{\circ} \text {. }\end{array}$ & 1 \\
\hline Araújo/ José de Sousa & Memorias Historicas do Rio de Janeiro & 1 \\
\hline \multirow[t]{4}{*}{ Azevedo Pizarro e/ } & Rio de Janeiro. 1820. $4^{\circ}$. & Tomo $2^{\circ}$ \\
\hline & $\begin{array}{l}\text { Archivos da Religião Christã } \\
\text { Coimbra. } 1823.4^{\circ} \text {. }\end{array}$ & $\begin{array}{c}1 \\
\text { Tomo } 2^{\circ}\end{array}$ \\
\hline & $\begin{array}{l}\text { Archivos da Religião Christã } \\
\text { Coimbra. } 1823.4^{\circ} .\end{array}$ & $\begin{array}{c}3 \\
\text { Tomo } 2^{\circ} \\
3^{\circ} \text { e } 5^{\circ}\end{array}$ \\
\hline & $\begin{array}{l}\text { Arganide /L'/ o Sia il Ritorno di Serse. Dramma } \\
\text { Lisboa. } 1804.8^{\circ}\end{array}$ & $\begin{array}{c}1 \\
\text { Exemplar } 2\end{array}$ \\
\hline \multirow[t]{2}{*}{$\begin{array}{l}\text { Argote/ Jerônimo } \\
\text { Contador de/ }\end{array}$} & $\begin{array}{l}\text { Vida, e Milagres de São Caetano Thiene } \\
\text { Lisboa. } 1722.4^{\circ} .\end{array}$ & 1 \\
\hline & $\begin{array}{l}\text { Argumentos da Obra Historica, Politica, Moral que } \\
\text { Representa Dezoito Acontecimentos da Passada Época } \\
\text { Lisboa. 1820. Fol. }\end{array}$ & 1 \\
\hline Aristóteles & $\begin{array}{l}\text { Politique: Traduite du Grec par Charles Millon } \\
\text { Paris. 1803. } 8^{\circ} .\end{array}$ & $\begin{array}{c}1 \\
\text { Tomo } 3^{\circ}\end{array}$ \\
\hline $\begin{array}{l}\text { Arnaud/ François- } \\
\text { Thomas-Marie de } \\
\text { Baculard D'/ }\end{array}$ & $\begin{array}{l}\text { Delassemens de I'Homme Sensible, } \\
\text { ou Anecdotes Diverses } \\
\text { Paris. } 1784.8^{\circ} .\end{array}$ & 6 \\
\hline $\begin{array}{l}\text { Arnaud/ François- } \\
\text { Thomas-Marie de } \\
\text { Baculard D'/ }\end{array}$ & $\begin{array}{l}\text { Épreuves du Sentiment } \\
\text { Paris. } 1792.8^{\circ} .\end{array}$ & 6 \\
\hline $\begin{array}{l}\text { Arnaud/ François- } \\
\text { Thomas-Marie de } \\
\text { Baculard D'/ }\end{array}$ & $\begin{array}{l}\text { Eufemia, ou o Triunfo da Religião. Traduzida } \\
\text { por Manuel Maria de Barbosa du Bocage } \\
\text { Rio de Janeiro. } 1811.4^{\circ} .\end{array}$ & 1 \\
\hline
\end{tabular}




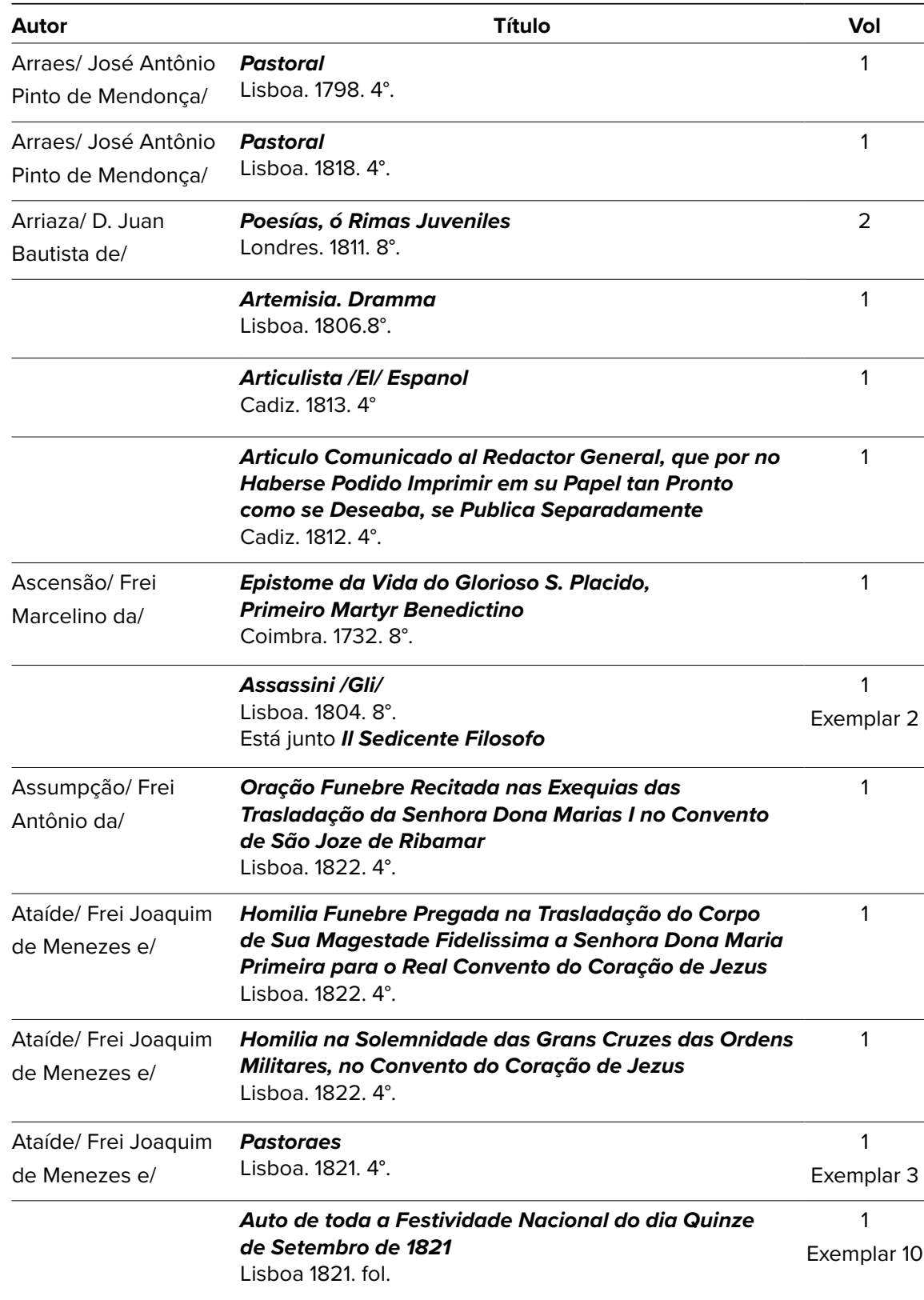




\begin{tabular}{|c|c|c|}
\hline Autor & Título & Vol \\
\hline & $\begin{array}{l}\text { Auto do Juramento da Constituição, } \\
\text { por El Rey Dom João VI } \\
\text { Rio de Janeiro. fol. }\end{array}$ & 1 \\
\hline $\begin{array}{l}\text { Ataíde/ Frei Joaquim } \\
\text { de Menezes e/ }\end{array}$ & $\begin{array}{l}\text { Autos de Libello Crime entre Partes: Author a Justiça } \\
\text { pela Pessoa de seu Reverendissimo Desembargador } \\
\text { Promotor, e Reo Joaõ Rodrigues Lopez } \\
\text { Lisboa. 1813. Fol. }\end{array}$ & 1 \\
\hline $\begin{array}{l}\text { Avellino/ Antônio } \\
\text { d’Annunciação/ }\end{array}$ & $\begin{array}{l}\text { Manifesto aos Bons Portuguzes } \\
\text { Lisboa. } 1823.4^{\circ} .\end{array}$ & 1 \\
\hline \multirow[t]{5}{*}{$\begin{array}{l}\text { Avellino/ Antonio } \\
\text { d’Annunciação/ }\end{array}$} & $\begin{array}{l}\text { A Religião de Jesus Christo Sustentada } \\
\text { em Theses Publicas } \\
\text { Rio de Janeiro. } 1816.4^{\circ}\end{array}$ & 1 \\
\hline & $\begin{array}{l}\text { Aventuras de Gil Blas de Santillana } \\
\text { Valência. } 1792.4^{\circ} \text {. }\end{array}$ & $\begin{array}{c}2 \\
\text { Tomo } 4^{\circ} \\
\text { e } 5^{\circ}\end{array}$ \\
\hline & $\begin{array}{l}\text { Aventuras de Gil Blas de Santillana } \\
\text { Madrid. } 1805.8^{\circ} .\end{array}$ & 5 \\
\hline & $\begin{array}{l}\text { Aventuras Pasmozas do Celebre Barão Munkausen } \\
\text { Rio de Janeiro. } 1814.8^{\circ} .\end{array}$ & 1 \\
\hline & $\begin{array}{l}\text { Aviso al Sencillo, pero Pueblo Espanol } \\
\text { Cadiz. 1812. } 4^{\circ} \text {. }\end{array}$ & 1 \\
\hline \multirow[t]{2}{*}{$\begin{array}{l}\text { Avrillon/ } \\
\text { Jean-Baptiste-Elie/ }\end{array}$} & $\begin{array}{l}\text { Retiro de Dez Dias. Traduzido do Francez } \\
\text { Lisboa. } 1783.8^{\circ} .\end{array}$ & 1 \\
\hline & $\begin{array}{l}\text { Axur Rei de Ormuz. Opera Séria-Comica } \\
\text { Rio de Janeiro. } 1814.8^{\circ}\end{array}$ & 1 \\
\hline Aires/ Francisco/ & $\begin{array}{l}\text { Theatro dos Triumphos Divinos contra } \\
\text { os Disprimores Humanos } \\
\text { Lisboa. } 1658.4^{\circ} .\end{array}$ & 1 \\
\hline $\begin{array}{l}\text { Azanza/ Miguel } \\
\text { José de/ } \\
\text { O-Farrill/ Gonzalo/ }\end{array}$ & $\begin{array}{l}\text { Memoria sobre los Hechos que Justifican } \\
\text { su Conducta Politica } \\
\text { Paris. } 1815.8^{\circ} .\end{array}$ & 1 \\
\hline $\begin{array}{l}\text { Azevedo/ Antônio } \\
\text { Maria de Castro e/ }\end{array}$ & $\begin{array}{l}\text { Nova Farça: O Medico Fingido, e a Doente Namorada } \\
\text { Lisboa. } 1831.4^{\circ} \text {. }\end{array}$ & 1 \\
\hline
\end{tabular}




\begin{tabular}{|c|c|c|}
\hline Autor & Título & Vol \\
\hline $\begin{array}{l}\text { Babié/ François/ } \\
\text { Beaumont/ L./ }\end{array}$ & $\begin{array}{l}\text { Galeries Militaire, ou Notices Historiques sur les } \\
\text { Generaux en Chef, Generaux de Division, etc Vici- } \\
\text { Amiraux, Contre Amiraux, etc Qui Ont Commandé les } \\
\text { Armées Francaises depuis le Commencement de la } \\
\text { Révolution jusqu'à l'An XIII } \\
\text { Paris. } 1805.8^{\circ}\end{array}$ & 7 \\
\hline \multirow[t]{2}{*}{$\begin{array}{l}\text { Bacelar/ Bernardo de } \\
\text { Lima Mello/ }\end{array}$} & $\begin{array}{l}\text { Diccionario da Lingoa Portugueza } \\
\text { Lisboa. 1783. } 4^{\circ} .\end{array}$ & 1 \\
\hline & $\begin{array}{l}\text { Bacharel /O/ de Salamanca, ou as Aventuras de Dom } \\
\text { Cherumbim de la Ronda. Traduzida do Francez por } \\
\text { Carlos José da Cunha } \\
\text { Lisboa. } 1802.12 .\end{array}$ & 2 \\
\hline \multirow[t]{2}{*}{$\begin{array}{l}\text { Baeta /Henrique } \\
\text { Xavier/ }\end{array}$} & $\begin{array}{l}\text { Extractos das Cartas de Maria Wollstonecraft Relativas } \\
\text { a Suecia, Noruega, e Dinamaca [e huma Breve Noticia } \\
\text { de Sua Vida] } \\
\text { Lisboa. } 1806.8^{\circ} .\end{array}$ & 1 \\
\hline & $\begin{array}{l}\text { Bando el Ayuntamento Constitucional de Ciudad } \\
\text { de Cadiz } \\
\text { Cadiz.1811. Fol. }\end{array}$ & 1 \\
\hline Banier/ Abade/ & $\begin{array}{l}\text { Cérémonies des Grandes et Petites Messes } \\
\text { Paris. } 1806.8^{\circ} .\end{array}$ & 1 \\
\hline $\begin{array}{l}\text { Barbosa/ Januário da } \\
\text { Cunha/ }\end{array}$ & $\begin{array}{l}\text { Oração de Graça da Chegada de Sua Alteza Real com } \\
\text { toda a Real Familia á Cidade do Rio de Janeiro } \\
\text { Rio de Janeiro. } 1813.8^{\circ} .\end{array}$ & 1 \\
\hline $\begin{array}{l}\text { Barbosa/ Januário da } \\
\text { Cunha/ }\end{array}$ & $\begin{array}{l}\text { Sermão de Acção de Graças pela Restauração } \\
\text { do Reyno de Portugal } \\
\text { Rio de Janeiro. } 1809.4^{\circ} .\end{array}$ & 1 \\
\hline $\begin{array}{l}\text { Barreto/ Domingos } \\
\text { Alvares Branco Muniz/ }\end{array}$ & $\begin{array}{l}\text { Indice Militar de todas as Leys, Alvarás, Cartas Regias, } \\
\text { Decretos, Reduções, Estatutos e Editaes Promulgados } \\
\text { desde o Anno de } 1758 \text { até } 1810 \\
\text { Rio de Janeiro. } 1812.4^{\circ} \text {. }\end{array}$ & 1 \\
\hline Barros/ João de/ & $\begin{array}{l}\text { Decadas da Azia } \\
\text { Lisboa. 1778. } 8^{\circ} .\end{array}$ & 9 \\
\hline Barruel/ Mr./ & $\begin{array}{l}\text { Memoires pour Servir à l'Histoire du Jacobinisme } \\
\text { Londres. } 1798.8^{\circ} .\end{array}$ & 1 \\
\hline Barruel/ Mr./ & $\begin{array}{l}\text { Memoires pour Servir à I'Histoire du Jacobinisme } \\
\text { Hamburgo. } 1803.8^{\circ} \text {. }\end{array}$ & 5 \\
\hline
\end{tabular}




\begin{tabular}{|c|c|c|}
\hline Autor & Título & Vol \\
\hline Barruel/ Mr./ & $\begin{array}{l}\text { Questão Nacional sobre a Authoridade e Direitos do } \\
\text { Povo em o Governo. Traduzida do Francez por Luiz } \\
\text { Gaspar Alves Martins } \\
\text { Lisboa. } 1823.4^{\circ} .\end{array}$ & 1 \\
\hline Barruel/ Mr./ & $\begin{array}{l}\text { O Segredo Revelado ou Manifestação do Systema } \\
\text { dos Pedreiros Livres, e Illuminados etc. Publicada } \\
\text { em Português por Joze Agostinho de Macedo } \\
\text { Lisboa. } 1810.8^{\circ} \text {. }\end{array}$ & 1 \\
\hline Barthélemy/ Abade/ & $\begin{array}{l}\text { Viage de Anacarsis el Joven por la Grecia. Traducido } \\
\text { por Don Ignacio Pablo Sandino de Castro } \\
\text { Mallorca. } 1811.8^{\circ} .\end{array}$ & 9 \\
\hline Barthélemy/ Abade/ & $\begin{array}{l}\text { Voyage du Jeune Anacharsis en Grèce } \\
\text { Paris. 1813. } 8^{\circ} .\end{array}$ & 7 \\
\hline \multirow[t]{3}{*}{ de Oliveira/ } & $\begin{array}{l}\text { Roteiro da Cidade de Belem do Gram-Pará } \\
\text { Rio de Janeiro. } 1811.8^{\circ} .\end{array}$ & 1 \\
\hline & $\begin{array}{l}\text { Bazes da Constituição Política da Nação Portugueza } \\
\text { Lisboa. 1821. Fol. }\end{array}$ & 1 \\
\hline & $\begin{array}{l}\text { Bazes da Constituição Política da Nação Portugueza } \\
\text { Lisboa. 1821. Fol. }\end{array}$ & 1 \\
\hline $\begin{array}{l}\text { Beaumont/ Madame } \\
\text { LePrince de/ }\end{array}$ & $\begin{array}{l}\text { Les Americaines, ou La Preuve de la Religion } \\
\text { Chretienne par les Lumieres Naturelles } \\
\text { Paris. } 1811.8^{\circ} \text {. }\end{array}$ & 1 \\
\hline \multirow[t]{2}{*}{$\begin{array}{l}\text { Beaumont/ Madame } \\
\text { LePrince de/ }\end{array}$} & $\begin{array}{l}\text { Magasin des Adolescentes ou Dialogues entre } \\
\text { Une Sage gouvernate et ses Élèves } \\
\text { Paris. } 1810.12 .\end{array}$ & 4 \\
\hline & $\begin{array}{l}\text { Beautés de I'Histoire du Bas-Empire } \\
\text { Paris. } 1814.8^{\circ} .\end{array}$ & 1 \\
\hline $\begin{array}{l}\text { Bellegarde/ } \\
\text { Abade de/ }\end{array}$ & $\begin{array}{l}\text { Arte de conhecer os homens. Traduzida Do Francez } \\
\text { por Ambrosio Antunes } \\
\text { Lisboa. } 1789.8^{\circ} .\end{array}$ & 1 \\
\hline $\begin{array}{l}\text { Bem/ Thomaz } \\
\text { Caetano de/ }\end{array}$ & $\begin{array}{l}\text { Vida do V. P. D. Alberto Maria Ambiveri } \\
\text { Lisboa. } 1782.8^{\circ} .\end{array}$ & 1 \\
\hline $\begin{array}{l}\text { Bem/ Thomaz } \\
\text { Caetano de/ }\end{array}$ & $\begin{array}{l}\text { Vida de Santo André Avellino } \\
\text { Lisboa. } 1767.4^{\circ} .\end{array}$ & 1 \\
\hline Benett/ Mistriss/ & $\begin{array}{l}\text { La Malédiction, ou I'Ombre de Mon Pére. } \\
\text { Traduit de I'Anglais } \\
\text { Paris. } 1808.8^{\circ} \text {. }\end{array}$ & 5 \\
\hline
\end{tabular}




\begin{tabular}{|c|c|c|}
\hline Autor & Título & Vol \\
\hline $\begin{array}{l}\text { Barchtold/ Conde } \\
\text { Leopoldo/ }\end{array}$ & $\begin{array}{l}\text { Ensaio sobre a Extenção dos Limites da Beneficiencia } \\
\text { a respeito, assim dos Homens, como dos mesmos } \\
\text { Animaes } \\
\text { Lisboa. } 1793.8^{\circ} .\end{array}$ & 1 \\
\hline $\begin{array}{l}\text { Bergamo/ Caetano } \\
\text { Maria de/ }\end{array}$ & $\begin{array}{l}\text { A humildade de Coração Ideada em Pensamentos, } \\
\text { e Affectos para Excitar a sua Pratica } \\
\text { Lisboa. } 1791.8^{\circ} .\end{array}$ & 1 \\
\hline Bergier/ Mr./ & $\begin{array}{l}\text { Le Déisme Réfuté par lui-meme } \\
\text { Paris. } 1771.8^{\circ} .\end{array}$ & 1 \\
\hline Bergier/ Mr./ & 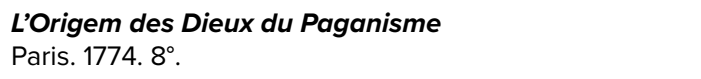 & 2 \\
\hline $\begin{array}{l}\text { Bernardes/ Padre } \\
\text { Manoel/ }\end{array}$ & $\begin{array}{l}\text { Luz e Calor. Obra Espiritual para os que Tratão do } \\
\text { Exercicio de Virtudes, e Caminho de Perfeição } \\
\text { Lisboa. } 1724.4^{\circ} .\end{array}$ & 1 \\
\hline \multirow[t]{4}{*}{ Berquim/M./ } & $\begin{array}{l}\text { L'Ami des Enfants } \\
\text { Paris. } 1792.8^{\circ} .\end{array}$ & 6 \\
\hline & $\begin{array}{l}\text { Biblia /A/ Sagrada. Traduzida em Portuguez } \\
\text { por Antonio Pereira de Figueiredo } \\
\text { Lisboa. 1803. Fol. }\end{array}$ & $\begin{array}{c}1 \\
\text { Tomo } 4^{\circ}\end{array}$ \\
\hline & $\begin{array}{l}\text { Biblia /La/. Traducida en Espanõl por el Padre Phelipe } \\
\text { Scio de San Miguel } \\
\text { Valência. 1791. Fol. }\end{array}$ & $\begin{array}{c}3 \\
\text { Tomos } 3^{\circ} \\
4^{\circ} \text { e } 5^{\circ}\end{array}$ \\
\hline & $\begin{array}{l}\text { Bible /La Sainte/ Contenant l'Ancien et le Nouveau } \\
\text { Testament Traduite en François sur la Vulgate par } \\
\text { Monsieur le Maistre de Saci } \\
\text { Paris. } 1789.4^{\circ} \text {. }\end{array}$ & 12 \\
\hline
\end{tabular}

Bible /La Sainte/ en Latin et en François, avec des

Notes Litterales, Critiques et Historiques, des Préfaces

et des Dissertations, Tirées du Commentaire de Don

Augustin Calmet etc

Paris. 1767. Fol.

Bibliotheca Historica de Portugal, e do Ultramar

Lisboa. 1797. $8^{\circ}$.

Bibliotheque Universelle des Dames

Paris. $8^{\circ}$.

Bitaubé/ Paul/ 


\begin{tabular}{|c|c|c|}
\hline Autor & Título & Vol \\
\hline Blanchard/ Pierre/ & $\begin{array}{l}\text { Beautés de l'Histoire de France } \\
\text { Paris. } 1810.8^{\circ} .\end{array}$ & 1 \\
\hline $\begin{array}{l}\text { Blanchard/ Jean- } \\
\text { Baptiste/ }\end{array}$ & $\begin{array}{l}\text { L'École des Moeurs ou Réflexions Morales et } \\
\text { Historiques sur les Maximes de la Sagesse } \\
\text { Lyon. } 1810.8^{\circ} .\end{array}$ & 3 \\
\hline Blanchard/ Pierre/ & $\begin{array}{l}\text { Thesouro de Meninos. Traduzido por Matheus José } \\
\text { da Costa } \\
\text { Lisboa. } 1817.8^{\circ} .\end{array}$ & $\begin{array}{c}3 \\
\text { T. } 3^{\circ}, 4^{\circ} \text { e } 5^{\circ} \\
3 \\
\text { Exemplares }\end{array}$ \\
\hline Blayney/ Lord/ & $\begin{array}{l}\text { Relation d'un Voyage Forcé en Espagne et en France, } \\
\text { dans les Années } 1810 \text { à } 1814 \\
\text { Paris. } 1815.8^{\circ} .\end{array}$ & 2 \\
\hline $\begin{array}{l}\text { Blumenbach/ Johann } \\
\text { Friedrich/ }\end{array}$ & $\begin{array}{l}\text { Manuel d'Histoire Naturelle Traduit de I'Allemand } \\
\text { par François Artand de Soulange } \\
\text { Metz. } 1803.8^{\circ} .\end{array}$ & 2 \\
\hline $\begin{array}{l}\text { Boaventura/ Frei } \\
\text { Fortunato de São/ }\end{array}$ & $\begin{array}{l}\text { O Mastigoforo } \\
\text { Lisboa. } 1824.4^{\circ} .\end{array}$ & $\begin{array}{l}2 \\
\text { Tomos }^{\circ} \\
\text { e } 2^{\circ}\end{array}$ \\
\hline $\begin{array}{l}\text { Boaventura/ Frei } \\
\text { Fortunato de São/ }\end{array}$ & $\begin{array}{l}\text { Modelos de Heroismo Christão } \\
\text { Coimbra. } 1823.4^{\circ} .\end{array}$ & $\begin{array}{c}1 \\
\text { Exemplar } 7\end{array}$ \\
\hline $\begin{array}{l}\text { Bocage/ Manuel } \\
\text { Maria Barbosa de/ }\end{array}$ & $\begin{array}{l}\text { Elogio aos Annos Faustissimos do Sereníssimo } \\
\text { Principe Regente de Portugal } \\
\text { Lisboa. } 1802.4^{\circ} .\end{array}$ & 1 \\
\hline $\begin{array}{l}\text { Bocage/ Manuel Maria } \\
\text { Barbosa de/ }\end{array}$ & $\begin{array}{l}\text { Rimas } \\
\text { Lisboa. 1800. } 8^{\circ} .\end{array}$ & 3 \\
\hline $\begin{array}{l}\text { Boise-Lucas/ M. } \\
\text { Delaunay de/ }\end{array}$ & $\begin{array}{l}\text { Télamon et Pholoe ou les Malheurs } \\
\text { de la Curiosité } \\
\text { Paris. } 1815.8^{\circ} .\end{array}$ & 1 \\
\hline $\begin{array}{l}\text { Bomtempo/ José } \\
\text { Maria/ }\end{array}$ & $\begin{array}{l}\text { Compendios de Materia Medica } \\
\text { Rio de Janeiro. } 1814.4^{\circ} .\end{array}$ & 1 \\
\hline $\begin{array}{l}\text { Bomtempo/ José } \\
\text { Maria/ }\end{array}$ & $\begin{array}{l}\text { Compendios de Medicina Pratica } \\
\text { Rio de Janeiro. } 1815.4^{\circ} \text {. }\end{array}$ & 1 \\
\hline $\begin{array}{l}\text { Giraudeau/ Père } \\
\text { Bonaventura/ }\end{array}$ & $\begin{array}{l}\text { Histoire et Paraboles } \\
\text { Paris. 1806. } 12 .\end{array}$ & 1 \\
\hline
\end{tabular}




\begin{tabular}{|c|c|c|}
\hline Autor & Título & Vol \\
\hline Boneta/ Joseph/ & $\begin{array}{l}\text { Graças da graça discretas agudezas dos Santos, } \\
\text { demonstraçam de algumas de suas virtudes } \\
\text { Lisboa. } 1753.8^{\circ} .\end{array}$ & 1 \\
\hline $\begin{array}{l}\text { Bosio/ Frei Francisco } \\
\text { de Paula/ }\end{array}$ & $\begin{array}{l}\text { Trezenario de São Francisco de Paula } \\
\text { Lisboa. } 1788.8^{\circ} .\end{array}$ & 1 \\
\hline $\begin{array}{l}\text { Bossuet/ Jacques } \\
\text { Benigne/ }\end{array}$ & $\begin{array}{l}\text { Avertissements aux Protestans sur les Lettres du } \\
\text { Ministre Jurieu contre I'Histoire des Variations } \\
\text { Paris. } 17348^{\circ} .\end{array}$ & $\begin{array}{l}2 \\
\text { Tomos } 3^{\circ} \\
\text { e } 4^{\circ}\end{array}$ \\
\hline $\begin{array}{l}\text { Bossuet/ Jacques } \\
\text { Benigne/ }\end{array}$ & $\begin{array}{l}\text { Discours sur I'Histoire Universelle } \\
\text { Paris. } 1804.8^{\circ} .\end{array}$ & 2 \\
\hline $\begin{array}{l}\text { Bossuet/ Jacques } \\
\text { Benigne/ }\end{array}$ & $\begin{array}{l}\text { Histoire des Variations des Eglises Protestantes } \\
\text { Paris. } 1734.8^{\circ} .\end{array}$ & 2 \\
\hline $\begin{array}{l}\text { Botelho/ José de São } \\
\text { Bernardino/ }\end{array}$ & $\begin{array}{l}\text { Salvação de Todos os Innocentes pela Redempção } \\
\text { de Jesus Christo } \\
\text { Lisboa. } 1822.8^{\circ} .\end{array}$ & 1 \\
\hline $\begin{array}{l}\text { Botelho/ José de São } \\
\text { Bernardino/ }\end{array}$ & $\begin{array}{l}\text { Ode ao Nascimento do Senhor Infante Dom João } \\
\text { Sem lug. nem Anno. } 4^{\circ} \text {. }\end{array}$ & 1 \\
\hline $\begin{array}{l}\text { Botelho/ José de São } \\
\text { Bernardino/ }\end{array}$ & $\begin{array}{l}\text { Ode ao Nascimento do Senhor Infante Dom Miguel } \\
\text { Lisboa. } 1802.4^{\circ} \text {. }\end{array}$ & $\begin{array}{c}1 \\
\text { Exemplar } 3\end{array}$ \\
\hline $\begin{array}{l}\text { Botelho/ José de São } \\
\text { Bernardino/ }\end{array}$ & $\begin{array}{l}\text { Ode ao Nascimento do Senhor Infante Dom Miguel } \\
\text { Lisboa. } 1802.4^{\circ} \text {. }\end{array}$ & 1 \\
\hline $\begin{array}{l}\text { Botado/ Duarte Gorjão } \\
\text { da Cunha Coimbra/ }\end{array}$ & $\begin{array}{l}\text { O Seculo XIX Explicado a vista da Biblia } \\
\text { Lisboa. } 1824.4^{\circ} \text {. }\end{array}$ & 1 \\
\hline Bourdaloue & $\begin{array}{l}\text { Morceaux Choisis } \\
\text { Paris } 1810.8^{\circ} .\end{array}$ & 1 \\
\hline $\begin{array}{l}\text { Braga/ Frei Manuel } \\
\text { de Santa Anna/ }\end{array}$ & $\begin{array}{l}\text { Historia Critica e Apologetica do Santissimo Milagre } \\
\text { da Villa de Santarem } \\
\text { Lisboa. } 1803.8^{\circ} .\end{array}$ & 1 \\
\hline $\begin{array}{l}\text { Bravo/ Joaquim } \\
\text { Plácido Franco/ }\end{array}$ & $\begin{array}{l}\text { Oração Feita a Sua Alteza Real O Principe Nosso } \\
\text { Senhor } \\
\text { Lisboa. } 1811.4^{\circ} .\end{array}$ & 1 \\
\hline $\begin{array}{l}\text { Bremond/ Santiago } \\
\text { Liniers y/ }\end{array}$ & $\begin{array}{l}\text { Proclamação aos Habitantes de Buenos Ayres } \\
\text { Buenos Aires. } 1808.4^{\circ} .\end{array}$ & 1 \\
\hline
\end{tabular}




\begin{tabular}{llc}
\hline Autor & \multicolumn{1}{c}{ Título } & Vol \\
\hline Breton / M. & $\begin{array}{l}\text { Histoire de I'Ancienne Grèce jusqu'à la Conquête } \\
\text { de ce Pays par les Romains } \\
\text { Paris. 1810. 12. }\end{array}$ & 9 \\
\hline
\end{tabular}

Breton / M.

Breviarium Romanum, ex Decreto Sacrosancti Concilii

2

Tridentini Restitutum S. Pio $5^{\circ}$ Pontificis Maximi

Lisboa. 1800. $8^{\circ}$.

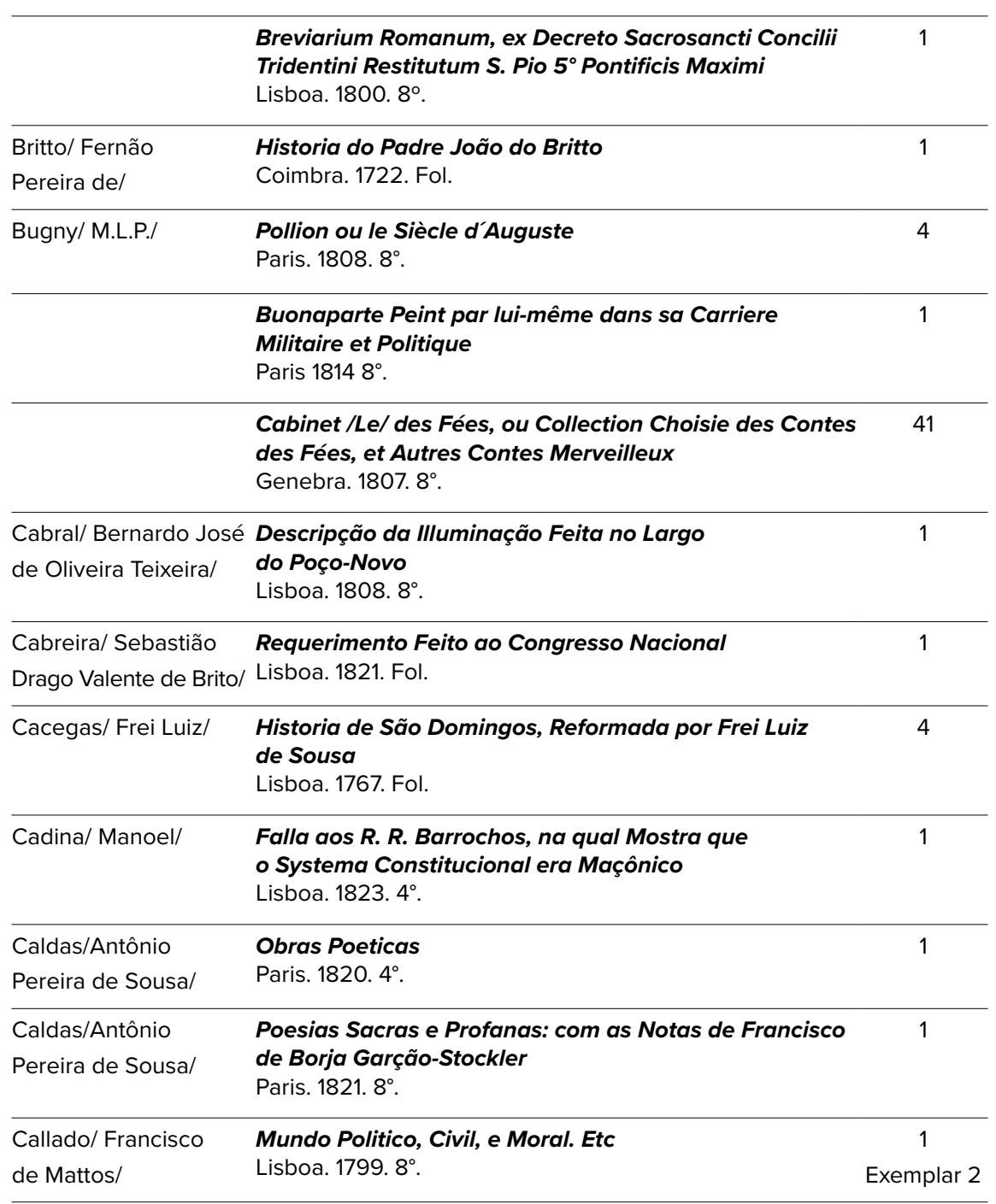




\begin{tabular}{|c|c|c|}
\hline Autor & Título & Vol \\
\hline Câmara/ José & Appolo, e Muzas, Canto Peninsular & 1 \\
\hline Manoel da/ & Rio de Janeiro. $1812.4^{\circ}$ & Exemplar 3 \\
\hline $\begin{array}{l}\text { Câmara/ José } \\
\text { Manoel da }\end{array}$ & $\begin{array}{l}\text { Discurso sobre o Voto de Castidade, que Professam } \\
\text { os Freires Conventuaes [da Ordem Militar] de São } \\
\text { Thiago da Espada } \\
\text { Rio de Janeiro. } 1815.4^{\circ} .\end{array}$ & 1 \\
\hline $\begin{array}{l}\text { Câmara/ José } \\
\text { Manoel da }\end{array}$ & $\begin{array}{l}\text { Oitavas a Sua Alteza Real o Principe Regente } \\
\text { Rio de Janeiro. } 1810.8^{\circ} .\end{array}$ & 1 \\
\hline Fénelon/ & $\begin{array}{l}\text { Aventuras de Telemaco, Hijo de Ulises } \\
\text { Madrid. } 1805.8^{\circ}\end{array}$ & 2 \\
\hline $\begin{array}{l}\text { Caminha/ Antônio } \\
\text { Lourenço/ } \\
\text { [Cícero]/ }\end{array}$ & $\begin{array}{l}\text { Lelio, ou Dialogo Sobre a Amizade } \\
\text { Lisboa. } 1785.8^{\circ} .\end{array}$ & 1 \\
\hline $\begin{array}{l}\text { Campomanes/ Pedro } \\
\text { Rodriguez/ }\end{array}$ & $\begin{array}{l}\text { Tratado de la Regalía de Amortización } \\
\text { Madrid. 1765. Fol. }\end{array}$ & 1 \\
\hline Camus/ Jean-Pierre/ & $\begin{array}{l}\text { Espirito e Doutrina do Glorioso São Francisco de Sales. } \\
\text { Extrahido, e Abreviado por Frei Francisco de Jezus } \\
\text { Maria Sarmento } \\
\text { Lisboa. } 1787.8^{\circ}\end{array}$ & 1 \\
\hline Canét/ José/ & $\begin{array}{l}\text { Breve Elocución al Pueblo Español } \\
\text { Palma. 1812. } 4^{\circ} .\end{array}$ & 1 \\
\hline Canét/ José/ & $\begin{array}{l}\text { El Grito de la Nacion por las Circunstancias del Dia. } \\
\text { Coloquio Gabernativo-Politico-Militar entre D. Fernando } \\
\text { etc y D. Juan etc } \\
\text { Mallorca. } 1811.4^{\circ} \text {. }\end{array}$ & 4 \\
\hline Canét/ José/ & $\begin{array}{l}\text { El Grito de la Nacion por las Circunstancias del Dia. } \\
\text { Coloquio Gabernativo-Politico-Militar entre D. Fernando } \\
\text { etc y D. Juan etc } \\
\text { Mallorca. } 1811.4^{\circ} \text {. }\end{array}$ & 3 \\
\hline Canét/ José/ & $\begin{array}{l}\text { La Verdadera Religion, Patriotismo y Lealtad. Reunion } \\
\text { de Diferentes y Útiles Escritos } \\
\text { Palma. } 1823.4^{\circ} .\end{array}$ & 1 \\
\hline \multirow[t]{2}{*}{ Bernardo Maria de/ } & $\begin{array}{l}\text { Diccionario da Lingua Bunda, ou Angolense } \\
\text { Lisboa. } 1804.4^{\circ} .\end{array}$ & 1 \\
\hline & $\begin{array}{l}\text { Cantata al Señor Don Fernando VII } \\
\text { Valência. } 1814.4^{\circ} \text {. }\end{array}$ & 1 \\
\hline
\end{tabular}




\begin{tabular}{|c|c|c|}
\hline Autor & Título & Vol \\
\hline Capmany/ Antonio & $\begin{array}{l}\text { Discurso Pronunciado en la Sesión Pública } \\
\text { de las Cortes } \\
\text { Cadiz. } 1813.4^{\circ} .\end{array}$ & 1 \\
\hline \multirow[t]{3}{*}{ Capmany/ Antonio } & $\begin{array}{l}\text { Sentinella contra Francezes } \\
\text { Lisboa. } 1809.4^{\circ} .\end{array}$ & 1 \\
\hline & $\begin{array}{l}\text { Caracteres da Verdadeira Religião Propostos á } \\
\text { Mocidade de Um e Outro Sexo. Traduzidos por } \\
\text { Joaquim Pedro Lopes } \\
\text { Lisboa. } 1817.8^{\circ} .\end{array}$ & 1 \\
\hline & $\begin{array}{l}\text { Caratteri /Gli Oppositi/. Dramma } \\
\text { Lisboa. } 1803.8^{\circ} .\end{array}$ & $\begin{array}{c}1 \\
\text { Exemplar } 2\end{array}$ \\
\hline Cardoso/ Padre Luís/ & $\begin{array}{l}\text { Receita Universal, ou Breve Noticia dos Santos } \\
\text { Lisboa. 1727. } 8^{\circ} .\end{array}$ & 1 \\
\hline $\begin{array}{l}\text { Carlos/ Frei Francisco } \\
\text { de São/ }\end{array}$ & $\begin{array}{l}\text { Oração de Acção de Graças pelo Nascimento da } \\
\text { Serenissima Senhora Dona Maria da Gloria } \\
\text { Rio de Janeiro. } 1819.8^{\circ} \text {. }\end{array}$ & 1 \\
\hline \multirow[t]{2}{*}{$\begin{array}{l}\text { Carlos/ Frei Francisco } \\
\text { de São/ }\end{array}$} & $\begin{array}{l}\text { Oração Funebre nas Exequias da Senhora Dona Maria I } \\
\text { Rio de Janeiro. } 1816.4^{\circ} .\end{array}$ & $\begin{array}{c}1 \\
\text { Exemplar } 2\end{array}$ \\
\hline & $\begin{array}{l}\text { Carolina de Lichtfield, ou o Triunfo da Virtude } \\
\text { Lisboa. } 1802.8^{\circ} .\end{array}$ & $\begin{array}{c}1 \\
\text { Tomo } 2^{\circ}\end{array}$ \\
\hline \multirow[t]{6}{*}{$\begin{array}{l}\text { Caroline/ Princesse } \\
\text { [Caroline d’Ansbach] }\end{array}$} & $\begin{array}{l}\text { Mémoires de la Princesse Caroline Adressés } \\
\text { à la Princesse Charlotte sa Fille } \\
\text { Paris. } 1813.8^{\circ} .\end{array}$ & 2 \\
\hline & $\begin{array}{l}\text { Carta Dirigida ao Senhor Antonio Lobo Barboza } \\
\text { Teixeira Girão } \\
\text { Lisboa. } 1822.4^{\circ} .\end{array}$ & 1 \\
\hline & $\begin{array}{l}\text { Carta do Enxota-Cães da Sé ao Thesoureiro d'Aldeia } \\
\text { Lisboa. } 1824.4^{\circ} \text {. }\end{array}$ & 1 \\
\hline & $\begin{array}{l}\text { Carta de [Nuestro Muy Amado Rei el Señor Don] } \\
\text { Fernando [Séptimo] a su Hermana la Serenísima } \\
\text { Señora Princesa Regente del Brasil y de Portugal } \\
\text { Cadiz. } 1811.4^{\circ} .\end{array}$ & 1 \\
\hline & $\begin{array}{l}\text { Carta sobre lo que Debe Hacer un Principe que Tenga } \\
\text { Colonias a Gran Distancia } \\
\text { Corunha. } 1813.4^{\circ} .\end{array}$ & 1 \\
\hline & $\begin{array}{l}\text { Carta /Quinta/ Crítica del Filósofo Rancio etc } \\
\text { Cadiz. } 1811.4^{\circ} .\end{array}$ & 1 \\
\hline
\end{tabular}




\begin{tabular}{|c|c|c|}
\hline Autor & Título & Vol \\
\hline & $\begin{array}{l}\text { Carta /Quinta/ Crítica del Filósofo Rancio etc } \\
\text { Cadiz. 1811. } 4^{\circ} \text {. }\end{array}$ & 1 \\
\hline \multirow[t]{5}{*}{$\begin{array}{l}\text { Caroline/ Princesse } \\
\text { [Caroline d’Ansbach] }\end{array}$} & $\begin{array}{l}\text { Carta ao Senhor Redactor do Diario do Governo } \\
\text { Lisboa. } 1822.4^{\circ} .\end{array}$ & 1 \\
\hline & $\begin{array}{l}\text { Carta de Sua Santidade Pio VII } \\
\text { Valência. 1815. Fol. }\end{array}$ & 1 \\
\hline & $\begin{array}{l}\text { Cartas en que se Impugna el Discurso Titulado Juicio } \\
\text { Historico-Canonico-Politico de la Autoridad de las } \\
\text { Naciones en los Bienes Eclesiasticos } \\
\text { Cadiz. } 1813.4^{\circ} .\end{array}$ & 1 \\
\hline & $\begin{array}{l}\text { Cartas de huma Mãi a Seu Filho pelas quaes Ihe Prova } \\
\text { a Verdade da Religião Christã } \\
\text { Lisboa. } 1787.8^{\circ} .\end{array}$ & 4 \\
\hline & $\begin{array}{l}\text { Cartas de huma Peruviana } \\
\text { Rio de Janeiro. } 1812.8^{\circ} .\end{array}$ & 2 \\
\hline \multirow{3}{*}{$\begin{array}{l}\text { Carvalho/ Porfirio } \\
\text { Hemeterio Homem de/ }\end{array}$} & $\begin{array}{l}\text { Primeiras Linhas do Direito Commercial deste Reino } \\
\text { Rio de Janeiro. } 1816.4^{\circ} \text {. }\end{array}$ & 1 \\
\hline & $\begin{array}{l}\text { Casa /La/ de los Locos, ou Carta Segunda del Politico } \\
\text { Machucho. Etc } \\
\text { Cadiz. 1823. } 4^{\circ} .\end{array}$ & 1 \\
\hline & $\begin{array}{l}\text { Casamento /O/ na Aldeia. Dramma Jocoso } \\
\text { Lisboa. } 1823.8^{\circ} .\end{array}$ & $\begin{array}{c}1 \\
\text { Exemplar } 2\end{array}$ \\
\hline Castéra/ Jean-Henri/ & $\begin{array}{l}\text { Histoire de Catherine II Impératrice de Russie } \\
\text { Paris. } 1809 .\end{array}$ & 3 \\
\hline $\begin{array}{l}\text { Castilho/ Antônio } \\
\text { Feliciano de/ }\end{array}$ & $\begin{array}{l}\text { A Exaltação do Senhor D. João } 6^{\circ} \text { ao Throno. Poema } \\
\text { Lisboa. } 1818.8^{\circ} \text {. }\end{array}$ & 1 \\
\hline $\begin{array}{l}\text { Castres/ Abbé } \\
\text { Sabatier de/ }\end{array}$ & $\begin{array}{l}\text { Les Caprices de la Fortune } \\
\text { Paris. 1809. } 8^{\circ} .\end{array}$ & 3 \\
\hline $\begin{array}{l}\text { Castro/ Afonso } \\
\text { Nunes de/ }\end{array}$ & $\begin{array}{l}\text { Historia da Vida de São Fernando Rey de Castella, e } \\
\text { Leam etc. Traduzida pelo Padre Joze Pereira Bayam } \\
\text { Lisboa. } 1728.4^{\circ} .\end{array}$ & 1 \\
\hline $\begin{array}{l}\text { Castro/ Frei Vicente } \\
\text { da Solenidade/ }\end{array}$ & $\begin{array}{l}\text { Pastoral } \\
\text { Lisboa. } 1821.4^{\circ}\end{array}$ & $\begin{array}{c}1 \\
\text { Exemplar } 3\end{array}$ \\
\hline
\end{tabular}




\begin{tabular}{|c|c|c|}
\hline Autor & Título & Vol \\
\hline $\begin{array}{l}\text { Castro/ Bernardo } \\
\text { José de Abrantes/ }\end{array}$ & $\begin{array}{l}\text { Supplica A Sua Alteza Real, O Principe Regente } \\
\text { Nosso Senhor } \\
\text { Londres. } 1810.8^{\circ} .\end{array}$ & 1 \\
\hline $\begin{array}{l}\text { Castro/ João } \\
\text { Baptista de/ }\end{array}$ & $\begin{array}{l}\text { Vida de Jesus Christo Senhor Nosso } \\
\text { Lisboa. } 1790.8^{\circ}\end{array}$ & 2 \\
\hline $\begin{array}{l}\text { Castro/ João } \\
\text { Baptista de/ }\end{array}$ & $\begin{array}{l}\text { Vida de São Joseph } \\
\text { Lisboa. 1761. } 4^{\circ}\end{array}$ & 1 \\
\hline $\begin{array}{l}\text { Castro/ Joaquim } \\
\text { Machado de/ }\end{array}$ & $\begin{array}{l}\text { Analyse Grafico Orthodoxa e Demosntrativa, de que } \\
\text { sem Escrupulo do Menor Erro Theologico, a Escultura } \\
\text { e Pintura Podem Figurar Anjos no Mysterio da } \\
\text { Encarnação } \\
\text { Lisboa. } 1805.4^{\circ} .\end{array}$ & 1 \\
\hline $\begin{array}{l}\text { Castro/ Joaquim } \\
\text { Machado de/ }\end{array}$ & $\begin{array}{l}\text { Descripção Analytica da Execução da Estatua Equestre } \\
\text { Lisboa. } 1810.4^{\circ} .\end{array}$ & \\
\hline $\begin{array}{l}\text { Castro/ José } \\
\text { Bernardes/ }\end{array}$ & $\begin{array}{l}\text { Parabens a Sua Magestade pelo Parto da Princeza Real } \\
\text { Rio de Janeiro.1819. } 4^{\circ} \text {. }\end{array}$ & Exemplar 8 \\
\hline $\begin{array}{l}\text { Castro/ José } \\
\text { Bernardes/ }\end{array}$ & $\begin{array}{l}\text { Parabens a Sua Magestade e aos Principes Reas } \\
\text { em Parafraze do Salmo } 44 \\
\text { Rio de Janeiro. } 1819.4^{\circ} .\end{array}$ & $\begin{array}{c}1 \\
\text { Exemplar } 3\end{array}$ \\
\hline $\begin{array}{l}\text { Castro/ José } \\
\text { Fernandez de/ }\end{array}$ & $\begin{array}{l}\text { Representación al Soberano Congresso } \\
\text { de las Cortes Nacionales } \\
\text { Cadiz. } 1811.4^{\circ} .\end{array}$ & 1 \\
\hline $\begin{array}{l}\text { Castro/ José } \\
\text { Fernandez de/ }\end{array}$ & $\begin{array}{l}\text { Respuesta que da D. Josef Fernandez de Castro } \\
\text { a la Expoxicion del Marques de Sobremonte } \\
\text { Cadiz. } 1811.4^{\circ} .\end{array}$ & 1 \\
\hline $\begin{array}{l}\text { Castro/ Martinho de } \\
\text { Moraes Correa/ }\end{array}$ & $\begin{array}{l}\text { Memoria Sobre sua Conduta Militar, e Civil na } \\
\text { Revolução de } 24 \text { de Agosto de } 1820 \\
\text { Salamanca. } 1823.4^{\circ} .\end{array}$ & 1 \\
\hline Catalá/ José Berni y/ & $\begin{array}{l}\text { Apuntamientos sobre las Leyes de Partida al Tenor } \\
\text { de las Leyes Recopiladas, Autos Acordados, Autores } \\
\text { Españoles y Practica Moderna } \\
\text { Valência. 1759. Fol. }\end{array}$ & 4 \\
\hline Catalani/ Giuseppe & $\begin{array}{l}\text { Vida do Veneravel Padre Bartholomeu do Quental. } \\
\text { Traduzido do Latim por Francisco Jozé Freire } \\
\text { Lisboa. } 1741.8^{\circ} \text {. }\end{array}$ & 1 \\
\hline
\end{tabular}




\begin{tabular}{|c|c|c|}
\hline Autor & Título & Vol \\
\hline & $\begin{array}{l}\text { Catalogo dos Livros que se hão de lêr para a } \\
\text { continuação do Diccionario da Lingua Portugueza } \\
\text { Mandado Publicar pela Academia Real das Sciencias } \\
\text { Lisboa. } 1799.4^{\circ} .\end{array}$ & 1 \\
\hline \multirow[t]{3}{*}{$\begin{array}{l}\text { Santa Catarina/ Frei } \\
\text { Lucas de }\end{array}$} & $\begin{array}{l}\text { Estrella Dominica Novamente Descoberta } \\
\text { no Ceo da Igreja } \\
\text { Lisboa. } 1709.8^{\circ} .\end{array}$ & 2 \\
\hline & $\begin{array}{l}\text { Causa Fundamental de la Extinción del Consejo } \\
\text { Supremo de Castilla } \\
\text { Madrid. } 1812.4^{\circ}\end{array}$ & 1 \\
\hline & $\begin{array}{l}\text { Cedula /Real/ de Sua Magestade y Señores del Consejo } \\
\text { Madrid 1823. Fol. }\end{array}$ & 1 \\
\hline Cevalhos/ Pedro/ & $\begin{array}{l}\text { Exposição dos Factos, e Maquinações com que se } \\
\text { Preparou a Usurpação da Coroa de Hespanha } \\
\text { Lisboa. } 1808.4^{\circ} .\end{array}$ & 1 \\
\hline Cevalhos/ Pedro/ & $\begin{array}{l}\text { Politica Peculiar de Buonaparte en cuanto } \\
\text { á la Religion Catolica } \\
\text { Cadiz. } 1811.4^{\circ} .\end{array}$ & 1 \\
\hline Cevallos/ Pedro & $\begin{array}{l}\text { Discurso Apologetico por la Devocion al Sagrado } \\
\text { Corazon de Jesus } \\
\text { Lisboa. } 1800.8^{\circ} .\end{array}$ & 1 \\
\hline $\begin{array}{l}\text { Chagas / Frei } \\
\text { Antônio das/ }\end{array}$ & $\begin{array}{l}\text { Escola de Penitencia, e Flagello de Viciosos Costumes } \\
\text { Lisboa. } 1763.4^{\circ} .\end{array}$ & 1 \\
\hline $\begin{array}{l}\text { Chagas / Frei } \\
\text { Antônio das/ }\end{array}$ & $\begin{array}{l}\text { Obras Espirituaes } \\
\text { Lisboa. } 1762.4^{\circ}\end{array}$ & 1 \\
\hline $\begin{array}{l}\text { Chagas / Frei } \\
\text { Antônio das/ }\end{array}$ & $\begin{array}{l}\text { Obras Espirituaes } \\
\text { Lisboa. } 1762.4^{\circ}\end{array}$ & 1 \\
\hline $\begin{array}{l}\text { Chaide / Frei Pedro } \\
\text { Malon de/ }\end{array}$ & $\begin{array}{l}\text { La Conversion de la Madalena, en que se Ponen los } \\
\text { Tres Estados que Tuvo de Pecadora, de Penitente, } \\
\text { y de Gracia } \\
\text { Valência. } 1794.4^{\circ} \text {. }\end{array}$ & 1 \\
\hline \multirow[t]{3}{*}{ Charlemont/ M./ } & $\begin{array}{l}\text { Vie du Maréchal Ney } \\
\text { Paris. Sem ano. } 12^{\circ} \text {. }\end{array}$ & 1 \\
\hline & $\begin{array}{l}\text { Charles de Fleval, ou les Aventures d'un Homme Jeune } \\
\text { Paris. } 1808.8^{\circ} .\end{array}$ & 2 \\
\hline & $\begin{array}{l}\text { Charles et Marie } \\
\text { Paris. } 1808.8^{\circ} .\end{array}$ & 1 \\
\hline
\end{tabular}




\begin{tabular}{|c|c|c|}
\hline Autor & Título & Vol \\
\hline $\begin{array}{l}\text { Chateaubriand/ } \\
\text { François Auguste/ }\end{array}$ & $\begin{array}{l}\text { Génie du Christianisme ou Beautés de la Religion } \\
\text { Chrétienne } \\
\text { Lyon. } 1809.8^{\circ} .\end{array}$ & 5 \\
\hline $\begin{array}{l}\text { Chateaubriand/ } \\
\text { François Auguste/ } \\
\text { Nascimento/ Francisco } \\
\text { Manoel do/ }\end{array}$ & $\begin{array}{l}\text { Os Martyres ou Triumpho da Religião Christã. Traduzido } \\
\text { em Portuguez por Francisco Manoel do Nascimento } \\
\text { Paris. } 1816.8^{\circ}\end{array}$ & 2 \\
\hline $\begin{array}{l}\text { Chaudon/ Louis- } \\
\text { Mayeul/ } \\
\text { Delandine/ Antoine- } \\
\text { François/ }\end{array}$ & $\begin{array}{l}\text { Nouveau Dictionnaire Historique } \\
\text { Lyon } 1805.8^{\circ} .\end{array}$ & 4 \\
\hline Chenedolle /Charles/ & $\begin{array}{l}\text { Le Genie de l'Homme /Poeme/ } \\
\text { Paris. } 1807.8^{\circ} \text {. }\end{array}$ & 1 \\
\hline $\begin{array}{l}\text { Cicatelli/ Padre } \\
\text { Sancho/ }\end{array}$ & $\begin{array}{l}\text { Vida de São Camillo de Lellis } \\
\text { Lisboa. } 1747.4^{\circ} .\end{array}$ & 1 \\
\hline \multirow[t]{4}{*}{$\begin{array}{l}\text { Cien-Fuegos/ Alvaro/ } \\
\text { Nunes/ José Ribeiro }\end{array}$} & $\begin{array}{l}\text { A Heroica Vida, Virtudes, e Milagres de São Francisco } \\
\text { de Borja. Traduzida por Joze Ribeiro Nunes } \\
\text { Coimbra. } 1757.4^{\circ} .\end{array}$ & 1 \\
\hline & $\begin{array}{l}\text { Circular del Excelentisimo Cabildo de Buenos-Ayres à } \\
\text { los del Reyno, y à los IIImos Prelados del Vireynato } \\
\text { Buenos Aires. } 1808.4^{\circ} .\end{array}$ & 1 \\
\hline & $\begin{array}{l}\text { Clarisse Harlowe. Nouvelle } \\
\text { Paris. } 1802.8^{\circ} .\end{array}$ & 14 \\
\hline & $\begin{array}{l}\text { Clémence de Lautrec } \\
\text { Paris. } 1807.8^{\circ} .\end{array}$ & 2 \\
\hline Clemente/ José/ & $\begin{array}{l}\text { Vida da Madre Tereza da Anunciada } \\
\text { Lisboa. 1763. Fol. }\end{array}$ & 1 \\
\hline $\begin{array}{l}\text { Casa/ Josef Iglesias } \\
\text { de la/ }\end{array}$ & $\begin{array}{l}\text { Poesías Póstumas } \\
\text { Salamanca. } 1798.8^{\circ} .\end{array}$ & 2 \\
\hline $\begin{array}{l}\text { Coelho/ Domingos } \\
\text { Lopes/ }\end{array}$ & $\begin{array}{l}\text { Historia da Vida de São Vicente Ferrer } \\
\text { Lisboa. } 1713.4^{\circ} .\end{array}$ & 1 \\
\hline $\begin{array}{l}\text { Coelho/ Romualdo } \\
\text { de Souza/ }\end{array}$ & $\begin{array}{l}\text { Oração Funebre Recitada nas Exequias de Sua } \\
\text { Magestade a Senhora Dona Maria I que se Celebrarão } \\
\text { na Cidade do Graõ-Pará } \\
\text { Rio de Janeiro. } 1817.4^{\circ} .\end{array}$ & 1 \\
\hline
\end{tabular}




\begin{tabular}{|c|c|c|}
\hline Autor & Título & Vol \\
\hline & $\begin{array}{l}\text { Colección de las Obras de Elocuencia y de Poesía } \\
\text { [Premiadas por la Real Academia Española] } \\
\text { Madrid. } 1799.8^{\circ} .\end{array}$ & 2 \\
\hline \multirow[t]{7}{*}{$\begin{array}{l}\text { Colares/ Padre } \\
\text { Nicolau Fernandes/ }\end{array}$} & $\begin{array}{l}\text { Descripção do Tormentoso Cabo da Enganosa } \\
\text { Esperança à Hora da Morte } \\
\text { Lisboa. } 1765.4^{\circ} .\end{array}$ & 2 \\
\hline & $\begin{array}{l}\text { Coleccion de Canciones Patrióticas } \\
\text { Cadiz. Sem ano. } 4^{\circ} .\end{array}$ & 1 \\
\hline & $\begin{array}{l}\text { Collecção de Noticias para a Historia e Geografia } \\
\text { das Nações Ultramarinas [que Vivem] nos Dominios } \\
\text { Portguguezes } \\
\text { Lisboa. } 1812.4^{\circ} .\end{array}$ & 3 \\
\hline & $\begin{array}{l}\text { Collecção das Poesias Distribuidas por Occasião do } \\
\text { Festejo da Feliz Chegada de Sua Magestade o Senhor } \\
\text { Dom João VI } \\
\text { Lisboa. } 1821.4^{\circ} .\end{array}$ & 1 \\
\hline & $\begin{array}{l}\text { Collecção das Poesias que o Regimento de Milicias } \\
\text { de Lisboa Occidental, Distribuiu nos dias 23, 24, e 25, } \\
\text { de Junho de } 1823 \\
\text { Lisboa. } 1823.4^{\circ} .\end{array}$ & 1 \\
\hline & $\begin{array}{l}\text { Collecção de Tragedias } \\
\text { Lisboa. } 1785.8^{\circ} .\end{array}$ & 1 \\
\hline & $\begin{array}{l}\text { Collecção dos Versos, e Descripções dos Quadros } \\
\text { Allegoricos, que em todas as Solemnidades Publicas da } \\
\text { Capital Mandou Imprimir José Pedro da Silva } \\
\text { Lisboa. } 1812.8^{\circ} .\end{array}$ & 1 \\
\hline Collet/ Pierre & $\begin{array}{l}\text { Vie de Saint Vicent de Paul. Etc } \\
\text { Paris. } 1816.8^{\circ} .\end{array}$ & 1 \\
\hline Colón/ José/ & $\begin{array}{l}\text { Conciliador /EI/ o Reflexiones sobre la Conversacion } \\
\text { entre un Forastero y un Vecino de Ia Isla de Leon } \\
\text { Cadiz. } 1811.8^{\circ} .\end{array}$ & 1 \\
\hline Colón/ José/ & $\begin{array}{l}\text { España Vindicada en sus Clases y Autoridades } \\
\text { de las Falsas Opiniones que se la Atribuyen } \\
\text { Madrid. } 1814.4^{\circ} .\end{array}$ & 1 \\
\hline Colón/ José/ & $\begin{array}{l}\text { España Vindicada en sus Clases y Autoridades } \\
\text { de las Falsas Opiniones que se la Atribuyen } \\
\text { Madrid. } 1811.4^{\circ} .\end{array}$ & 1 \\
\hline
\end{tabular}




\begin{tabular}{|c|c|c|}
\hline Autor & Título & Vol \\
\hline & $\begin{array}{l}\text { Compendio en que se Manifiestan los Principios } \\
\text { del Sistema Constitucional } \\
\text { Lisboa. } 1823.4^{\circ} .\end{array}$ & $\begin{array}{c}1 \\
\text { Exemplar } 4\end{array}$ \\
\hline Colón/ José/ & $\begin{array}{l}\text { Comte /Le/ de Waldheim et son Intendant Wildman. } \\
\text { Traduit de I'Allemand, par Madame Isabelle } \\
\text { de Montolieu } \\
\text { Paris. } 1812.8^{\circ} .\end{array}$ & 1 \\
\hline $\begin{array}{l}\text { Conceição/ Frei } \\
\text { Claudio da/ }\end{array}$ & $\begin{array}{l}\text { Gabinete Historico } \\
\text { Lisboa. } 1818.8^{\circ}\end{array}$ & 7 \\
\hline $\begin{array}{l}\text { Conceição/ Frei } \\
\text { Claudio da/ }\end{array}$ & $\begin{array}{l}\text { Memoria do que aconteceo ao Santo Milagre } \\
\text { de Santarem pela Invasão dos Franceses etc } \\
\text { Lisboa. } 1811.8^{\circ} .\end{array}$ & 1 \\
\hline $\begin{array}{l}\text { Conceição/ Frei } \\
\text { Claudio da/ }\end{array}$ & $\begin{array}{l}\text { Memoria Historica da Enfermidade, Procissões de } \\
\text { Preces com Devotissimas Imagens, Morte, e Funeral } \\
\text { do Senhor Dom João VI } \\
\text { Lisboa. } 1826.8^{\circ} \text {. }\end{array}$ & $\begin{array}{c}1 \\
\text { Exemplar } 3\end{array}$ \\
\hline $\begin{array}{l}\text { Conceição/ Frei } \\
\text { Claudio da/ }\end{array}$ & $\begin{array}{l}\text { Memoria da Prodigiosa Imagem da Senhora do Cabo } \\
\text { Lisboa. } 1817.8^{\circ} .\end{array}$ & $\begin{array}{c}1 \\
\text { Parte } 1^{\mathrm{a}}\end{array}$ \\
\hline $\begin{array}{l}\text { Conceição/ Frei } \\
\text { Claudio da/ }\end{array}$ & $\begin{array}{l}\text { Novena da Senhora da Conceição da Rocha } \\
\text { Lisboa. } 1825.8^{\circ} .\end{array}$ & 1 \\
\hline $\begin{array}{l}\text { Conceição/ Frei } \\
\text { Claudio da/ }\end{array}$ & $\begin{array}{l}\text { Oração Funebre nas Exequias do Visconde } \\
\text { de Santarem } \\
\text { Lisboa. } 1818.8^{\circ} .\end{array}$ & $\begin{array}{c}1 \\
\text { Exemplar } 7\end{array}$ \\
\hline \multirow[t]{3}{*}{$\begin{array}{l}\text { Conceição/ Frei } \\
\text { Claudio da/ }\end{array}$} & $\begin{array}{l}\text { Sermão de Acção de Graças no Santissimo Milagre } \\
\text { de Santarem } \\
\text { Lisboa. } 1811.8^{\circ} .\end{array}$ & 1 \\
\hline & $\begin{array}{l}\text { Conciliador /EI/ o Reflexiones sobre la Conversacion } \\
\text { entre un Forastero Etc } \\
\text { Lisboa. } 1811.4^{\circ} .\end{array}$ & 1 \\
\hline & $\begin{array}{l}\text { Conclusion Fiscal en el Proceso Militar Formado contra } \\
\text { el Excmo. Sr. Marques de Sobre-Monte } \\
\text { Cadiz. } 1813.4^{\circ} .\end{array}$ & $\begin{array}{c}1 \\
\text { Exemplar } 3\end{array}$ \\
\hline Condillac/ & $\begin{array}{l}\text { Oeuvres Metaphysiques } \\
\text { Paris. } 1802.8^{\circ}\end{array}$ & 4 \\
\hline Condorcet/ & $\begin{array}{l}\text { Esquisse d'un Tableau Historique des Progrès } \\
\text { de l'Esprit Humain } \\
\text { Paris. } 1798.8^{\circ} \text {. }\end{array}$ & 1 \\
\hline
\end{tabular}




\begin{tabular}{|c|c|c|}
\hline Autor & Título & Vol \\
\hline Consciencia/ Padre & Vida de São Filippe Neri & 1 \\
\hline Manoel da/ & Lisboa. 1738. Fol. & \\
\hline \multirow[t]{12}{*}{$\begin{array}{l}\text { Consciencia/ Padre } \\
\text { Manoel da/ }\end{array}$} & $\begin{array}{l}\text { Consideraciones Filosófico-Políticas, Sobre el Artículo } \\
22 \text { Cap. } 4 \text { Tít. } 2 \text { del Proyecto de Constitucion } \\
\text { Cadiz. } 1811.4^{\circ} .\end{array}$ & 1 \\
\hline & $\begin{array}{l}\text { Constitucion Fundamental y Secreta de los } \\
\text { Libertadores del Género Humano } \\
\text { Málaga. Sem Año. } 4^{\circ}\end{array}$ & 1 \\
\hline & $\begin{array}{l}\text { Constitucion Politica de la Monarquia Española } \\
\text { Cadiz. 1812. Fol. }\end{array}$ & 1 \\
\hline & $\begin{array}{l}\text { Constitucion Politica de la Monarquia Española } \\
\text { Cadiz. } 1812.8^{\circ} .\end{array}$ & 1 \\
\hline & $\begin{array}{l}\text { Constituição Politica da Monarquia Portugueza } \\
\text { Lisboa. } 1821.8^{\circ} .\end{array}$ & 1 \\
\hline & $\begin{array}{l}\text { Constituição Politica da Monarquia Portugueza } \\
\text { Lisboa. } 1821.4^{\circ} \text {. }\end{array}$ & $\begin{array}{c}1 \\
\text { Exemplar } 3\end{array}$ \\
\hline & $\begin{array}{l}\text { Contessina /La/ Contrastata. Dramma } \\
\text { Lisboa. } 1806.8^{\circ} .\end{array}$ & 1 \\
\hline & $\begin{array}{l}\text { Contextacion al Miserable Duende de los Cafees, sobre } \\
\text { sus Imposturas y Calumnias contra el Superintendente } \\
\text { de la Fábrica del Tabaco Don José Espinosa } \\
\text { Cadiz. } 1813.4^{\circ} .\end{array}$ & 1 \\
\hline & $\begin{array}{l}\text { Continuação da Memoria sobre os Acontecimentos } \\
\text { da Ribeira de Jamor } \\
\text { Lisboa. } 1822 \text {. Fol. }\end{array}$ & 1 \\
\hline & $\begin{array}{l}\text { Continuacion y Conclusion del Proyecto de } \\
\text { Constitucion Politica de la Monarquía Española } \\
\text { Cadiz. } 1811.4^{\circ} .\end{array}$ & 1 \\
\hline & $\begin{array}{l}\text { Continuacion y Conclusion del Proyecto de } \\
\text { Constitucion Politica de la Monarquía Española } \\
\text { Cadiz. } 1811.4^{\circ} .\end{array}$ & 1 \\
\hline & $\begin{array}{l}\text { Convenção entre o Principe Regente de Portugal, } \\
\text { e El Rey da Grande Bretanha Sobre a Indemnização } \\
\text { da Perda do Trafico dos Negros } \\
\text { Rio de Janeiro. 1815. Fol. }\end{array}$ & 1 \\
\hline
\end{tabular}




\begin{tabular}{|c|c|c|}
\hline Autor & Título & Vol \\
\hline & $\begin{array}{l}\text { Conversacion entre un Forastero y un Vecino de la Isla } \\
\text { de Leon, sobre los Derechos de la Princesa del Brasil, } \\
\text { Infanta de España, Doña Carlota Joaquina de Borbon, } \\
\text { á la Sucesion Eventual del Trono de España } \\
\text { Cadiz. 1811. } 4^{\circ} .\end{array}$ & 1 \\
\hline \multirow[t]{2}{*}{ Cook } & $\begin{array}{l}\text { Methodo [do Capitão Cook], com o qual Preparava } \\
\text { a Saude dos seus Marinheiros } \\
\text { Lisboa. } 1795.4^{\circ} \text {. }\end{array}$ & 1 \\
\hline & $\begin{array}{l}\text { Copia da Sentença Proferida a favor do Tenente } \\
\text { Coronel Raimundo Joze Pinheiro } \\
\text { Sem lugar, nem ano. Fol. }\end{array}$ & 1 \\
\hline \multirow[t]{8}{*}{ Cornejo/ Frei Damián/ } & $\begin{array}{l}\text { Chronica Seraphica. [Vida del Glorioso Patriarca San } \\
\text { Francisco, y de sus Primeiros Discípulos]. Dedicada } \\
\text { a la [Excelentisima] Señora Duquesa de Aveyro Etc } \\
\text { Madrid. } 1684 . \text { Fol. }\end{array}$ & 1 \\
\hline & $\begin{array}{l}\text { Coroa das Sete Dores da Virgem Maria Senhora Nossa } \\
\text { Lisboa. } 1790.12^{\circ} .\end{array}$ & 1 \\
\hline & $\begin{array}{l}\text { Corografia Brazilica, ou Relação Historico-Geografica } \\
\text { do Reino do Brazil } \\
\text { Rio de Janeiro. } 1817.4^{\circ} .\end{array}$ & 1 \\
\hline & $\begin{array}{l}\text { Correio Braziliense ou Armazem Literario } \\
\text { Londres. } 1808.4^{\circ} \text {. }\end{array}$ & 12 \\
\hline & $\begin{array}{l}\text { Correio Braziliense ou Armazem Literario } \\
\text { Londres. } 1809 \text { a } 1810.4^{\circ} .\end{array}$ & 10 \\
\hline & $\begin{array}{l}\text { Correio Braziliense ou Armazem Literario } \\
\text { Londres. } 1815.4^{\circ} .\end{array}$ & 1 \\
\hline & $\begin{array}{l}\text { Correspondence Secrette entre Ninon de Lenclos, } \\
\text { le Marquis de Villarceaux, et Madame de M. } \\
\text { Paris. } 1797.12^{\circ} \text {. }\end{array}$ & 2 \\
\hline & $\begin{array}{l}\text { Corriola /Novo Entremez/ } \\
\text { Lisboa. } 1776.4^{\circ} .\end{array}$ & 1 \\
\hline Câmara/ José & Corso /O/. Grito Portuguez & 1 \\
\hline Manuel da & Rio de Janeiro. 1811. $8^{\circ}$. & \\
\hline $\begin{array}{l}\text { Costa/ Joaquim } \\
\text { Raurino da/ }\end{array}$ & $\begin{array}{l}\text { Monologo Offerecido a Sua Magestade } \\
\text { o Senhor Dom João VI } \\
\text { Porto. } 1823.8^{\circ} \text {. }\end{array}$ & 1 \\
\hline
\end{tabular}




\begin{tabular}{|c|c|c|}
\hline Autor & Título & Vol \\
\hline $\begin{array}{l}\text { Costa/ José Daniel } \\
\text { Rodrigues da/ }\end{array}$ & $\begin{array}{l}\text { Almocreve de Petas, ou Moral Disfarçada para } \\
\text { Correcção das Miudezas da Vida } \\
\text { Lisboa. } 1798.4^{\circ} .\end{array}$ & 1 \\
\hline $\begin{array}{l}\text { Costa/ José Daniel } \\
\text { Rodrigues da/ }\end{array}$ & $\begin{array}{l}\text { O Balão, aos Habitantes da Lua. Poema } \\
\text { Lisboa. } 1819.8^{\circ} .\end{array}$ & 1 \\
\hline $\begin{array}{l}\text { Costa/ José Daniel } \\
\text { Rodrigues da/ }\end{array}$ & $\begin{array}{l}\text { Barco da Carreira dos Tolos } \\
\text { Lisboa. } 1803.4^{\circ} .\end{array}$ & 1 \\
\hline $\begin{array}{l}\text { Costa/ José Daniel } \\
\text { Rodrigues da/ }\end{array}$ & $\begin{array}{l}\text { Camara Optica } \\
\text { Lisboa. } 1807.4^{\circ} .\end{array}$ & 4 \\
\hline $\begin{array}{l}\text { Costa/ José Daniel } \\
\text { Rodrigues da/ }\end{array}$ & $\begin{array}{l}\text { Camara Optica } \\
\text { Lisboa. } 1808.4^{\circ} .\end{array}$ & 1 \\
\hline $\begin{array}{l}\text { Costa/ José Daniel } \\
\text { Rodrigues da/ }\end{array}$ & $\begin{array}{l}\text { Carta de Parabens que Dá a Ciudad de Rodrigo } \\
\text { á Praça de Badajoz } \\
\text { Lisboa. } 1812.4^{\circ} .\end{array}$ & 1 \\
\hline $\begin{array}{l}\text { Costa/ José Daniel } \\
\text { Rodrigues da/ }\end{array}$ & $\begin{array}{l}\text { Comboy de Mentiras Vindo do Reino Petista com } \\
\text { a Fragata Verdade Encoberta por Capitania } \\
\text { Lisboa. } 1801.4^{\circ} .\end{array}$ & 1 \\
\hline $\begin{array}{l}\text { Costa/ José Daniel } \\
\text { Rodrigues da/ }\end{array}$ & $\begin{array}{l}\text { Conversação Nocturna das Esquinas } \\
\text { do Rocio de Lisboa } \\
\text { Lisboa } 1812.4^{\circ}\end{array}$ & 1 \\
\hline $\begin{array}{l}\text { Costa/ José Daniel } \\
\text { Rodrigues da/ }\end{array}$ & $\begin{array}{l}\text { Descripção Resumida do Prazer, com que Forão, } \\
\text { Recebidas as Tropas Portuguezas pelos Habitantes } \\
\text { da Rua Direita dos Anjos } \\
\text { Lisboa. } 1814.4^{\circ} .\end{array}$ & 1 \\
\hline $\begin{array}{l}\text { Costa/ José Daniel } \\
\text { Rodrigues da/ }\end{array}$ & $\begin{array}{l}\text { Embarque dos Apaixonados dos Francezes } \\
\text { Lisboa. } 1808.8^{\circ} .\end{array}$ & 1 \\
\hline $\begin{array}{l}\text { Costa/ José Daniel } \\
\text { Rodrigues da/ }\end{array}$ & $\begin{array}{l}\text { O Encontro na Eternidade do General Marmont, } \\
\text { com o General Bonet } \\
\text { Lisboa. } 1812.4^{\circ} .\end{array}$ & 1 \\
\hline $\begin{array}{l}\text { Costa/ José Daniel } \\
\text { Rodrigues da/ }\end{array}$ & $\begin{array}{l}\text { Entrada que Deo no Inferno a Illustrissima e } \\
\text { Excelentissima Senhora Dona Constituição } \\
\text { Lisboa. } 1823.4^{\circ} .\end{array}$ & 1 \\
\hline $\begin{array}{l}\text { Costa/ José Daniel } \\
\text { Rodrigues da/ }\end{array}$ & $\begin{array}{l}\text { O Espreitador do Mundo-Novo } \\
\text { Lisboa. } 1802.4^{\circ} .\end{array}$ & 1 \\
\hline $\begin{array}{l}\text { Costa/ José Daniel } \\
\text { Rodrigues da/ }\end{array}$ & $\begin{array}{l}\text { Hospital do Mundo } \\
\text { Lisboa. } 1805.4^{\circ} .\end{array}$ & 1 \\
\hline
\end{tabular}




\begin{tabular}{|c|c|c|}
\hline Autor & Título & Vol \\
\hline $\begin{array}{l}\text { Costa/ José Daniel } \\
\text { Rodrigues da/ }\end{array}$ & $\begin{array}{l}\text { Idéas Vagas sobre Varios Assumptos para Recreio } \\
\text { de Todas as Pessoas de Ambos os Sexos } \\
\text { Lisboa. } 1822.8^{\circ} .\end{array}$ & 1 \\
\hline $\begin{array}{l}\text { Costa/ José Daniel } \\
\text { Rodrigues da/ }\end{array}$ & $\begin{array}{l}\text { Jantar Imaginado com Sobremeza, Café e Palitos } \\
\text { Lisboa. } 1826.4^{\circ} .\end{array}$ & 1 \\
\hline $\begin{array}{l}\text { Costa/ José Daniel } \\
\text { Rodrigues da/ }\end{array}$ & $\begin{array}{l}\text { Jogo dos Dotes para Recreio das Sociedades } \\
\text { Lisboa. } 1802.8^{\circ} .\end{array}$ & 1 \\
\hline $\begin{array}{l}\text { Costa/ José Daniel } \\
\text { Rodrigues da/ }\end{array}$ & $\begin{array}{l}\text { Partidista contra Partidistas, e Jacobinos Praguejados } \\
\text { Lisboa. } 1809.4^{\circ} .\end{array}$ & 1 \\
\hline $\begin{array}{l}\text { Costa/ José Daniel } \\
\text { Rodrigues da/ }\end{array}$ & $\begin{array}{l}\text { Partidista contra Partidistas, e Jacobinos Praguejados } \\
\text { Lisboa. } 1809.4^{\circ} .\end{array}$ & 1 \\
\hline $\begin{array}{l}\text { Costa/ José Daniel } \\
\text { Rodrigues da/ }\end{array}$ & $\begin{array}{l}\text { Portugal Convalescido pela Dezejada, e Feliz Vinda } \\
\text { do Senhor Dom João VI } \\
\text { Lisboa. 1821. Fol. }\end{array}$ & 1 \\
\hline $\begin{array}{l}\text { Costa/ José Daniel } \\
\text { Rodrigues da/ }\end{array}$ & $\begin{array}{l}\text { Portugal Enfermo por Vicios, e Abusos de Ambos } \\
\text { os Sexos } \\
\text { Lisboa. } 1819.8^{\circ} .\end{array}$ & 2 \\
\hline $\begin{array}{l}\text { Costa/ José Daniel } \\
\text { Rodrigues da/ }\end{array}$ & $\begin{array}{l}\text { Protecção á Franceza } \\
\text { Lisboa. } 1808.4^{\circ}\end{array}$ & 1 \\
\hline $\begin{array}{l}\text { Costa/ José Daniel } \\
\text { Rodrigues da/ }\end{array}$ & $\begin{array}{l}\text { Quadras aos Annos do Serenissimo Senhor Infante } \\
\text { Dom Miguel } \\
\text { Lisboa. } 1823.4^{\circ} .\end{array}$ & 1 \\
\hline $\begin{array}{l}\text { Costa/ José Daniel } \\
\text { Rodrigues da/ }\end{array}$ & $\begin{array}{l}\text { Queixas á Fortuna. } \\
\text { Lisboa. } 1823.4^{\circ} .\end{array}$ & 1 \\
\hline $\begin{array}{l}\text { Costa/ José Daniel } \\
\text { Rodrigues da/ }\end{array}$ & $\begin{array}{l}\text { Resposta de Proclamação do General Angerau } \\
\text { Lisboa. } 1809.4^{\circ} \text {. Vide Camara Optica. }\end{array}$ & 1 \\
\hline $\begin{array}{l}\text { Costa/ José Daniel } \\
\text { Rodrigues da/ }\end{array}$ & $\begin{array}{l}\text { Rimas Offerecidas ao Illustrissimo Senhor Theotonio } \\
\text { Gomes de Carvalho } \\
\text { Lisboa. } 1795.8^{\circ} .\end{array}$ & 3 \\
\hline $\begin{array}{l}\text { Costa/ José Daniel } \\
\text { Rodrigues da/ }\end{array}$ & $\begin{array}{l}\text { Sonetos no Festivo Dia dos Annos do Serenissimo } \\
\text { Senhor Infante D. Miguel } \\
\text { Lisboa. } 1823.4^{\circ} .\end{array}$ & 1 \\
\hline $\begin{array}{l}\text { Costa/ José Daniel } \\
\text { Rodrigues da/ }\end{array}$ & $\begin{array}{l}\text { Surriada a Massena em Portugal, e Encontro das Duas } \\
\text { Rivaes no Palacio Imperial de França } \\
\text { Lisboa. } 1811.4^{\circ} .\end{array}$ & 1 \\
\hline
\end{tabular}




\begin{tabular}{|c|c|c|}
\hline Autor & Título & Vol \\
\hline $\begin{array}{l}\text { Costa/ José Daniel } \\
\text { Rodrigues da/ }\end{array}$ & $\begin{array}{l}\text { Segunda Parte da Surriada a Massena Etc } \\
\text { Lisboa. } 1811.4^{\circ} .\end{array}$ & 1 \\
\hline $\begin{array}{l}\text { Costa/ José Daniel } \\
\text { Rodrigues da/ }\end{array}$ & $\begin{array}{l}\text { Testamento que Fez o Dom Quixote da França, Antes } \\
\text { de Partir para a Sonhada Conquista da Russia } \\
\text { Lisboa. } 1813.4^{\circ} .\end{array}$ & 1 \\
\hline $\begin{array}{l}\text { Costa/ José Daniel } \\
\text { Rodrigues da/ }\end{array}$ & $\begin{array}{l}\text { Tribunal da Razão } \\
\text { Lisboa. } 1814.4^{\circ} .\end{array}$ & 1 \\
\hline $\begin{array}{l}\text { Costa/ José Daniel } \\
\text { Rodrigues da/ }\end{array}$ & $\begin{array}{l}\text { A Voz da Fortuna } \\
\text { Lisboa. } 1824.4^{\circ}\end{array}$ & 1 \\
\hline $\begin{array}{l}\text { Costa/ José Daniel } \\
\text { Rodrigues da/ }\end{array}$ & $\begin{array}{l}\text { Novena de Nossa Senhora da Luz } \\
\text { Lisboa. } 1817.8^{\circ} .\end{array}$ & 1 \\
\hline $\begin{array}{l}\text { Costa/ Paulo } \\
\text { Francisco Gomes da/ }\end{array}$ & $\begin{array}{l}\text { Oração em Acção de Graças pela Chegada de Sua } \\
\text { Magestade o Senhor Dom João VI } \\
\text { Lisboa. } 1821.8^{\circ} .\end{array}$ & 1 \\
\hline $\begin{array}{l}\text { Costa/ Rodrigo } \\
\text { Ferreira da/ }\end{array}$ & $\begin{array}{l}\text { Principios de Musica } \\
\text { Lisboa. } 1820.4^{\circ} .\end{array}$ & 1 \\
\hline $\begin{array}{l}\text { Costa/ Vicente José } \\
\text { Ferreira Cardozo da/ }\end{array}$ & $\begin{array}{l}\text { Compilação Systematica das Leys Extravagantes } \\
\text { de Portugal } \\
\text { Lisboa. } 1799.4^{\circ} .\end{array}$ & 1 \\
\hline $\begin{array}{l}\text { Costa/ Vicente José } \\
\text { Ferreira Cardozo da/ }\end{array}$ & $\begin{array}{l}\text { Memoria Sobre a Avaliação dos Bens de Prazo } \\
\text { Lisboa. } 1802.4^{\circ}\end{array}$ & 1 \\
\hline $\begin{array}{l}\text { Costa/ Vicente José } \\
\text { Ferreira Cardozo da/ }\end{array}$ & $\begin{array}{l}\text { Oração Dirigida ao Senhor Dom João Principe Regente: } \\
\text { Offerecendo-Ihe a Medalha que a Cidade do Porto } \\
\text { Mandou Cunhar Etc } \\
\text { Lisboa. } 1800.4^{\circ} \text {. }\end{array}$ & 1 \\
\hline $\begin{array}{l}\text { Coutinho/ Dionísio } \\
\text { Miguel Leitão/ }\end{array}$ & $\begin{array}{l}\text { Refutação da Allegação Juridica em que o } \\
\text { Excelentissimo [e Reverendissimo] Dom Jose } \\
\text { Joaquim da Cunha de Azevedo Coutinho, [Bispo de } \\
\text { Pernambuco, Eleito de Bragança e Miranda], Pertendeo } \\
\text { Mostrar Ser do Padroado da Coroa, e não da Ordem } \\
\text { Militar de Christo as Igrejas, [Dignidades], e Beneficios } \\
\text { dos Bispados do Cabo de Bojador para o Sul, [em que } \\
\text { se Comprehendem os Bispados de Cabo-Verde, São } \\
\text { Thomé, Angola, Brasil, India] até á China } \\
\text { Lisboa. 1806. } 4^{\circ} \text {. }\end{array}$ & 1 \\
\hline $\begin{array}{l}\text { Coutinho/ Gastão } \\
\text { Fausto da Câmara/ }\end{array}$ & $\begin{array}{l}\text { O Juramento dos Nunes /Dramma/ } \\
\text { Rio de Janeiro. } 1813.8^{\circ} \text {. }\end{array}$ & 1 \\
\hline
\end{tabular}




\begin{tabular}{|c|c|c|}
\hline Autor & Título & Vol \\
\hline Coutinho/ José & Carta Pastoral & 1 \\
\hline Caetano da Silva/ & Rio de Janeiro. 1819. $4^{\circ}$. & \\
\hline Coutinho/ José & Estatutos da Santa Igreja Chathedral do Rio de Janeiro & 1 \\
\hline Caetano da Silva/ & Rio de Janeiro. $1811.4^{\circ}$. & \\
\hline Coutinho/ José & Pastoral & 1 \\
\hline Caetano da Silva/ & Rio de Janeiro. 1811. Fol. & \\
\hline Coutinho/ José & Pastoraes & 2 \\
\hline Caetano da Silva/ & Rio de Janeiro. 1811. Fol. & \\
\hline $\begin{array}{l}\text { Coutinho/ José } \\
\text { Joaquim da Cunha } \\
\text { de Azevedo/ }\end{array}$ & $\begin{array}{l}\text { Alegasaõ Juridica na qual se Mostra, que Saõ do } \\
\text { Padroado da Coroa, e naõ da Ordem Militar de } \\
\text { Christo as Igrejas [Dignidades], e Beneficios dos } \\
\text { Bispados do Cabo de Bojador para o Sul, [em que } \\
\text { se Comprehendem os bispados de Cabo-Verde, São } \\
\text { Thomé, Angola, Brasil, India] até á China } \\
\text { Lisboa. } 1804.4^{\circ} \text {. }\end{array}$ & 1 \\
\hline Couto/ Antônio & Relação Historica da Revolução do Algarve & 1 \\
\hline Maria do/ & Lisboa. 1809. $4^{\circ}$. & \\
\hline Couto/ Diogo/ & $\begin{array}{l}\text { Decadas da Azia } \\
\text { Lisboa. } 1778.8^{\circ} .\end{array}$ & 14 \\
\hline $\begin{array}{l}\text { Couto/ Matheus } \\
\text { Valente de/ }\end{array}$ & $\begin{array}{l}\text { Tratado de Trigonometria Rectilinea e } \\
\text { [de Trigonometria] Spherica } \\
\text { Lisboa. } 1819.4^{\circ} .\end{array}$ & 1 \\
\hline $\begin{array}{l}\text { Couto/ Matheus } \\
\text { Valente de/ }\end{array}$ & $\begin{array}{l}\text { Tratado de Trigonometria Rectilinea e } \\
\text { [de Trigonometria] Spherica } \\
\text { Lisboa. } 1819.4^{\circ} .\end{array}$ & 1 \\
\hline \multirow[t]{2}{*}{ Crasset/ Padre João/ } & $\begin{array}{l}\text { Historia da Igreja do Japão. Vertida em Portuguez por } \\
\text { Dom Maria Antonia de São Boaventura, e Menezes } \\
\text { Lisboa. 1749. } 4^{\circ} \text {. }\end{array}$ & 3 \\
\hline & $\begin{array}{l}\text { Les Crimes de Robespierre, et de ses Principaux } \\
\text { Complices, etc } \\
\text { Paris } 1802.16 .\end{array}$ & 4 \\
\hline \multirow{3}{*}{$\begin{array}{l}\text { Cruce/ José } \\
\text { Joaquim da/ }\end{array}$} & Oratio Academica pro Celebrandis Natalibus & 1 \\
\hline & $\begin{array}{l}\text { [Celsissimae] Mariae a Gloria } \\
\text { Coimbra. 1820. Fol. }\end{array}$ & \\
\hline & $\begin{array}{l}\text { Cuidados Literarios do Prelado de Beja em Graça } \\
\text { do seu Bispado } \\
\text { Lisboa. } 1791.4^{\circ} .\end{array}$ & 1 \\
\hline
\end{tabular}




\begin{tabular}{|c|c|c|}
\hline Autor & Título & Vol \\
\hline & $\begin{array}{l}\text { Cultos Sagrados, e Religiosos que em Nove Dias se } \\
\text { Consagraõ ao Bemaventurado Simão de Roxas } \\
\text { Lisboa. } 1772.8^{\circ} .\end{array}$ & 1 \\
\hline $\begin{array}{l}\text { Damásio/ Frei Manoel } \\
\text { de São Caetano }\end{array}$ & $\begin{array}{l}\text { Thebaida Portugueza } \\
\text { Lisboa. 1793. } 8^{\circ} .\end{array}$ & 1 \\
\hline $\begin{array}{l}\text { Darrac/ Francisco de } \\
\text { Laiglesia y/ }\end{array}$ & $\begin{array}{l}\text { Canción Guerrera del Soldado Español } \\
\text { en el Campo de Batalla } \\
\text { Sevilla. } 1809.8^{\circ} .\end{array}$ & 1 \\
\hline $\begin{array}{l}\text { Darrac/ Francisco de } \\
\text { Laiglesia y/ }\end{array}$ & $\begin{array}{l}\text { Los Cantos del Trovador. Estrofas Cantadas a [Nuestro } \\
\text { Amado e Inocente Soberano] Don Fernando VI en su } \\
\text { Escandalosa Prision } \\
\text { Cadiz. } 809.4^{\circ} .\end{array}$ & 1 \\
\hline $\begin{array}{l}\text { Darrac/ Francisco de } \\
\text { Laiglesia y/ }\end{array}$ & $\begin{array}{l}\text { El Mejor Triunfo del Amor, ó el Vaticinio Cumplido } \\
\text { Cadiz } 1816.4^{\circ} .\end{array}$ & 1 \\
\hline $\begin{array}{l}\text { Daun/ José Sebastião } \\
\text { de Saldanha Oliveira/ }\end{array}$ & $\begin{array}{l}\text { Diorama de Portugal nos } 33 \text { Mezes Constitucionaes } \\
\text { ou Golpe de Vista sobre a Revolução de } 1820 \text { - A } \\
\text { Constituição de } 1822 \text { - a Restauração de } 1823 \\
\text { Lisboa. } 1823.4^{\circ} .\end{array}$ & 1 \\
\hline \multirow[t]{3}{*}{$\begin{array}{l}\text { Davila/ Eurico } \\
\text { Caterino/ }\end{array}$} & $\begin{array}{l}\text { Historia de las Guerras Civiles de Francia, con las } \\
\text { Adiciones [a la Historia] de Basilio Varen de Soto } \\
\text { Antuérpia. 1826. Fol. }\end{array}$ & 1 \\
\hline & $\begin{array}{l}\text { Deducção dos Votos no Supremo Conselho Provisorio, } \\
\text { Feito ao Chefe de Divizão Rodrigo José Ferreira Lobo } \\
\text { Londres. } 1817.8^{\circ} .\end{array}$ & 1 \\
\hline & $\begin{array}{l}\text { Defensa y Vindicacion de las Glorias é Independencia } \\
\text { de la Nacion } \\
\text { Cadiz. } 1813.4^{\circ} .\end{array}$ & 1 \\
\hline Deffand/ Marquise du/ & $\begin{array}{l}\text { Lettres à Horace Walpole } \\
\text { Paris } 1813.8^{\circ} .\end{array}$ & 4 \\
\hline $\begin{array}{l}\text { Grandpré/ Louis-Marie- } \\
\text { Joseph Ohier de/ }\end{array}$ & $\begin{array}{l}\text { Voyage à la Côte Occidentale d’Afrique } \\
\text { Paris } 1801.8^{\circ} .\end{array}$ & 2 \\
\hline Delabre/ Antoine/ & $\begin{array}{l}\text { Notice sur l'Ancien Royaume des Auvergnats, } \\
\text { et sur la Ville de Clermont } \\
\text { Clermont. } 1805.8^{\circ} .\end{array}$ & 1 \\
\hline Delille/ Jacques/ & $\begin{array}{l}\text { La Conversation. Poème } \\
\text { Paris. } 1812.8^{\circ} .\end{array}$ & 1 \\
\hline
\end{tabular}




\begin{tabular}{|c|c|c|}
\hline Autor & Título & Vol \\
\hline & $\begin{array}{l}\text { Demonstração Analitica dos Barbaros, e Inauditos } \\
\text { Procedimentos Adoptados como Meios de Justiça pelo } \\
\text { Imperador dos Franceses para a Usurpação do Throno } \\
\text { da Serenissima [e Augustissima] Casa de Bragança Etc } \\
\text { Lisboa. } 1810.4^{\circ} \text {. }\end{array}$ & 1 \\
\hline \multirow[t]{8}{*}{$\begin{array}{l}\text { Descourtilz/ Michel- } \\
\text { Etienne/ }\end{array}$} & $\begin{array}{l}\text { Voyages d'un Naturaliste, et ses Observations Faites } \\
\text { sur les Trois Règnes de la Nature, etc } \\
\text { Paris. } 1809.8^{\circ} .\end{array}$ & 3 \\
\hline & $\begin{array}{l}\text { Descripção das Festas que Fizeram Alguns Moradores } \\
\text { da Villa de Benavente em Acção de Graças pela } \\
\text { Elevação de Sua Magestade ao seu Augusto Throno } \\
\text { Lisboa. } 1823.4^{\circ} .\end{array}$ & 1 \\
\hline & $\begin{array}{l}\text { Descripção da Illuminação Symbolica, que Fez } \\
\text { o Coronel Antonio Joaquim da Silva Braga, pelo } \\
\text { Nascimento da Senhora Princeza D. Maria da Gloria } \\
\text { Rio de Janeiro. } 1819.4^{\circ} \text {. }\end{array}$ & 1 \\
\hline & $\begin{array}{l}\text { Descripción de la Decoración Arquitectónica con } \\
\text { que se que Puso la lluminación que la Noche del día } \\
20 \text { de Marzo Hubo en Cádiz en Casa del Sr. Conde } \\
\text { de Palmela, Ministro de Portugal, en Celebridad } \\
\text { de la Publicación de la Constitución Política [de la } \\
\text { Monarquía] Española } \\
\text { Cadiz. } 1812.4^{\circ} \text {. }\end{array}$ & 1 \\
\hline & $\begin{array}{l}\text { Descripción de las Fiestas de la Ciudad de Cadiz } \\
\text { en los Dias de la Llegada y Mansion de su Reyna } \\
\text { y Señora Infanta } \\
\text { Cadiz. 1816. Fol. }\end{array}$ & 1 \\
\hline & $\begin{array}{l}\text { Description Historique de I'Italie } \\
\text { Avignon. } 1790.8^{\circ} .\end{array}$ & 2 \\
\hline & $\begin{array}{l}\text { Descubrimiento de la Mina de los Publicistas de Cadiz } \\
\text { Folha avulsa. }\end{array}$ & 1 \\
\hline & $\begin{array}{l}\text { Desenfado Patriotico } \\
\text { Cadiz 1810. } 8^{\circ} .\end{array}$ & 1 \\
\hline \multirow[t]{2}{*}{$\begin{array}{l}\text { Fantin-Desodoards/ } \\
\text { Antoine/ }\end{array}$} & $\begin{array}{l}\text { Histoire Philosophique de la Révolution de France } \\
\text { depuis la Première Assemblée des Notables, } \\
\text { jusqu'à la Paix de } 1801 \\
\text { Paris. } 1801.8^{\circ} .\end{array}$ & 9 \\
\hline & $\begin{array}{l}\text { Despedida de Washington al Pueblo } \\
\text { de los Estados Unidos } \\
\text { Buenos Aires. } 1813.8^{\circ} .\end{array}$ & 1 \\
\hline
\end{tabular}




\begin{tabular}{|c|c|c|}
\hline Autor & Título & Vol \\
\hline & $\begin{array}{l}\text { Despertador, ou Unico Meio de Salvar a Hespanha. } \\
\text { Traduzida em Portuguez } \\
\text { Lisboa. } 1811.4^{\circ} .\end{array}$ & 1 \\
\hline \multirow[t]{8}{*}{$\begin{array}{l}\text { Fantin-Desodoards/ } \\
\text { Antoine/ }\end{array}$} & $\begin{array}{l}\text { Devocion al Glorioso San Felix de Cantalicio } \\
\text { Madrid.1768. } 24^{\circ} \text {. }\end{array}$ & 1 \\
\hline & $\begin{array}{l}\text { Diálogo Imparcial sobre el Generalato del Excelentísimo } \\
\text { Señor Duque de Ciudad-Rodrigo } \\
4^{\circ} \text {. }\end{array}$ & 1 \\
\hline & $\begin{array}{l}\text { Diálogo entre Don Justo Claro y Don Prudencio Bueno } \\
\text { Madrid. } 1823.4^{\circ} .\end{array}$ & 1 \\
\hline & $\begin{array}{l}\text { Dialogo Moral } \\
\text { Lisboa. } 1803.8^{\circ} .\end{array}$ & 1 \\
\hline & $\begin{array}{l}\text { Diario das Cortes Geraes e Extraordinarias } \\
\text { da Nação Portugueza } \\
\text { Lisboa. 1821. Fol. }\end{array}$ & 3 \\
\hline & $\begin{array}{l}\text { Dictamen Imparcial: sobre la Resolucion que Podria } \\
\text { Tomar, con Arreglo a Nuestra Sabia a Constituicion, } \\
\text { el Soberano Congreso de las Cortes } \\
\text { Cadiz. } 1812.4^{\circ} .\end{array}$ & 1 \\
\hline & $\begin{array}{l}\text { Dictionnaire de l'Académie Française } \\
\text { Paris 1799. Fol. }\end{array}$ & 2 \\
\hline & $\begin{array}{l}\text { Dictionary /A Compendious Geographical/ Containing } \\
\text { a Concise Description of the Most Remarkable Places, } \\
\text { Ancient and Modern, in Europe, Asia, Africa \& America } \\
\text { Londres. } 1804.8^{\circ} .\end{array}$ & 4 \\
\hline \multirow[t]{4}{*}{ Dilworth/ Thomas/ } & $\begin{array}{l}\text { A New Guide to the English Tongue } \\
\text { Londres. 1793. } 8^{\circ} .\end{array}$ & 1 \\
\hline & $\begin{array}{l}\text { Discurso /Breve/ mui Util en las Circunstancias } \\
\text { Actuales de Europa } \\
\text { Cadiz. } 1811.4^{\circ} \text {. }\end{array}$ & 1 \\
\hline & $\begin{array}{l}\text { Discurso que a Sua Magestade Fidelissima o Senhor } \\
\text { Dom João VI, Dirigio o [Mui Honrado] Juiz do Povo de } \\
\text { Lisboa } \\
\text { Lisboa. } 1824.4^{\circ} \text {. }\end{array}$ & 1 \\
\hline & $\begin{array}{l}\text { Discurso Politico-Moral en Acción de Gracias, por los } \\
\text { Enlaces del Señor Don Fernando VII, y el Señor Infante } \\
\text { Don Carlos } \\
\text { Cartagena. } 1816.4^{\circ} .\end{array}$ & 1 \\
\hline
\end{tabular}




\begin{tabular}{|c|c|c|}
\hline Autor & Título & Vol \\
\hline \multirow[t]{9}{*}{ Dilworth/ Thomas/ } & $\begin{array}{l}\text { Discurso Religioso-Politico [no qual se Mostra não só } \\
\text { pelos Fundamentos da Religião, mas também pelos } \\
\text { Argumentos Tirados do Direito Publico, e Lei Natural } \\
\text { Tanto a Authoridade da Igreja como a Legitima } \\
\text { Propriedade dos seus Bens] } \\
\text { Lisboa. } 1823.4^{\circ} .\end{array}$ & 1 \\
\hline & $\begin{array}{l}\text { Discursos que a EI Rey Fernando VII y lo Serenisimo } \\
\text { Infante Don Carlos Hicieron los Excelentisimos General } \\
\text { en jefe Don Francisco Xavier Elio, y el Brigadier Don } \\
\text { João de Potous y Moxica etc } \\
\text { Valência. 1812. } 4^{\circ} \text {. }\end{array}$ & 1 \\
\hline & $\begin{array}{l}\text { Discusion del Proyecto de Decreto sobre el Tribunal } \\
\text { de Ia Inquisicion } \\
\text { Cadiz. } 1813.4^{\circ} .\end{array}$ & 1 \\
\hline & $\begin{array}{l}\text { Dissertação sobre os Regulares } \\
\text { Lisboa. } 1821.4^{\circ} .\end{array}$ & 1 \\
\hline & $\begin{array}{l}\text { Divertimento Instructivo, ou Collecção Escolhida } \\
\text { de Novellas, Historias, [Contos Moraes], Anedoctas } \\
\text { [Interessantes, Parabolas, Fabulas, Ditos Filosoficos, } \\
\text { Contos para Rir, etc] } \\
\text { Lisboa. } 1804.8^{\circ} .\end{array}$ & 1 \\
\hline & $\begin{array}{l}\text { Divertimento Instructivo, ou Collecção Escolhida } \\
\text { de Novellas, Historias, [Contos Moraes], Anedoctas } \\
\text { [Interessantes, Parabolas, Fabulas, Ditos Filosoficos, } \\
\text { Contos para Rir, etc] } \\
\text { Lisboa. } 1805.8^{\circ} .\end{array}$ & 2 \\
\hline & $\begin{array}{l}\text { Documentos que authorisão a Verdadeira Agoa } \\
\text { de Inglaterra } \\
\text { Lisboa. } 1810 . \text { Fol. }\end{array}$ & 1 \\
\hline & $\begin{array}{l}\text { Documentos Relativos ao Juramento da Rainha } \\
\text { Lisboa. } 1822.4^{\circ} \text {. }\end{array}$ & 1 \\
\hline & $\begin{array}{l}\text { Donne /Le/ Cambiate } \\
\text { Lisboa. } 1804.8^{\circ} .\end{array}$ & 1 \\
\hline $\begin{array}{l}\text { Dores/ Frei Manuel } \\
\text { Inácio das/ }\end{array}$ & $\begin{array}{l}\text { Carta Pastoral } \\
\text { Lisboa. } 1811.4^{\circ} .\end{array}$ & 1 \\
\hline $\begin{array}{l}\text { Drake/ Frei José de } \\
\text { Almeida }\end{array}$ & $\begin{array}{l}\text { Oração Funebre: Recitada nas Exequias da Senhora } \\
\text { Dona Maria I, Rainha de Portugal } \\
\text { Lisboa. } 1816.4^{\circ} .\end{array}$ & 1 \\
\hline
\end{tabular}




\begin{tabular}{|c|c|c|}
\hline Autor & Título & Vol \\
\hline $\begin{array}{l}\text { Drake/ Frei José de } \\
\text { Almeida }\end{array}$ & $\begin{array}{l}\text { Drama aos Annos da Rainha Fidelissima Dona Maria I } \\
\text { Lisboa. } 1805.8^{\circ} .\end{array}$ & 1 \\
\hline Droz/ Joseph/ & $\begin{array}{l}\text { Lina ou les Enfants du Ministre Albert } \\
\text { Paris. } 1805.8^{\circ} .\end{array}$ & 1 \\
\hline Ducray-Duminil/ & $\begin{array}{l}\text { Alexis, ou la Maisonnette dans les Bois } \\
\text { Toulouse. } 1793.12^{\circ} \text {. }\end{array}$ & 4 \\
\hline Ducray-Duminil/ & $\begin{array}{l}\text { Jules, ou le Toit Paternel } \\
\text { Paris. } 1806.8^{\circ} .\end{array}$ & 4 \\
\hline Ducray-Duminil/ & $\begin{array}{l}\text { Madame de Valnoir, ou l'École des Familles } \\
\text { Paris. } 1813.8^{\circ} .\end{array}$ & 4 \\
\hline Ducray-Duminil/ & $\begin{array}{l}\text { Le Petit Carrillonneur } \\
\text { Paris. } 1809.8^{\circ} .\end{array}$ & 4 \\
\hline \multirow[t]{2}{*}{ Ducray-Duminil/ } & $\begin{array}{l}\text { Paul, ou la Ferme Abandonnée } \\
\text { Paris. 1801. } 12 .^{\circ}\end{array}$ & 4 \\
\hline & $\begin{array}{l}\text { Dueto de Laberco e Taralhão com que o Anão dos } \\
\text { Assobios dá os Parabens a Rabi Goibinhas Etc } \\
\text { Lisboa. } 1825.4^{\circ} .\end{array}$ & 1 \\
\hline Echard/ Lorenzo/ & $\begin{array}{l}\text { Diccionario Geographico, etc. Traducido del Francés } \\
\text { al Castellano por D. Juan de Ia Serna } \\
\text { Madrid. } 1750.4^{\circ} .\end{array}$ & 2 \\
\hline Edgeworth/ Maria & $\begin{array}{l}\text { Conseils à Mon Fils. [Traduction Libre de l'Anglais } \\
\text { par Bertin] } \\
\text { Paris. } 1814.8^{\circ} .\end{array}$ & 2 \\
\hline \multirow[t]{4}{*}{ Edgeworth/ Maria } & $\begin{array}{l}\text { Léonora. Traduit de le Anglais, [par } C^{* * *} \text {. } C^{* * *} \text { ] } \\
\text { Paris } 1807.8^{\circ} \text {. }\end{array}$ & 3 \\
\hline & $\begin{array}{l}\text { Éléments de l'Histoire Romaine } \\
\text { Paris. } 1809.8^{\circ} .\end{array}$ & 4 \\
\hline & $\begin{array}{l}\text { Elena e Constantino. Drama } \\
\text { Lisboa. } 1821.8^{\circ} .\end{array}$ & 1 \\
\hline & $\begin{array}{l}\text { Elevaçoens da Alma e Reflexoens Eucharisticas a } \\
\text { Jesus Christo Quando o S.S. Sacramento Está Exposto. } \\
\text { Traduzidas do Francez por João Baptista Bonavie } \\
\text { Lisboa. } 1787.8^{\circ} .\end{array}$ & 1 \\
\hline
\end{tabular}




\begin{tabular}{|c|c|c|}
\hline Autor & Título & Vol \\
\hline \multirow[t]{13}{*}{ Edgeworth/ Maria } & $\begin{array}{l}\text { Elogio aos Annos de Sua Magestade a Rainha } \\
\text { Nossa Senhora } \\
\text { Lisboa. } 1805.8^{\circ} .\end{array}$ & 1 \\
\hline & $\begin{array}{l}\text { Elogio aos Felizes Annos do Principe Regente } \\
\text { Nosso Senhor } \\
\text { Sem lugar e ano. } 4^{\circ} .\end{array}$ & 1 \\
\hline & $\begin{array}{l}\text { Elysa, e Luso, ou o Templo de Venus. Elogio Dramatico } \\
\text { Lisboa. 1821. } 4^{\circ} .\end{array}$ & 1 \\
\hline & $\begin{array}{l}\text { Émilie et Alphonse } \\
\text { Paris. } 1808.8^{\circ} .\end{array}$ & 3 \\
\hline & $\begin{array}{l}\text { Engenheiro /O/ Civil Portuguez, Respondendo } \\
\text { aos Quesitos que se Ihe Propõem, Relativos } \\
\text { á sua Profissão Etc } \\
\text { Lisboa. } 1804.4^{\circ} \text {. Caderno } 1 .^{\circ}\end{array}$ & 1 \\
\hline & $\begin{array}{l}\text { Ensaio sobre Perigos das Sepulturas dentro } \\
\text { das Cidades, e nos seus Contornos } \\
\text { Rio de Janeiro. } 1812.8^{\circ} .\end{array}$ & 1 \\
\hline & $\begin{array}{l}\text { Entrada y Recibimiento de Su Majestad como Reina de } \\
\text { España D. Maria Josefa Amalia de Sajonia } \\
\text { Madrid. } 1819.4^{\circ} \text {. }\end{array}$ & 1 \\
\hline & $\begin{array}{l}\text { Épitres /Les/ et Evangiles des Dimanches et Fêtes de } \\
\text { l'Année, avec des Courtes Prières Durant la Messe } \\
\text { Paris. } 1813.12^{\circ} \text {. }\end{array}$ & 1 \\
\hline & $\begin{array}{l}\text { Esboço /Rapido/ sobre a Maçoneria } \\
\text { Lisboa. } 1823.8^{\circ} .\end{array}$ & 1 \\
\hline & $\begin{array}{l}\text { Essai d'Instruction Morale ou les Devoirs envers Dieu, } \\
\text { le Prince et la Patrie, la Société et Soi-Même } \\
\text { Paris } 1813.8^{\circ} .\end{array}$ & 2 \\
\hline & $\begin{array}{l}\text { Establecimiento del Tribunal de la Santa Inquisición } \\
\text { en España } \\
\text { Cadiz. } 1813 .\end{array}$ & 1 \\
\hline & $\begin{array}{l}\text { Estatutos de la Real Orden de la Reina María Luisa } \\
\text { Fol. }\end{array}$ & 1 \\
\hline & $\begin{array}{l}\text { Estatutos do Recolhimento de Nossa Senhora da Gloria } \\
\text { do Lugar da Boa Vista de Pernambuco } \\
\text { Lisboa } 1798.4^{\circ} .\end{array}$ & 1 \\
\hline
\end{tabular}




\begin{tabular}{|c|c|c|}
\hline Autor & Título & Vol \\
\hline Edgeworth/Maria & $\begin{array}{l}\text { Estatutos da Sociedade do Giro dos Vinagres } \\
\text { do Alto Douro } \\
\text { Porto. } 1822.4^{\circ} .\end{array}$ & 1 \\
\hline \multirow[t]{11}{*}{ Neves/ João Antônio/ } & $\begin{array}{l}\text { O Hymeneo /Drama/ } \\
\text { Lisboa. } 1818.8^{\circ} .\end{array}$ & 1 \\
\hline & $\begin{array}{l}\text { Les Études Convenables aux Demoiselles Etc } \\
\text { Paris. } 1803.8^{\circ} .\end{array}$ & 2 \\
\hline & $\begin{array}{l}\text { Études de la Nature. Nouvelle Édition Revue et } \\
\text { Corrigée, par Jacques-Bernardin Henri Saint-Pierre } \\
\text { Paris. } 1804.8^{\circ} .\end{array}$ & 5 \\
\hline & $\begin{array}{l}\text { O Evangelho em Triunfo, ou Historia de hum Filisofo } \\
\text { Desenganado. Traduzida do Castelhano } \\
\text { Lisboa. } 1802.8^{\circ} .\end{array}$ & 8 \\
\hline & $\begin{array}{l}\text { Les Exercices de la Vie Interieure, ou l'Esprit Interieur } \\
\text { Angers. } 8^{\circ} .\end{array}$ & 1 \\
\hline & $\begin{array}{l}\text { Exhortação ás Nobres e Illustres Damas Lisbonenses, e } \\
\text { Brazilienses, e ao Sexo Feminino de Todas as Classes } \\
\text { Lisboa. } 1809.4^{\circ} .\end{array}$ & 1 \\
\hline & $\begin{array}{l}\text { Explicação de hum Painel Oferecido a Sua Alteza Real } \\
\text { o Principe Regente } \\
\text { Lisboa. } 1810.4^{\circ} .\end{array}$ & 1 \\
\hline & $\begin{array}{l}\text { Exposição Analytica, e Justificativa da Conducta, } \\
\text { e Vida Publica do Visconde do Rio Secco } \\
\text { Rio de Janeiro. 1821. Fol. }\end{array}$ & 1 \\
\hline & $\begin{array}{l}\text { Breve Exposição do Comportamento Publico } \\
\text { do Visconde do Rio Secco } \\
\text { Lisboa. } 1821.4^{\circ} .\end{array}$ & 1 \\
\hline & $\begin{array}{l}\text { Exposicion que hace un Oficial [Subalterno á sus } \\
\text { Compañeros de Armas] sobre la Decadencia de los } \\
\text { Exércitos Españoles } \\
\text { Cadiz. } 1813.4^{\circ} .\end{array}$ & 1 \\
\hline & $\begin{array}{l}\text { [Explicacion] Legal y Genuina de la Nueva } \\
\text { Constituicion á los Edictores del Conciso } \\
\text { Cadiz. } 1812.4^{\circ} .\end{array}$ & 1 \\
\hline
\end{tabular}




\begin{tabular}{|c|c|c|}
\hline Autor & Título & Vol \\
\hline \multirow[t]{2}{*}{ Neves/ João Antônio/ } & $\begin{array}{l}\text { Exposicion del Secretario de Estado y del Despacho } \\
\text { de Gracia y Justicia, [que Forma Parte del Expediente } \\
\text { General Remetido] de Órden de la Regencia del Reyno } \\
\text { á las Córtes Generales Extraordinarias sobre } \\
\text { el Restablecimiento de Conventos etc } \\
\text { Cadiz. } 1812.4^{\circ} .\end{array}$ & 1 \\
\hline & $\begin{array}{l}\text { Fablier /Le/ du Second Âge, ou Choix de Fables } \\
\text { à la Portée des Adolescens } \\
\text { Paris. } 1810.8^{\circ} .\end{array}$ & 1 \\
\hline Fabri/ Giovanni/ & $\begin{array}{l}\text { Ariovaldo Rei dos Longobardos. Baile Historico } \\
\text { Lisboa. } 1823.8^{\circ} \text {. } \\
\text { Está junto ao Cazamento na Aldêa. }\end{array}$ & 1 \\
\hline \multirow[t]{2}{*}{ Faca/ Zacarias Alves/ } & $\begin{array}{l}\text { Academia das Mulheres ou o Liberalismo do Seculo } \\
\text { Combatido até pela Fraqueza deste Sexo } \\
\text { Coimbra. } 1823.4^{\circ} \text {. }\end{array}$ & 1 \\
\hline & $\begin{array}{l}\text { Falla Feita aos Povos de Campo-Maior } \\
\text { Fol. }\end{array}$ & 1 \\
\hline \multirow[t]{2}{*}{$\begin{array}{l}\text { Farfan/ D. Fernando } \\
\text { de la Torre/ }\end{array}$} & $\begin{array}{l}\text { Fiestas de la S. Iglesia Metropolitana, } \\
\text { y Patriarcal de Sevilla etc } \\
\text { Sevilla. 1671. Fol }\end{array}$ & 1 \\
\hline & $\begin{array}{l}\text { Fayel /Dramma/ } \\
\text { Lisboa. } 1823.8^{\circ}\end{array}$ & 1 \\
\hline $\begin{array}{l}\text { Fénelon/ François } \\
\text { Salignac de la Mothe/ }\end{array}$ & $\begin{array}{l}\text { Les Aventures de Télémaque } \\
\text { Paris } 1808.12 .^{\circ}\end{array}$ & 4 \\
\hline $\begin{array}{l}\text { Fénelon/ François } \\
\text { Salignac de la Mothe/ }\end{array}$ & $\begin{array}{l}\text { Fables } \\
\text { Paris. 1809. } 8^{\circ} .\end{array}$ & 1 \\
\hline $\begin{array}{l}\text { Fénelon/ François } \\
\text { Salignac de la Mothe/ }\end{array}$ & $\begin{array}{l}\text { Morceaux Choisis } \\
\text { Paris. } 1813.8^{\circ} .\end{array}$ & 1 \\
\hline $\begin{array}{l}\text { Fénelon/ François } \\
\text { Salignac de la Mothe/ }\end{array}$ & $\begin{array}{l}\text { Oeuvres Philosophiques } \\
\text { Paris. } 1786.8^{\circ} .\end{array}$ & 1 \\
\hline $\begin{array}{l}\text { Fénelon/ François } \\
\text { Salignac de la Mothe/ }\end{array}$ & $\begin{array}{l}\text { Oeuvres Spirituelles } \\
\text { Paris. } 1810.8^{\circ} .\end{array}$ & 4 \\
\hline \multirow[t]{2}{*}{ Manoel/ } & $\begin{array}{l}\text { Alma Instruida } \\
\text { Lisboa. } 1638.4^{\circ} .\end{array}$ & 3 \\
\hline & $\begin{array}{l}\text { Fernandino /EI/ Periodico } \\
\text { Valência. } 1814.4^{\circ} \text {. }\end{array}$ & 1 \\
\hline
\end{tabular}




\begin{tabular}{|c|c|c|}
\hline Autor & Título & Vol \\
\hline Figueiredo/ Antônio & Analyse da Profissão da Fé do Santo Padre Pio IV & 1 \\
\hline Pereira de/ & Lisboa. 1791. $4^{\circ}$. & \\
\hline Figueiredo/ Antônio & Appendix e Illustração da Tentativa Theologica & 1 \\
\hline Pereira de/ & Lisboa. 1768. $4^{\circ}$ & \\
\hline Figueiredo/ Antônio & Novo Methodo da Grammatica Latina & 1 \\
\hline Pereira de/ & Lisboa. $1814.8^{\circ}$. & \\
\hline Figueiredo/ Antônio & O Reinado do Amor, Dissertação Filologica Etc & 1 \\
\hline Pereira de/ & Lisboa. 1789. $4^{\circ}$ & \\
\hline Figueiredo/ Antônio & Tentativa Theologica & 1 \\
\hline Pereira de/ & Lisboa. 1769. $4^{\circ}$. & \\
\hline Filangieri/ Gaetano/ & $\begin{array}{l}\text { La Science de la Législation } \\
\text { Paris. } 1786.8^{\circ} .\end{array}$ & 7 \\
\hline \multirow[t]{2}{*}{ Filopolita/ Antonio/ } & $\begin{array}{l}\text { Sueño del Marqués del Palacio, y Desvelos } \\
\text { de la Provincia de Cataluña } \\
\text { Cadiz. } 1812.4^{\circ} .\end{array}$ & 1 \\
\hline & $\begin{array}{l}\text { Filosofa /A/ por Amor, ou Cartas de Dous Amantes } \\
\text { Apaixonados, e Virtuosos } \\
\text { Lisboa. } 1806.12 .\end{array}$ & 1 \\
\hline $\begin{array}{l}\text { Flávio/ Josefo/ } \\
\text { José Roberto Monteiro }\end{array}$ & $\begin{array}{l}\text { Historia dos Judeos. Traduzida em Portuguez por José } \\
\text { Roberto Monteiro de Campos Coelho e Souza } \\
\text { Lisboa. } 1793.8^{\circ} .\end{array}$ & 6 \\
\hline Fleury/ & $\begin{array}{l}\text { Catéchisme des Fêtes et Autres Solennités } \\
\text { et Observances de l'Église } \\
\text { Langres. } 1802.8^{\circ} .\end{array}$ & 1 \\
\hline Florian/ & $\begin{array}{l}\text { Estelle, Pastorale } \\
\text { Paris } 1812.8^{\circ} .\end{array}$ & 1 \\
\hline Florian/ & $\begin{array}{l}\text { Guillaume Tell, ou la Suisse Libre } \\
\text { Paris. } 1801.8^{\circ} .\end{array}$ & 1 \\
\hline Florian/ & $\begin{array}{l}\text { Numa Pompilio, Segundo Rei de Roma } \\
\text { Lisboa. } 1805.8^{\circ} \text {. }\end{array}$ & 1 \\
\hline Florian/ & $\begin{array}{l}\text { Numa Pompilio, Segundo Rei de Roma } \\
\text { Paris. 1801. } 8^{\circ} \text {. }\end{array}$ & 2 \\
\hline Florian/ & $\begin{array}{l}\text { A Restauração da Liberdade de hum Pai, e a Felicidade } \\
\text { de Dous Amantes /Novella/ } \\
\text { Lisboa. } 1805.8^{\circ} .\end{array}$ & 1 \\
\hline
\end{tabular}




\begin{tabular}{|c|c|c|}
\hline Autor & Título & Vol \\
\hline \multirow[t]{3}{*}{$\begin{array}{l}\text { Fonseca/ Frei João } \\
\text { Mariano de Nossa } \\
\text { Senhora do Carmo/ }\end{array}$} & $\begin{array}{l}\text { Relação Abreviada dos Factos mais Recomendaveis } \\
\text { da Revolução de Campo Maior em } 1808 \\
\text { Lisboa. } 1813.8^{\circ} .\end{array}$ & 1 \\
\hline & $\begin{array}{l}\text { La Forêt de Hohenelbe ou Albert de Wetzlar. Traduit } \\
\text { de l'Anglais } \\
\text { Paris. } 1807.8^{\circ} .\end{array}$ & 5 \\
\hline & $\begin{array}{l}\text { La Forêt de Montalbano, Ou le Fils Généreux. Traduit } \\
\text { de l'Anglais de l'Auteur des Visions du Château des } \\
\text { Pyrenées } \\
\text { Paris. } 1813.8^{\circ} .\end{array}$ & 5 \\
\hline \multirow[t]{2}{*}{$\begin{array}{l}\text { Jesus/ Soror } \\
\text { Teresa Angélica } \\
\text { Peregrina de/ }\end{array}$} & $\begin{array}{l}\text { A Formosura de Deos, Inferida, e Declarada pelas } \\
\text { suas Infinitas Perfeições etc. Traduzida por Soror } \\
\text { Teresa Angélica } \\
\text { Lisboa. } 1785.8^{\circ} .\end{array}$ & 1 \\
\hline & $\begin{array}{l}\text { Formulaire de Prières, à l'Usage des Pensionnaires } \\
\text { des Religieuses Ursulines } \\
\text { Sem lugar e ano. } 8^{\circ} \text {. }\end{array}$ & 1 \\
\hline Fourcroy/ & $\begin{array}{l}\text { Filosofia Quimica ou Verdades Fundamentaes da } \\
\text { Quimica Moderna. Traduzida em Portuguez por } \\
\text { Manoel Joaquim Henriques da Silva } \\
\text { Lisboa. } 1801.4^{\circ} .\end{array}$ & 1 \\
\hline $\begin{array}{l}\text { Frances/ Madame } \\
\text { Sophie }\end{array}$ & $\begin{array}{l}\text { Angelo Guicciardini, ou le Bandit des Alpes. } \\
\text { Traduit de I'Anglais } \\
\text { Paris } 1817.8^{\circ} .\end{array}$ & 6 \\
\hline $\begin{array}{l}\text { Frances/ Madame } \\
\text { Sophie }\end{array}$ & $\begin{array}{l}\text { Constance de Lindensdorf, ou La Tour de Wolfenstad. } \\
\text { Traduit de l'anglais } \\
\text { Paris. } 1808.8^{\circ} .\end{array}$ & 4 \\
\hline $\begin{array}{l}\text { Frances/ Madame } \\
\text { Sophie }\end{array}$ & $\begin{array}{l}\text { L'Inconnu ou la Galerie Mystérieuse. Traduit de Anglais } \\
\text { par Madame de Viterne } \\
\text { Paris } 1810.8^{\circ} .\end{array}$ & 5 \\
\hline \multirow[t]{2}{*}{$\begin{array}{l}\text { Frances/ Madame } \\
\text { Sophie }\end{array}$} & $\begin{array}{l}\text { La Soeur de la Miséricorde, ou la Veille de la Toussaint. } \\
\text { Traduit de l'Anglais par Madame de Viterne } \\
\text { Paris. } 1809.8^{\circ} .\end{array}$ & 4 \\
\hline & $\begin{array}{l}\text { Francilia, Pastora do Tejo. Poezias de D. T. P. P. C. } \\
\text { Lisboa. } 1816.8^{\circ} .\end{array}$ & 1 \\
\hline $\begin{array}{l}\text { Franzini/ Marino } \\
\text { Miguel/ }\end{array}$ & $\begin{array}{l}\text { Conta da Receita, e Despeza da Cordoaria Nacional } \\
\text { e Real de Lisboa } \\
\text { Lisboa. } 1821.8^{\circ} .\end{array}$ & 1 \\
\hline
\end{tabular}




\begin{tabular}{|c|c|c|}
\hline Autor & Título & Vol \\
\hline $\begin{array}{l}\text { Freire/ Jerônimo } \\
\text { Ezequiel da Costa/ }\end{array}$ & $\begin{array}{l}\text { Hymno a Voz da Gratidão } \\
\text { Lisboa } 1825.4^{\circ} .\end{array}$ & 1 \\
\hline $\begin{array}{l}\text { Freitas/ Joaquim } \\
\text { Agostinho de/ }\end{array}$ & $\begin{array}{l}\text { Elogio Dedicado ao Serenissimo Senhor } \\
\text { e Infante Dom Miguel } \\
\text { Lisboa. } 1824.4^{\circ} .\end{array}$ & 1 \\
\hline $\begin{array}{l}\text { Freitas/ Joaquim } \\
\text { Agostinho de/ }\end{array}$ & $\begin{array}{l}\text { Elogio dirigido a Sua Alteza Real o Principe Regente } \\
\text { Nosso Senhor, por Occasião dos seus Felizes Annos } \\
\text { Lisboa. } 1806.4^{\circ} \text {. }\end{array}$ & 1 \\
\hline $\begin{array}{l}\text { Fresnoy/ Abade } \\
\text { Lenglet du/ }\end{array}$ & $\begin{array}{l}\text { Tablettes Chronologiques de l'Histoire Universelle } \\
\text { Sacrée et Profane, Ecclésiastique et Civile } \\
\text { Paris } 1778.8^{\circ} \text {. }\end{array}$ & 2 \\
\hline $\begin{array}{l}\text { Furtado/ Gregório } \\
\text { de Mendonça/ }\end{array}$ & $\begin{array}{l}\text { Ordenança de Campanha Destinada ás Tropas } \\
\text { Ligeiras, etc } \\
\text { Lisboa. } 1809.8^{\circ} .\end{array}$ & 1 \\
\hline $\begin{array}{l}\text { Gacon-Dufour/ } \\
\text { Madame/ }\end{array}$ & $\begin{array}{l}\text { La Cour de Catherine de Médicis, de Charles IX, } \\
\text { de Henri III et de Henri IV } \\
\text { Paris. } 1809.8^{\circ} .\end{array}$ & 2 \\
\hline Galaup/ Jean François/ & $\begin{array}{l}\text { / Voyage de la Pérouse autour du Monde } \\
\text { Paris. 1797. Fol. }\end{array}$ & 3 \\
\hline Gama/ Leonarda Gil/ & $\begin{array}{l}\text { Brados do Desengano contra o Profundo Sono } \\
\text { do Esquecimento } \\
\text { Lisboa. } 1736.8^{\circ} .\end{array}$ & 1 \\
\hline Gassier/ J. M./ & $\begin{array}{l}\text { Les Bourbons, ou Recueil Historique etc } \\
\text { Paris. } 1814.12^{\circ} .\end{array}$ & 1 \\
\hline \multirow[t]{2}{*}{ Gattel/ C. M./ } & $\begin{array}{l}\text { Nouveau Dictionnaire Portatif de la Langue Françoise } \\
\text { Lion. } 1803.8^{\circ} .\end{array}$ & 2 \\
\hline & $\begin{array}{l}\text { Gaceta de Madrid } \\
\text { Madrid. } 1814,1815,1816.4^{\circ} .\end{array}$ & 6 \\
\hline Gaioso/ Inácio Xavier/ & $\begin{array}{l}\text { Divertimento em Forma de Analysi sobre a Analysi dos } \\
\text { Cathecismos dos Pedreiros Livres, etc. Primeira Parte } \\
\text { Lisboa. } 1823.4^{\circ} .\end{array}$ & 1 \\
\hline Gaioso/Inácio Xavier/ & $\begin{array}{l}\text { Divertimento em Forma de Analysi sobre a Analysi } \\
\text { dos Cathecismos dos Pedreiros Livres, etc. } \\
\text { Primeira Parte e Segunda } \\
\text { Lisboa. } 1823.4^{\circ} .\end{array}$ & 1 \\
\hline
\end{tabular}




\begin{tabular}{|c|c|c|}
\hline Autor & Título & Vol \\
\hline \multirow[t]{2}{*}{ Gaioso/Inácio Xavier/ } & $\begin{array}{l}\text { Divertimento em Forma de Analysi sobre a Analysi } \\
\text { dos Cathecismos dos Pedreiros Livres, etc. } \\
\text { Primeira Parte e Segunda } \\
\text { Lisboa. } 1823.8^{\circ} .\end{array}$ & 1 \\
\hline & $\begin{array}{l}\text { Gazeta Universal [Politica, Litteraria e Mercantil] } \\
\text { Lisboa. 1821. Fol. }\end{array}$ & 2 \\
\hline \multirow[t]{2}{*}{$\begin{array}{l}\text { Legendre/ Adrien- } \\
\text { Marie/ }\end{array}$} & $\begin{array}{l}\text { Elementos de Geometria. Traduzidos do Francez } \\
\text { por Manoel Ferreira d'Araujo Guimarães } \\
\text { Rio de Janeiro. } 1809.8^{\circ} .\end{array}$ & 1 \\
\hline & $\begin{array}{l}\text { Le Génie de Bossuet } \\
\text { Paris. } 1808.8^{\circ} \text {. }\end{array}$ & 1 \\
\hline Genlis/ Madame de/ & $\begin{array}{l}\text { Les Annales de la Vertu, ou Histoire Universelle } \\
\text { Paris. } 1811.8^{\circ} .\end{array}$ & 2 \\
\hline Genlis/ Madame de/ & $\begin{array}{l}\text { L'Épouse Impertinente par Air } \\
\text { Paris. } 1804.8^{\circ} .\end{array}$ & 1 \\
\hline Genlis/ Madame de/ & $\begin{array}{l}\text { Madame de Maintenon, pour Servir de Suite à l'Histoire } \\
\text { de la Duchese de la Vallière } \\
\text { Paris. } 1813.8^{\circ} .\end{array}$ & 2 \\
\hline Genlis/ Madame de/ & $\begin{array}{l}\text { Les Mères Rivales, ou la Calomnie } \\
\text { Paris. } 1801.12^{\circ} .\end{array}$ & 6 \\
\hline Gessner/ M.'/ & $\begin{array}{l}\text { Morte d'Abel: Poëme [de Gessner], Traduit par Hubert } \\
\text { Paris. 1793. Fol. }\end{array}$ & 1 \\
\hline Gessner/ M.r/ & $\begin{array}{l}\text { La Muerte de Abel, ó El Fratricidio: Poema en Prosa } \\
\text { Madrid. } 1803.8^{\circ} \text {. }\end{array}$ & 1 \\
\hline Gessner/ M.'\% & $\begin{array}{l}\text { Oeuvres } \\
\text { Paris. [1797]. } 8^{\circ} \text {. }\end{array}$ & 2 \\
\hline Gessner/ M.r/ & $\begin{array}{l}\text { O Primeiro Navegante. Poema [de Gessner] } \\
\text { Lisboa. 1791. } 8^{\circ} \text {. }\end{array}$ & 1 \\
\hline Gilpin/ William/ & $\begin{array}{l}\text { Trois Essais sur le Beau Pittoresque; sur les Voyages } \\
\text { Pittoresques, et sur l'Art d'Esquisser le Paysage. Etc. } \\
\text { Traduit de l'Anglais par le Baron de Blumenstein } \\
\text { Breslau. } 1799.8^{\circ} .\end{array}$ & 3 \\
\hline Girard/ Abbé/ & $\begin{array}{l}\text { Synonymes François } \\
\text { Paris. 1796. } 8^{\circ} \text {. }\end{array}$ & 2 \\
\hline
\end{tabular}




\begin{tabular}{|c|c|c|}
\hline Autor & Título & Vol \\
\hline Gobinet/ Charles/ & $\begin{array}{l}\text { Instruction de la Jeunesse en la piété Chrétienne } \\
\text { Paris. } 1780.8^{\circ} .\end{array}$ & 1 \\
\hline $\begin{array}{l}\text { Godinho/ Padre } \\
\text { Manoel/ }\end{array}$ & $\begin{array}{l}\text { Vida, Virtudes, e Morte [com Opiniaõ de Santidade] } \\
\text { do Veneravel Padre Frei Antonio das Chagas } \\
\text { Lisboa. } 1762.4^{\circ} .\end{array}$ & 1 \\
\hline Goethe/ & $\begin{array}{l}\text { Alfred, ou les Années d'Apprentissage de Wilhelm } \\
\text { Meister. Traduit de l'Allemand, par C.-L. Sevelinges } \\
\text { Paris. } 1802.8^{\circ} .\end{array}$ & 3 \\
\hline Goldoni/ M./ & $\begin{array}{l}\text { Mémoires [de Goldoni] pour Servir a l'Histoire de sa Vie, } \\
\text { [et a celle de son Théatre] } \\
\text { Paris. } 1787.8^{\circ} .\end{array}$ & 3 \\
\hline $\begin{array}{l}\text { Gomes/ Bernardino } \\
\text { Antônio/ }\end{array}$ & $\begin{array}{l}\text { Ensaio Dermosographico, ou Succinta e Systematica } \\
\text { Descripção das Doenças Cutaneas } \\
\text { Lisboa. } 1820.4^{\circ} \text {. }\end{array}$ & 1 \\
\hline Gomez/ Madame de/ & $\begin{array}{l}\text { Les Cent Nouvelles Nouvelles } \\
\text { Liège. } 1772.8^{\circ} .\end{array}$ & 20 \\
\hline $\begin{array}{l}\text { Gordo/ Joaquim José } \\
\text { Ferreira/ }\end{array}$ & $\begin{array}{l}\text { Fontes Proximas da Compilação Filippina } \\
\text { Lisboa. } 1792.4^{\circ} .\end{array}$ & 1 \\
\hline Gordoa/ José Miguel/ & $\begin{array}{l}\text { Discurso Pronunciado [por el Señor Don José Miguel } \\
\text { Gordoa, Presidente de] las Córtes [Generales y } \\
\text { Extraordinarias el Último Dia de sus Sesiones } 14 \\
\text { de Setiembre de 1813] } \\
\text { Cadiz. } 1813.4^{\circ} .\end{array}$ & 1 \\
\hline \multirow[t]{2}{*}{ Legouvé/ } & $\begin{array}{l}\text { O Merecimento das Mulheres. Poema } \\
\text { Rio de Janeiro. } 1813.8^{\circ} \text {. }\end{array}$ & 1 \\
\hline & $\begin{array}{l}\text { Gramática de la Lengua Castellana } \\
\text { Madrid. 1796. } 8^{\circ} .\end{array}$ & 1 \\
\hline Granada/ Frei Luís de/ & $\begin{array}{l}\text { Introdução ao Symbolo da Fé. [Composta na Lingua } \\
\text { Hespanhola pelo Mestre Frei Frei Luiz de Granada]. } \\
\text { Traduzida do Espanhol } \\
\text { Lisboa. } 1780.8^{\circ} .\end{array}$ & 2 \\
\hline $\begin{array}{l}\text { Grellmaun/ Heinrich } \\
\text { Moritz Gottlieb/ }\end{array}$ & $\begin{array}{l}\text { Histoire des Bohémiens, ou Tableau des Moeurs, } \\
\text { Usages et Coutumes de ce Peuple Nomade } \\
\text { Paris. } 1816.8^{\circ} .\end{array}$ & 1 \\
\hline Gresset/ & $\begin{array}{l}\text { Oeuvres } \\
\text { Rouen. } 1788.8^{\circ} .\end{array}$ & 2 \\
\hline
\end{tabular}




\begin{tabular}{|c|c|c|}
\hline Autor & Título & Vol \\
\hline Griffet/ Henri/ & $\begin{array}{l}\text { Exercice de Piété pour la Communion } \\
\text { Paris. } 1766.8^{\circ} .\end{array}$ & 1 \\
\hline \multirow[t]{2}{*}{ Grivel/ } & $\begin{array}{l}\text { A Ilha Incognita, ou Memorias do Cavalheiro } \\
\text { de Gastines } \\
\text { Lisboa. } 1802.8^{\circ} .\end{array}$ & 6 \\
\hline & $\begin{array}{l}\text { Grizelda ou a Virtude em Prova. Drama } \\
\text { Rio de Janeiro. } 1815.8^{\circ} .\end{array}$ & 1 \\
\hline $\begin{array}{l}\text { Guedes/ Tomás } \\
\text { de Brito Moniz e/ }\end{array}$ & $\begin{array}{l}\text { Reflexões Politicas sobre o Estado Actual } \\
\text { da Nação Portugueza } \\
\text { Coimbra. 1823. Fol. }\end{array}$ & 1 \\
\hline \multirow[t]{2}{*}{ Guerner/ Cristóvão/ } & $\begin{array}{l}\text { Discurço Historico e Analytico sobre o Estabelecimento } \\
\text { da Companhia Geral da Agricultura das Vinhas } \\
\text { do Alto Douro } \\
\text { Lisboa. } 1814.8^{\circ} .\end{array}$ & 1 \\
\hline & $\begin{array}{l}\text { Guerre /La/ d'Espagne. Poème } \\
\text { Paris. } 1823.8^{\circ} .\end{array}$ & 1 \\
\hline $\begin{array}{l}\text { Guizot/ Madame } \\
\text { Pauline/ }\end{array}$ & $\begin{array}{l}\text { Les Enfants. Contes à l'Usage de la Jeunesse } \\
\text { Paris. Sem ano. } 8^{\circ} .\end{array}$ & 2 \\
\hline \multirow[t]{2}{*}{$\begin{array}{l}\text { Guizot/ Madame } \\
\text { Pauline/ }\end{array}$} & $\begin{array}{l}\text { Les Enfants. Contes à l'Usage de la Jeunesse } \\
\text { Paris. Sem ano. } 8^{\circ} .\end{array}$ & 2 \\
\hline & $\begin{array}{l}\text { O Novo Gulliver, ou Viagem de João Gulliver, Filho do } \\
\text { Capitão Gulliver. Traduzida de Hum Manuscripto Inglez } \\
\text { pelo Abbade des Fontaines } \\
\text { Lisboa. } 1804.8^{\circ} .\end{array}$ & 4 \\
\hline $\begin{array}{l}\text { Hausen/ Frei } \\
\text { Leonardo/ } \\
\text { Frei Domingos Freire }\end{array}$ & $\begin{array}{l}\text { Vida Admiravel, e Morte Precioza da Bemaventurada } \\
\text { Santa Roza de Santa Maria. Etc. Traduzida } \\
\text { em Portuguez pelo Reverendo Padre Mestre } \\
\text { Frei Domingos Freire } \\
\text { Lisboa. } 1674.4^{\circ} .\end{array}$ & 1 \\
\hline \multirow[t]{2}{*}{ Helme/ Elisabeth/ } & $\begin{array}{l}\text { Le Pélerin de la Croix. Traduit de l'Anglais } \\
\text { Paris. } 1807.8^{\circ} .\end{array}$ & 3 \\
\hline & $\begin{array}{l}\text { Henriqueta de Orleans, ou o Heroismo } \\
\text { Lisboa. } 1819.8^{\circ} .\end{array}$ & 2 \\
\hline $\begin{array}{l}\text { Hermida/ Benito } \\
\text { Ramón/ }\end{array}$ & $\begin{array}{l}\text { Breve Noticia de las Cortes, Govierno, ó Llámese } \\
\text { Constitucion del Reyno de Navarra } \\
\text { Cadiz. } 1811.4^{\circ} .\end{array}$ & 1 \\
\hline
\end{tabular}




\begin{tabular}{|c|c|c|}
\hline Autor & Título & Vol \\
\hline \multirow[t]{14}{*}{ Hervieux/ } & $\begin{array}{l}\text { Tratado sobre o Modo de Crear os Passaros Canarios } \\
\text { Lisboa. } 1801.8^{\circ} .\end{array}$ & 1 \\
\hline & $\begin{array}{l}\text { Nouvelles Heures à l'Usage des Enfans } \\
\text { Paris. 1801. } 12 .\end{array}$ & 1 \\
\hline & $\begin{array}{l}\text { Nouvelles Heures a l'Usage des Enfans } \\
\text { Paris. 1801. } 16 .\end{array}$ & 1 \\
\hline & $\begin{array}{l}\text { Hippolyto de Euripides. Vertido do Grego em Portuguez } \\
\text { Lisboa. } 1803.4^{\circ} \text {. }\end{array}$ & 1 \\
\hline & $\begin{array}{l}\text { Histoire de l'Ancien et du Nouveau Testament, } \\
\text { et des Juifs } \\
\text { Nîmes. } 1780.8^{\circ} \text {. }\end{array}$ & 3 \\
\hline & $\begin{array}{l}\text { Histoire de César-Auguste, Premier Empereur de Rome } \\
\text { Paris. } 1812.8^{\circ} .\end{array}$ & 2 \\
\hline & $\begin{array}{l}\text { Histoire Générale et Impartiale des Erreurs, des Fautes } \\
\text { et des Crimes Commis Pendant la Révolution Française } \\
\text { Paris. } 1797.8^{\circ} .\end{array}$ & 6 \\
\hline & $\begin{array}{l}\text { Histoire de Napoléon Bonaparte depuis sa Naissance } \\
\text { jusqu'à sa Deuxième Abdication } \\
\text { Paris. Sem ano. } 8^{\circ} \text {. }\end{array}$ & 4 \\
\hline & $\begin{array}{l}\text { Histoire de Pologne, depuis son Origine jusqu'en } 1795 \\
\text { Paris. } 1807.8^{\circ} \text {. }\end{array}$ & 2 \\
\hline & $\begin{array}{l}\text { Histoires de Richard Savage et de J. Thompson. } \\
\text { Traduites de I'Anglois par M. le Tourneur } \\
\text { Paris. } 1771.8^{\circ} .\end{array}$ & 1 \\
\hline & $\begin{array}{l}\text { Histoires Saintes les plus Remarquables et les plus } \\
\text { Intéressantes de l'Ancien Testament } \\
\text { Paris. } 1811.8^{\circ} .\end{array}$ & 1 \\
\hline & $\begin{array}{l}\text { Historia de Alexandre Magno } \\
\text { Lisboa. } 1789.8^{\circ} .\end{array}$ & 1 \\
\hline & $\begin{array}{l}\text { Historia dos Descobrimentos e Conquistas } \\
\text { dos Portuguezes no Novo Mundo } \\
\text { Lisboa. } 1786.8^{\circ} .\end{array}$ & 4 \\
\hline & $\begin{array}{l}\text { Historia de Gil Braz de Santilhana. } \\
\text { Traduzida em Portuguez } \\
\text { Lisboa. } 1808.8^{\circ} .\end{array}$ & 4 \\
\hline
\end{tabular}




\begin{tabular}{|c|c|c|}
\hline Autor & Título & Vol \\
\hline Hervieux/ & $\begin{array}{l}\text { Historia e Memorias da Academia Real das Sciencias } \\
\text { de Lisboa } \\
\text { Lisboa. } 1820.4^{\circ} .\end{array}$ & 2 \\
\hline $\begin{array}{l}\text { Lopes / Joaquim } \\
\text { José Pedro/ }\end{array}$ & $\begin{array}{l}\text { Historia Secreta da Corte, e Gabinete de S. Cloud, } \\
\text { ou de Buonaparte. Traduzida do Inglez em Portuguez } \\
\text { por Joaquim Jozé Pedro Lopes } \\
\text { Lisboa. } 1810.8^{\circ} .\end{array}$ & 1 \\
\hline \multirow[t]{3}{*}{ D. Luiz de D/ } & $\begin{array}{l}\text { Historia Certa da Seita dos Franc-Massões: sua } \\
\text { Origem, Doutrina, e Maximas. Pelo Presbytero D. Luiz D } \\
\text { Lisboa. } 1817.8^{\circ} .\end{array}$ & 1 \\
\hline & $\begin{array}{l}\text { Historia /Breve/ da Vida do Padre Frei Antonio } \\
\text { da Madre de Deos } \\
\text { Lisboa. } 1777.8^{\circ} .\end{array}$ & 1 \\
\hline & $\begin{array}{l}\text { Historia da Vida do Papa Ganganelli. Clemente XIV, } \\
\text { [da Ordem de S. Francisco] } \\
\text { Lisboa. } 1790.8^{\circ} .\end{array}$ & 5 \\
\hline $\begin{array}{l}\text { Homem/ Dom Luís } \\
\text { de Brito/ }\end{array}$ & $\begin{array}{l}\text { Pastoraes } \\
\text { Maranhão. 1808. } 4^{\circ} \text {. }\end{array}$ & 1 \\
\hline $\begin{array}{l}\text { Homem/ Frei Manuel } \\
\text { Joaquim da Mãe dos/ }\end{array}$ & $\begin{array}{l}\text { Academia Filozofica das Artes, e das Sciencias } \\
\text { Rio de Janeiro. } 1817.8^{\circ} .\end{array}$ & 5 \\
\hline $\begin{array}{l}\text { Homem/ Frei Manuel } \\
\text { Joaquim da Mãe dos/ }\end{array}$ & $\begin{array}{l}\text { Academia Filozofica das Artes, e das Sciencias } \\
\text { Rio de Janeiro. } 1817.8^{\circ} .\end{array}$ & 2 \\
\hline $\begin{array}{l}\text { Homem/ Frei Manuel } \\
\text { Joaquim da Mãe dos/ }\end{array}$ & $\begin{array}{l}\text { Academia Filozofica das Artes, e das Sciencias } \\
\text { Rio de Janeiro. } 1817.8^{\circ} \text {. }\end{array}$ & 2 \\
\hline $\begin{array}{l}\text { Homem/ Frei Manuel } \\
\text { Joaquim da Mãe dos/ }\end{array}$ & $\begin{array}{l}\text { Academia Filozofica das Artes, e das Sciencias } \\
\text { Rio de Janeiro. } 1817.8^{\circ} .\end{array}$ & $\begin{array}{c}3 \\
\text { Tomos } 1 \\
2 \text { e } 4\end{array}$ \\
\hline $\begin{array}{l}\text { Homem/ Frei Manuel } \\
\text { Joaquim da Mãe dos/ }\end{array}$ & $\begin{array}{l}\text { Academia Filozofica das Artes, e das Sciencias } \\
\text { Rio de Janeiro. } 1817.8^{\circ} .\end{array}$ & $\begin{array}{c}1 \\
\text { Tomo } 4\end{array}$ \\
\hline \multirow[t]{3}{*}{ Hue/ François/ } & $\begin{array}{l}\text { Dernières Années du Règne et de la Vie de Louis XVI } \\
\text { Londres. } 1806.4^{\circ} .\end{array}$ & 1 \\
\hline & $\begin{array}{l}\text { Hymno Constitucional } \\
\text { Rio de Janeiro. 1821. } 4^{\circ} \text {. }\end{array}$ & 1 \\
\hline & $\begin{array}{l}\text { Himno a Badajoz [Vencedora]: el } 11 \text { de Febrero de } 1810, \\
\text { [Puesto en Música Pa. Piano-Forte] } \\
\text { Cadiz. 1810. } 4^{\circ} .\end{array}$ & 1 \\
\hline
\end{tabular}




\begin{tabular}{|c|c|c|}
\hline Autor & Título & Vol \\
\hline \multirow[t]{3}{*}{ Hue/ François/ } & $\begin{array}{l}\text { Hymno em louvor de Nossa Ssenhora do Cabo, } \\
\text { Offerecido pelos Devotos da Freguezia d'Ajuda } \\
\text { Lisboa. } 1821.4^{\circ} .\end{array}$ & 1 \\
\hline & $\begin{array}{l}\text { Idea de la Causa Formada por Orden de las Cortes a } \\
\text { los Catorce Ministros del Supremo Consejo de Castilla } \\
\text { Cadiz. } 1812.4^{\circ} .\end{array}$ & 1 \\
\hline & $\begin{array}{l}\text { Idea /Breve/ de las Fiestas que se Han de Celebrar } \\
\text { en esta M.N.Y.M.L Ciudad de Sevilla [con el Plausible } \\
\text { Motivo de Ia] Entrada de SS.AA.RR. Ias Señoras } \\
\text { Infantas de Portugal Doña Maria Isabel Francisca y } \\
\text { Doña María Francisca de Asis } \\
\text { Sem lugar, nem ano. } 4^{\circ} \text {. }\end{array}$ & 1 \\
\hline $\begin{array}{l}\text { Lopes/ Joaquim } \\
\text { José Pedro }\end{array}$ & $\begin{array}{l}\text { Ideas /As/ Liberaes, Ultimo Refugio dos Inimigos } \\
\text { da Religião e do Throno. Traduzidas do Italiano por } \\
\text { Joaquim Joze Pedro Lopes } \\
\text { Lisboa. } 1823.8^{\circ}\end{array}$ & 1 \\
\hline \multirow[t]{6}{*}{ Illescas/ Gonçalo de/ } & $\begin{array}{l}\text { Historia Pontifical, y Catholica, en la qual se Contienen } \\
\text { las Vidas y Hechos Notables de todos los Summos } \\
\text { Pontifices Romanos } \\
\text { Barcelona. 1596. Fol. }\end{array}$ & 6 \\
\hline & $\begin{array}{l}\text { Imitation /L'/ de Jésus-Christ } \\
\text { Sem local, nem ano. } 8^{\circ} \text {. }\end{array}$ & 1 \\
\hline & $\begin{array}{l}\text { L'Imitation de Jésus-Christ /Les quatre livres de/. } \\
\text { Traduits par M. Beauzée } \\
\text { Paris. } 1801.8^{\circ} .\end{array}$ & 1 \\
\hline & $\begin{array}{l}\text { Imposteurs /Les/ Démasqués et les Usurpateurs Punis } \\
\text { Paris. 1776. } 8^{\circ} \text {. }\end{array}$ & 1 \\
\hline & $\begin{array}{l}\text { Independiente } / \text { El/. Periodico } \\
\text { Buenos Aires. } 1815.4^{\circ} \text {. Números } 1^{\circ} \text { até } 10^{\circ} .\end{array}$ & 1 \\
\hline & $\begin{array}{l}\text { Informe sobre el Tribunal de la Inquisición con } \\
\text { el Proyecto de Decreto acerca de los Tribunales } \\
\text { Protectores de la Religión } \\
\text { Cadiz. } 1812.4^{\circ} .\end{array}$ & 1 \\
\hline \multirow[t]{2}{*}{$\begin{array}{l}\text { Siqueira/ João de } \\
\text { Nossa Senhora } \\
\text { da Porta }\end{array}$} & $\begin{array}{l}\text { Instrucção /Breve/ do Amor de Deos. Traduzido } \\
\text { do Francez por D. João de Nossa Senhora } \\
\text { da Porta Siqueira } \\
\text { Porto. } 1787.8^{\circ} .\end{array}$ & 1 \\
\hline & $\begin{array}{l}\text { Instrucção Christã Dirigida a todo o Fiel Devoto } \\
\text { Lisboa. } 1807.12^{\circ} .\end{array}$ & 1 \\
\hline
\end{tabular}




\begin{tabular}{|c|c|c|}
\hline Autor & Título & Vol \\
\hline \multirow[t]{8}{*}{$\begin{array}{l}\text { Siqueira/ João de } \\
\text { Nossa Senhora } \\
\text { da Porta }\end{array}$} & $\begin{array}{l}\text { Instrucção para os Viajantes e Empregados nas } \\
\text { Colonias sobre a Maneira de Colher, Conservar, } \\
\text { e Remeter os Objectos de Historia Natural } \\
\text { Rio de Janeiro. } 1819.4^{\circ} \text {. }\end{array}$ & 1 \\
\hline & $\begin{array}{l}\text { Instrucções para as Eleições dos Deputados das Côrtes } \\
\text { Lisboa. 1821. Fol. }\end{array}$ & 1 \\
\hline & $\begin{array}{l}\text { Instrucções para Facilitar as Eleições dos } \\
\text { Compromissarios, e Eleitores Parochiaes } \\
\text { Lisboa. } 1820.8^{\circ} .\end{array}$ & 1 \\
\hline & $\begin{array}{l}\text { Instrucções Geraes que Devem Servir de Regulamento } \\
\text { [ás Diferentes Pessoas] que se Empregão nas Obras } \\
\text { Militares etc } \\
\text { Lisboa. } 1811.4^{\circ} .\end{array}$ & 1 \\
\hline & $\begin{array}{l}\text { Instrucções que Regularão as Eleições dos Deputados } \\
\text { no Anno de } \mathbf{1 8 2 1} \\
\text { Lisboa. 1821. Fol. }\end{array}$ & 1 \\
\hline & $\begin{array}{l}\text { Instrucção para os Viajantes e Empregados nas } \\
\text { Colonias sobre a Maneira de Colher, Conservar, } \\
\text { e Remeter os Objectos de Historia Natural } \\
\text { Rio de Janeiro. } 1819.4^{\circ} \text {. }\end{array}$ & 1 \\
\hline & $\begin{array}{l}\text { Investigador /O/ Portuguez em Inglaterra, } \\
\text { ou Jornal Literario, Politico, etc } \\
\text { Londres. } 1811.8^{\circ} \text {. }\end{array}$ & 6 \\
\hline & $\begin{array}{l}\text { Investigador /O/ Portuguez em Inglaterra ou Jornal } \\
\text { Literario, Politico, Etc } \\
\text { Londres. } 1813.8^{\circ} . \text { Números de } 30 \text { até } 46 \text { Truncados }\end{array}$ & 12 \\
\hline $\begin{array}{l}\text { Iribarren/ Miguel } \\
\text { Maria/ }\end{array}$ & $\begin{array}{l}\text { Manifiesto de las Acciones del Mariscal de Campo D. } \\
\text { Francisco Espoz y Mina } \\
\text { Cadiz. 1810. } 4 .\end{array}$ & 1 \\
\hline \multirow[t]{2}{*}{$\begin{array}{l}\text { Irisarri/ Alfonso } \\
\text { Fernando de/ }\end{array}$} & $\begin{array}{l}\text { Retiro de Damas, con los Exercicios que deben } \\
\text { practicarse en él } \\
\text { Madrid. } 1782.8^{\circ} .\end{array}$ & 1 \\
\hline & $\begin{array}{l}\text { Itinerario para Uso da Colonia Suissa na Sua Jornada } \\
\text { desde o Porto do Rio de Janeiro ate o Morro Queimado, } \\
\text { no Districto da Villa de S. Pedro de Cantagallo } \\
\text { Rio de Janeiro. 1819. Fol. }\end{array}$ & 2 \\
\hline Jacob/ André/ & $\begin{array}{l}\text { Novo e Infalivel Methodo de Substituir o Leme } \\
\text { de Qualquer Navio no Alto Mar } \\
\text { Rio de Janeiro. } 1817.4^{\circ} \text {. }\end{array}$ & 1 \\
\hline
\end{tabular}




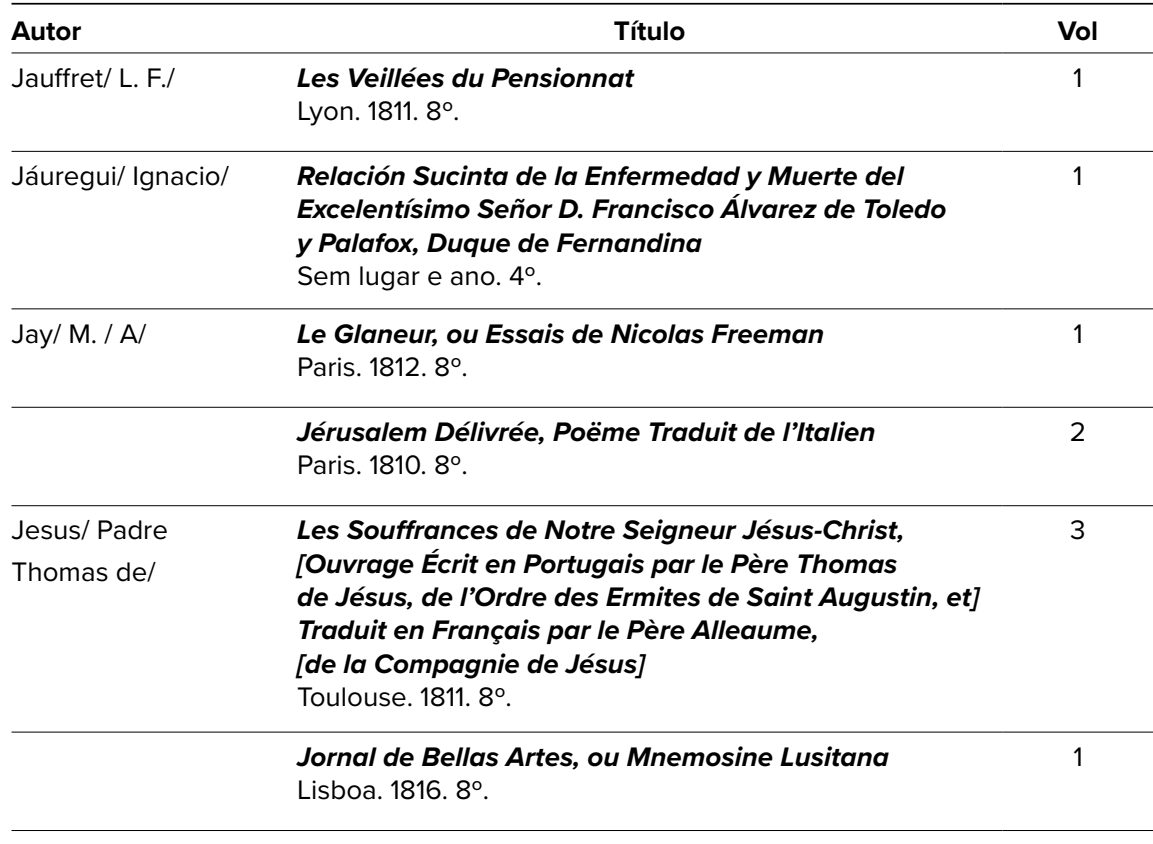

Jornal de Coimbra

Lisboa. 1812 a $1814.4^{\circ} .25$ números truncados.

\begin{tabular}{|c|c|c|}
\hline $\begin{array}{l}\text { José II/ Cardeal } \\
\text { Patriarca/ }\end{array}$ & $\begin{array}{l}\text { Pastoral } \\
\text { Lisboa. 1801. } 4^{\circ} .\end{array}$ & 1 \\
\hline & $\begin{array}{l}\text { Journée /La Bonne/ ou Manière de Sanctifier la Journée } \\
\text { pour les Gens de la Campagne } \\
\text { Langres. } 1805.12^{\circ} \text {. }\end{array}$ & 1 \\
\hline & $\begin{array}{l}\text { Journée Chrétienne, Sanctifée par la Prière } \\
\text { et la Méditation } \\
\text { Saint-Brieuc. } 1789.12^{\circ} .\end{array}$ & 1 \\
\hline $\begin{array}{l}\text { São José/ Frei } \\
\text { Caetano de/ }\end{array}$ & $\begin{array}{l}\text { Vida do B. Fr. Simão de Roxas da Ordem da SS. } \\
\text { Trindade, [Confessor da Augustissima Rainha } \\
\text { D. Isabel de Bourbon] } \\
\text { Lisboa. } 1772.8^{\circ} \text {. }\end{array}$ & 1 \\
\hline & $\begin{array}{l}\text { Juicio Imparcial sobre las Letras en Forma de Breve } \\
\text { que Ha Publicado la Curia Romana } \\
\text { Madrid. 1769. Fol. }\end{array}$ & 1 \\
\hline & $\begin{array}{l}\text { Julie de St-OImont, ou les Premières Illusions } \\
\text { de l'Amour } \\
\text { Paris. } 1805.8^{\circ} \text {. }\end{array}$ & 3 \\
\hline
\end{tabular}




\begin{tabular}{|c|c|c|}
\hline Autor & Título & Vol \\
\hline Keralio-Robert/ & Rose et Albert, ou le Tombeau D'Emma & 2 \\
\hline Madame & Paris. $1810.8^{\circ}$. & \\
\hline Kotzebue/ & $\begin{array}{l}\text { Philibert, ou les Amis d'Enfance. Traduit de l'Allemand } \\
\text { par Mr. Breton } \\
\text { Paris. } 1810.8^{\circ} .\end{array}$ & 2 \\
\hline Labillardiére/ & $\begin{array}{l}\text { Relation du Voyage a la Recherche de la Pérouse etc } \\
\text { Paris. 1800. Fol. }\end{array}$ & 1 \\
\hline Lacerda/ Fernando & Historia da Vida de São João da Cruz & 1 \\
\hline Correa de/ & Lisboa. 1680. $4^{\circ}$. & \\
\hline Lacerda/ Fernando & Virtuosa Vida, e Santa Morte da Princeza Dona Joanna & 1 \\
\hline Correa de/ & Lisboa. 1674. $4^{\circ}$. & \\
\hline Lacomba/ Luiz & $\begin{array}{l}\text { Adelia, ou a Selvagem. Baile } \\
\text { Rio de Janeiro. } 1813.8^{\circ} .\end{array}$ & 1 \\
\hline Lacomba/ Luiz & $\begin{array}{l}\text { Cyrce. Baile Heroico. } \\
\text { Rio de Janeiro. 1814. } 8^{\circ} .\end{array}$ & 1 \\
\hline Lacretelle/ Charles/ & $\begin{array}{l}\text { Histoire de France pendant le Dix-Huitième Siècle } \\
\text { Paris. } 1812.8^{\circ} .\end{array}$ & 9 \\
\hline \multirow[t]{2}{*}{$\begin{array}{l}\text { Delacroix/ Jacques- } \\
\text { Vincent }\end{array}$} & $\begin{array}{l}\text { Le Danger des Souvenirs } \\
\text { Paris. } 1805.8^{\circ} .\end{array}$ & 2 \\
\hline & $\begin{array}{l}\text { Ladouski et Floriska } \\
\text { Paris. } 1801.8^{\circ} .\end{array}$ & 4 \\
\hline Lafontaine/ Auguste/ & $\begin{array}{l}\text { Amélie, ou le Secret d'Être Heureux. Traduit de } \\
\text { l'Allemand par Berton } \\
\text { Paris. } 1812.8^{\circ} .\end{array}$ & 2 \\
\hline Lafontaine/ Auguste/ & $\begin{array}{l}\text { Aline de Riesentein, ou le Tableau de la vie } \\
\text { Paris. } 1810.8^{\circ} \text {. }\end{array}$ & 4 \\
\hline Lafontaine/ Auguste/ & $\begin{array}{l}\text { Barneck et Saldorf, ou le Triomphe de l'Amitié } \\
\text { Paris. } 1810.8^{\circ} .\end{array}$ & 3 \\
\hline \multirow[t]{2}{*}{ Lafontaine/ Jean de la } & $\begin{array}{l}\text { Fables Choisies } \\
\text { Luasanne. 1792. } 8^{\circ} .\end{array}$ & 4 \\
\hline & $\begin{array}{l}\text { Lagarde /O/ Portuguez, ou Gazeta para depois } \\
\text { de Jantar } \\
\text { Lisboa. } 1809.4^{\circ} .\end{array}$ & 1 \\
\hline
\end{tabular}




\begin{tabular}{llc}
\hline Autor & \multicolumn{1}{c}{ Título } & Vol \\
\hline Lambertini/ Prospero/ & $\begin{array}{l}\text { Annotazioni sopra la Feste di Nostro Signore e della } \\
\text { Beatissima Vergine } \\
\text { Bolonha. 1740. Fol. }\end{array}$ & 2 \\
\hline
\end{tabular}

\begin{tabular}{ll}
\hline Lasausse/ Abade/ & $\begin{array}{l}\text { L'Heureuse Année, ou l'Année Sanctifiée par la } \\
\text { Méditation des Sentences et des Exemples des Saints } \\
\text { Roen. 1811. } 8^{\circ} .\end{array}$
\end{tabular}

Roen. 1811. $8^{\circ}$.

Leão/ Miguel

Lopes de/
Allegação Historico-Juridica sobre a Successão do Morgado e Casa de Pancas Lisboa. 1803. Fol.
1

Exemplar 2

Lecture pour les Enfants, ou Choix de Petits Contes etc

Paris. 1785. 12.

\begin{tabular}{ll}
\hline Ledesma/ Francisco & Discurso [Pronunciado por el Señor Francisco \\
Rodríguez de/ & $\begin{array}{l}\text { Rodríguez de Ledesma, Presidente de] } \\
\text { Ias Cortes Generales Ordinarias etc } \\
\text { Cadiz. 1813. } 4^{\circ} .\end{array}$
\end{tabular}

Lee/ Sophie/

Savinia Rivers, ou le Danger d'Aimer.

Traduit de l'Anglais

Paris. 1808. $8^{\circ}$.

\begin{tabular}{l} 
Saint-Légier/ \\
Madame de/ \\
\hline Leitão/ Antônio José \\
Osorio de Pina de \\
\hline Leitão/ Antônio José \\
Osorio de Pina de
\end{tabular}

Albert et Ernestine, ou le Pouvoir de la Maternité 2 Paris. 1810. $8^{\circ}$.

Paris. $1810.8^{\circ}$

Alfonsiada, Poema Heroico [da Fundação da

Monarquia Portugueza pelo Senhor Rey Dom Afonso

Henriques]

Bahia. 1818. $4^{\circ}$.

Ode Pindarica, [Oferecida a Magestade d'El Rey Nosso

Senhor Dom João Sexto, na Occasião do Fautissimo

Parto da Princeza Real]

Rio de Janeiro. 1819. $4^{\circ}$.

Leitão/ Paulino
Joaquim/

Elogio á Esquadra Portugueza [que Transportou aos

Estados do Brazil os Soberanos de Portugal]

Rio de Janeiro. 1812. $8^{\circ}$.

\begin{tabular}{ll}
\hline Leitão/ Paulino & Epicedio á Morte do Serenissimo Senhor Infante Dom \\
Joaquim/ & Pedro Carlos de Bourbon e Bragança \\
& Rio de Janeiro. 1812. $8^{\circ}$.
\end{tabular}

Leite/ Antônio

A União Venturosa. Drama com Musica etc

Bressane/

Sem lugar. 1811. $8^{\circ}$.

Exemplar 2

Leite/ Antônio

A Virtude Triunfante. Elogio Dramatico 1

Bressane/

Rio de Janeiro. 1811. $4^{\circ}$. 


\begin{tabular}{|c|c|c|}
\hline Autor & Título & Vol \\
\hline \multirow[t]{5}{*}{ Lenclos/ Ninon de/ } & $\begin{array}{l}\text { Lettres [de Ninon de Lenclos] au Marquis } \\
\text { de Sevigné avec Sa Vie } \\
\text { Amsterdam. } 1767.8^{\circ} .\end{array}$ & $\begin{array}{c}1 \\
\text { Tomo } 2\end{array}$ \\
\hline & $\begin{array}{l}\text { Léontine, ou la Grotte Allemande } \\
\text { Paris. } 1804.8^{\circ} .\end{array}$ & 2 \\
\hline & $\begin{array}{l}\text { Léontine, ou la Grotte Allemande } \\
\text { Paris. } 1804.8^{\circ} .\end{array}$ & 2 \\
\hline & $\begin{array}{l}\text { Lettres /Les/ et Épîtres Amoureuses d'Héloïse et } \\
\text { d'Abeilard. Traduites par M. de Bussy Rabutin Etc } \\
\text { Paris. } 1784.8^{\circ} .\end{array}$ & $\begin{array}{c}1 \\
\text { Tomo } 1\end{array}$ \\
\hline & $\begin{array}{l}\text { Lettres d'un Persan en Angleterre, à son Ami à Ispahan, } \\
\text { [ou Nouvelles Lettres Persannes] } \\
\text { Londres. } 1770.8^{\circ} .\end{array}$ & 1 \\
\hline $\begin{array}{l}\text { Levesque/ Pierre } \\
\text { Charles/ }\end{array}$ & $\begin{array}{l}\text { Histoire Critique de la République Romaine } \\
\text { Paris } 1807 \mathrm{Em} 8^{\circ}\end{array}$ & 3 \\
\hline Lewis/M. G./ & $\begin{array}{l}\text { Les Orphelines de Werdenberg. Traduit de l'Anglais } \\
\text { par } R \text {. J. Durdent } \\
\text { Paris. } 1810.8^{\circ} \text {. }\end{array}$ & 4 \\
\hline Ligny/ P. de/ & $\begin{array}{l}\text { Histoire de la Vie de Jésus-Christ } \\
\text { Paris. } 1804.4^{\circ} .\end{array}$ & 2 \\
\hline $\begin{array}{l}\text { Ligório/ Afonso } \\
\text { Maria de/ }\end{array}$ & $\begin{array}{l}\text { Visitas al Santísimo Sacramento y a María Santísima } \\
\text { para Todos los Días del Mes } \\
\text { Barcelona. Sem ano. } 12^{\circ} \text {. }\end{array}$ & $\begin{array}{c}1 \\
\text { Exemplar } 4\end{array}$ \\
\hline $\begin{array}{l}\text { Ligório/ Afonso } \\
\text { Maria de/ }\end{array}$ & $\begin{array}{l}\text { Visites au Saint Sacrement et à la Sainte Vierge } \\
\text { pour Chaque Jour du Mois } \\
\text { Saumur. } 1810 .\end{array}$ & 1 \\
\hline Lima/ Frei José de/ & $\begin{array}{l}\text { Sermão de Acção de Graças pela Restituição dos } \\
\text { Direitos Magestaticos de El-Rey Nosso Senhor } \\
\text { Porto. } 1823.8^{\circ} .\end{array}$ & 1 \\
\hline Lima/ Frei Manoel de/ & $\begin{array}{l}\text { Agiologio Dominico das Vidas dos Santos, Beatos, } \\
\text { Martyres, etc da Ordem dos Pregadores } \\
\text { Lisboa. 1753. Fol. }\end{array}$ & 6 \\
\hline Limon/Mr./ & $\begin{array}{l}\text { Vida de Luiz XVI, Rey de França. Traduzido do Francez } \\
\text { Lisboa. } 1801.8^{\circ} .\end{array}$ & 1 \\
\hline Lisboa/ Joaquim José/ & $\begin{array}{l}\text { Elogio ao Illustrissimo e Excelentissimo Senhor } \\
\text { Francisco da Silveira Pinto da Fonseca } \\
\text { Lisboa. } 1809.4^{\circ} .\end{array}$ & 1 \\
\hline
\end{tabular}




\begin{tabular}{llc}
\hline Autor & \multicolumn{1}{c}{ Título } & Vol \\
\hline Lisboa/ Joaquim José/ Joquino, e Tamira. Versos Pastoris & 1 \\
& Lisboa. 1802. $8^{\circ}$. \\
\hline Lisboa/ José da Silva// & $\begin{array}{l}\text { Observações sobre o Commercio Franco } \\
\text { Rio de Janeiro. 1808. } 4^{\circ} .\end{array}$ & 1 \\
\hline Lisboa/ José da Silva// & $\begin{array}{l}\text { Observações sobre a Prosperidade do Estado pelos } \\
\text { Principios Liberaes da Nova Legis/ação do Brazil } \\
\text { Rio de Janeiro. 1810. } 8^{\circ} .\end{array}$ & 1 \\
\hline Lisboa/ José da Silva// & $\begin{array}{l}\text { Razões dos Lavradores do Vice-Reinado } \\
\text { de Buenos-Ayres etc } \\
\text { Rio de Janeiro. 1810. } 4^{\circ} .\end{array}$ \\
\hline $\begin{array}{l}\text { Lista dos Cavalleiros, Freires, Capellães Conventoaes, } \\
\text { [e Serventes d'Armas do Venerado Priorado } \\
\text { de Portugal] } \\
\text { Lisboa. 1800. } 4^{\circ} .\end{array}$
\end{tabular}

Lista Geral dos Accionistas do Banco do Brazil

Rio de Janeiro. 1821. Fol.

\begin{tabular}{|c|c|c|}
\hline & $\begin{array}{l}\text { Lista Geral dos Deputados da Nacão Portugueza } \\
\text { Lisboa. 1826. Fol. }\end{array}$ & 1 \\
\hline & $\begin{array}{l}\text { Lista dos Nomes dos Senhores Deputados } \\
\text { no Soberano Congresso } \\
\text { Sem lugar. 1823. Fol. }\end{array}$ & 1 \\
\hline & $\begin{array}{l}\text { Lista dos Socios da Academia Real das Sciencias } \\
\text { em } 1821 \\
\text { Lisboa. } 1821.4^{\circ} .\end{array}$ & 1 \\
\hline & $\begin{array}{l}\text { Livro /Novo/, ou Jogo de Sortes } \\
\text { Lisboa. } 1800.8^{\circ} .\end{array}$ & 1 \\
\hline \multirow[t]{3}{*}{$\begin{array}{l}\text { Llorente/ } \\
\text { Juan Antonio/ }\end{array}$} & $\begin{array}{l}\text { Memoria Histórica sobre qual Ha Sido la Opinión } \\
\text { Nacional de España acerca del Tribunal de la } \\
\text { Inquisición } \\
\text { Madrid. } 1812.8^{\circ} .\end{array}$ & 1 \\
\hline & $\begin{array}{l}\text { Loa en que la Ciudad de Cádiz, Manifiesta el Gozo por } \\
\text { los Esponsales que S. M. ha Contraido con Doña Maria } \\
\text { Izabel de Bourbon... } \\
\text { San Fernando. } 1816.8^{\circ} .\end{array}$ & 1 \\
\hline & $\begin{array}{l}\text { Loas da Senhora do Cabo, pelo Cirio da Ajuda } \\
\text { Lisboa. } 1822.4^{\circ} .\end{array}$ & $\begin{array}{c}1 \\
\text { Exemplar } 5\end{array}$ \\
\hline
\end{tabular}




\begin{tabular}{|c|c|c|}
\hline Autor & Título & Vol \\
\hline Lobo/ Roque Ferreira/ & $\begin{array}{l}\text { Historia da Feliz Aclamação do Senhor Rei Dom João } \\
\text { o Quarto etc } \\
\text { Lisboa. } 1803.8^{\circ} .\end{array}$ & $\begin{array}{c}1 \\
\text { Exemplar } 2\end{array}$ \\
\hline Lobo/ Roque Ferreira/ & $\begin{array}{l}\text { Lições de hum Pay a huma Filha Sua, na Primeira Idade } \\
\text { Lisboa. } 1803.8^{\circ} .\end{array}$ & $\begin{array}{c}1 \\
\text { Exemplar } 4\end{array}$ \\
\hline Lobo/ Roque Ferreira/ & $\begin{array}{l}\text { Oração Panegyrica [Offerecida á Muito Alta } \\
\text { e Poderosa] Senhora Dona Carlota Joaquina, } \\
\text { Serenissima Princeza do Brazil } \\
\text { Lisboa. } 1798.4^{\circ} .\end{array}$ & 1 \\
\hline $\begin{array}{l}\text { Locela/ Frei Rafael } \\
\text { Lasala y/ }\end{array}$ & $\begin{array}{l}\text { Catecismo Mayor de la Doctrina Christiana } \\
\text { Cervera. 1791. Fol. }\end{array}$ & 1 \\
\hline $\begin{array}{l}\text { Longo/ Frei Ramón } \\
\text { Valvidares y/ }\end{array}$ & $\begin{array}{l}\text { Fabulas Satiricas, Politicas y Morales sobre el Actual } \\
\text { Estado de la Europa } \\
\text { Sem lugar. } 1811.8^{\circ} .\end{array}$ & 1 \\
\hline $\begin{array}{l}\text { Longo/ Frei Ramón } \\
\text { Valvidares y/ }\end{array}$ & $\begin{array}{l}\text { La Iberiada. Poema Épico á la Gloriosa Defensa } \\
\text { de Zaragoza } \\
\text { Cadiz } 1813 \mathrm{Em} 4^{\circ}\end{array}$ & 2 \\
\hline $\begin{array}{l}\text { Lopes/ Joaquim José } \\
\text { Pedro/ }\end{array}$ & $\begin{array}{l}\text { As Idéas Liberaes, Ultimo Refugio dos Inimigos } \\
\text { da Religião e do Throno } \\
\text { Lisboa. } 1819 .\end{array}$ & 1 \\
\hline López/ Tómas & $\begin{array}{l}\text { Geografía Histórica de España } \\
\text { Madrid. 1788. } 8^{\circ} .\end{array}$ & $\begin{array}{c}1 \\
\text { Tomo } 2\end{array}$ \\
\hline Louise/ Madame/ & $\begin{array}{l}\text { Athanasie de Réalmont } \\
\text { Paris. } 1817.8^{\circ} .\end{array}$ & 2 \\
\hline $\begin{array}{l}\text { Lourenço/ Antônio } \\
\text { Gomes/ }\end{array}$ & $\begin{array}{l}\text { Dissertação Pratica do Exostose, e da Caria dos Ossos } \\
\text { Lisboa. } 1772.8^{\circ} .\end{array}$ & 1 \\
\hline $\begin{array}{l}\text { São Lourenço/ } \\
\text { Justiniano }\end{array}$ & $\begin{array}{l}\text { Da Perfeição da Vida Monastica, e da Vida Solitaria: } \\
\text { Dous Tratados [de São Lourenço Justiniano]. } \\
\text { Traduzidos do Latim em Portuguez pela Senhora } \\
\text { Infanta Dona Catharina } \\
\text { Lisboa. } 1791.4^{\circ} .\end{array}$ & 1 \\
\hline Lucena/ João de/ & $\begin{array}{l}\text { Historia da Vida do Padre São Francisco Xavier } \\
\text { Lisboa. } 1788.8^{\circ} .\end{array}$ & 4 \\
\hline $\begin{array}{l}\text { Luiz/ Frei Francisco } \\
\text { de São/ }\end{array}$ & $\begin{array}{l}\text { Ensaio sobre Alguns Synonymos da Lingua Portugueza } \\
\text { Lisboa. } 1821.4^{\circ} .\end{array}$ & 1 \\
\hline
\end{tabular}




\begin{tabular}{|c|c|c|}
\hline Autor & Título & Vol \\
\hline Lunardi/Vicenzo/ & $\begin{array}{l}\text { An Account of Five Aerial Voyages in Scotland } \\
\text { London. } 1786.8^{\circ} \text {. }\end{array}$ & 1 \\
\hline \multirow[t]{2}{*}{$\begin{array}{l}\text { Luque/ Eduardo } \\
\text { Malo de/ }\end{array}$} & $\begin{array}{l}\text { Historia Politica de los Establecimientos Ultramarinos } \\
\text { de la Naciones Europeas } \\
\text { Madrid. } 1784.4^{\circ} .\end{array}$ & 5 \\
\hline & $\begin{array}{l}\text { Lusitania Triunfante, e Final Queda de Bonaparte } \\
\text { Lisboa. } 1811.4^{\circ} \text {. }\end{array}$ & 1 \\
\hline Luz/ Joaquim José da/ & $\begin{array}{l}\text { Defeza de hum Cidadão } \\
\text { Lisboa. } 1821.4^{\circ} .\end{array}$ & 1 \\
\hline \multirow[t]{2}{*}{ Luz/ Joaquim José da/ } & $\begin{array}{l}\text { Discurso sobre os Procedimentos da Commissão } \\
\text { Encarregada do Melhoramento das Cadêas } \\
\text { Lisboa. } 1822.4^{\circ} .\end{array}$ & 1 \\
\hline & $\begin{array}{l}\text { Lysia Triunfante /Epigramma/ } \\
\text { Lisboa. } 1817.8^{\circ} .\end{array}$ & 1 \\
\hline Mably/ Abbé de/ & $\begin{array}{l}\text { Collection Complète des Oeuvres [de l'Abbé de Mably] } \\
\text { Paris. } 1795.8^{\circ} .\end{array}$ & 15 \\
\hline $\begin{array}{l}\text { Macedo/ José } \\
\text { Agostinho de/ }\end{array}$ & $\begin{array}{l}\text { Considerações Christãs e Politicas sobre a Enormidade } \\
\text { dos Libellos Infamatorios } \\
\text { Lisboa. } 1811.8^{\circ} .\end{array}$ & 1 \\
\hline $\begin{array}{l}\text { Macedo/ José } \\
\text { Agostinho de/ }\end{array}$ & $\begin{array}{l}\text { Inventario da Refutação Analytica } \\
\text { Lisboa. } 1810.8^{\circ} .\end{array}$ & 1 \\
\hline $\begin{array}{l}\text { Macedo/ José } \\
\text { Agostinho de/ }\end{array}$ & $\begin{array}{l}\text { Justa Defesa do Livro Intitulado Os Sebastianistas } \\
\text { Lisboa. } 1810.8^{\circ} .\end{array}$ & 1 \\
\hline $\begin{array}{l}\text { Macedo/ José } \\
\text { Agostinho de/ }\end{array}$ & $\begin{array}{l}\text { O Novo Argonauta /Poema/ } \\
\text { Lisboa. } 1809.8^{\circ} .\end{array}$ & 1 \\
\hline $\begin{array}{l}\text { Macedo/ José } \\
\text { Agostinho de/ }\end{array}$ & $\begin{array}{l}\text { Oração Funebre Recitada nas Exequias do Illustrissimo } \\
\text { e Excelletissimo Conde de Rio Maior, Celebradas na } \\
\text { Igreja do Convento dos Religiosos de São Pedro } \\
\text { de Alcantara } \\
\text { Lisboa. } 1826.8^{\circ} .\end{array}$ & 1 \\
\hline $\begin{array}{l}\text { Macedo/ José } \\
\text { Agostinho de/ }\end{array}$ & $\begin{array}{l}\text { Os Sebastianistas } \\
\text { Lisboa. } 1810.8^{\circ}\end{array}$ & 1 \\
\hline $\begin{array}{l}\text { Macedo/ José } \\
\text { Agostinho de/ }\end{array}$ & $\begin{array}{l}\text { Os Sebastianistas } \\
\text { Lisboa. } 1810.8^{\circ}\end{array}$ & 1 \\
\hline
\end{tabular}




\begin{tabular}{|c|c|c|}
\hline Autor & Título & Vol \\
\hline $\begin{array}{l}\text { Macedo/ José } \\
\text { Agostinho de/ }\end{array}$ & $\begin{array}{l}\text { Sermão em Acção de Graças pelo Benificio } \\
\text { da Paz Geral da Europa } \\
\text { Lisboa. } 1814.8^{\circ} .\end{array}$ & 1 \\
\hline $\begin{array}{l}\text { Macedo/ José } \\
\text { Agostinho de/ }\end{array}$ & $\begin{array}{l}\text { Sermão de Acção de Graças pelo Restabelecimento } \\
\text { da Monarquia Independente } \\
\text { Lisboa. } 1823.4^{\circ} \text {. }\end{array}$ & 1 \\
\hline $\begin{array}{l}\text { Machado/ Cyrillo } \\
\text { Volkmar/ }\end{array}$ & $\begin{array}{l}\text { Collecção de Memorias Relativas ás Vidas dos Pintores, } \\
\text { e Escultores, Architetos, e Gravadores Portuguezes } \\
\text { Lisboa. } 1823.4^{\circ} \text {. }\end{array}$ & 1 \\
\hline \multirow[t]{2}{*}{ Maquiavel } & $\begin{array}{l}\text { Oeuvres. Traduit par Jean Guiraudet } \\
\text { Paris. } 1799.8^{\circ} .\end{array}$ & 8 \\
\hline & $\begin{array}{l}\text { Maçonismo Desmascarado, ou Manifesto } \\
\text { contra os Pedreiros Livres } \\
\text { Lisboa. } 1823.4^{\circ} .\end{array}$ & 1 \\
\hline $\begin{array}{l}\text { Madre de Deus/ } \\
\text { Faustino José da/ }\end{array}$ & $\begin{array}{l}\text { Elogio á Nação Britanica } \\
\text { Lisboa. } 1808.8^{\circ} .\end{array}$ & 1 \\
\hline $\begin{array}{l}\text { Madureira Feijó/ João } \\
\text { de Moraes }\end{array}$ & $\begin{array}{l}\text { Orthographia, ou Arte de Escrever, e Pronunciar } \\
\text { com acerto a Lingua Portugueza } \\
\text { Lisboa. } 1815.4^{\circ} .\end{array}$ & 1 \\
\hline Maineri/ Alexandre/ & $\begin{array}{l}\text { Vida de Santa Catharina de Genova } \\
\text { Lisboa. } 1790.4^{\circ} .\end{array}$ & 1 \\
\hline \multirow[t]{5}{*}{ Maineri/ Alexandre/ } & $\begin{array}{l}\text { Vida de Santa Catharina de Genova. } \\
\text { Traduzida do Italiano por J. C. C. } \\
\text { Lisboa. } 1790.4^{\circ} .\end{array}$ & 1 \\
\hline & $\begin{array}{l}\text { Manifesto Justificativo da Retirada do Negociante } \\
\text { Manoel Pereira de Carvalho para esta Corte Vindo } \\
\text { do Maranhão } \\
\text { Lisboa. } 1821.4^{\circ} .\end{array}$ & 1 \\
\hline & $\begin{array}{l}\text { Manifesto da Nação Portugueza, aos Soberanos } \\
\text { e Povos da Europa } \\
\text { Lisboa. } 1820 . \text { Fol. }\end{array}$ & 1 \\
\hline & $\begin{array}{l}\text { Manifiesto del Congreso a los Pueblos } \\
\text { Buenos Aires. } 1816.4^{\circ} .\end{array}$ & 1 \\
\hline & $\begin{array}{l}\text { Manifiesto de Fernando Septimo a la Nacion Española } \\
\text { Madrid. } 1815.4^{\circ} .\end{array}$ & 1 \\
\hline
\end{tabular}




\begin{tabular}{|c|c|c|}
\hline Autor & Título & Vol \\
\hline \multirow[t]{7}{*}{ Maineri/ Alexandre/ } & $\begin{array}{l}\text { Manifiesto de la Felíz llegada á esta Corte de Madrid } \\
\text { de la Reyna Nuestra Señora con la Serenísima Señora } \\
\text { Infanta su Hermana y el Serenísimo Señor Infante Don } \\
\text { Antonio, etc } \\
\text { Sem lugar. } 1816.4^{\circ} .\end{array}$ & 1 \\
\hline & $\begin{array}{l}\text { Manifiesto de la Justiça, de la Importancia y de la } \\
\text { Necesidad que Halla EI Rey Nuestro Señor para } \\
\text { Oponerse á la Agression del Usurpador Buonaparte } \\
\text { Madrid. } 1815.4^{\circ} .\end{array}$ & 1 \\
\hline & $\begin{array}{l}\text { Manifiesto de los Procedimientos del Consejo Real Etc } \\
\text { Madrid. } 1808.4^{\circ} .\end{array}$ & 1 \\
\hline & $\begin{array}{l}\text { Manifiesto de la Regencia de las Españas Etc } \\
\text { Cadiz. } 1812.4^{\circ} .\end{array}$ & 1 \\
\hline & $\begin{array}{l}\text { Manifiesto de la Regencia de las Españas sobre } \\
\text { Cesacion en el Mando del Quarto Exército y Capitanía } \\
\text { General de las Andalucias [del Excelentísimo Señor Don } \\
\text { Francisco Ballesteros] } \\
\text { Cadiz. } 1812.4^{\circ} .\end{array}$ & 1 \\
\hline & $\begin{array}{l}\text { Manifiesto de la Regencia de las Españas } \\
\text { Cadiz. } 1813.4^{\circ} \text {. }\end{array}$ & 1 \\
\hline & $\begin{array}{l}\text { Manobra das Peças Ligeiras de Campanha } \\
\text { Sem lugar, nem ano. } 8^{\circ} \text {. }\end{array}$ & 1 \\
\hline Manuel/ M/ & $\begin{array}{l}\text { L'Année Francoise, Vies des Hommes Qui Ont Honoré la } \\
\text { France, etc } \\
\text { Paris. } 1782.8^{\circ} .\end{array}$ & 2 \\
\hline María/ Juan de Santa/ & $\begin{array}{l}\text { Chronica de la Provincia de San Joseph } \\
\text { Madrid. 1615. Fol. }\end{array}$ & 1 \\
\hline $\begin{array}{l}\text { Maria/ Isidoro de } \\
\text { Santa/ }\end{array}$ & $\begin{array}{l}\text { Exercicios Teresianos muito Uteis para Conseguir as } \\
\text { Misericordias de Deos por Intercessão [da Reformadora } \\
\text { do Carmo], Santa Teresa de Jesus } \\
\text { Lisboa. } 1809.8^{\circ} \text {. }\end{array}$ & 1 \\
\hline $\begin{array}{l}\text { Maria/ Isidoro de } \\
\text { Santa/ }\end{array}$ & $\begin{array}{l}\text { Exercicios Teresianos muito Uteis para Conseguir as } \\
\text { Misericordias de Deos por Intercessão [da Reformadora } \\
\text { do Carmo], Santa Teresa de Jesus } \\
\text { Lisboa. } 1809.8^{\circ} \text {. }\end{array}$ & 1 \\
\hline $\begin{array}{l}\text { Maria Santíssima/ } \\
\text { Manoel de/ }\end{array}$ & $\begin{array}{l}\text { Historia da Fundação do Real Convento e Seminario } \\
\text { de Varatojo com a Compendiosa Noticia da Vida do } \\
\text { Veneravel Padre Frei Antonio das Chagas Etc } \\
\text { Porto. } 1799.8^{\circ} .\end{array}$ & 2 \\
\hline
\end{tabular}




\begin{tabular}{|c|c|c|}
\hline Autor & Título & Vol \\
\hline \multirow{4}{*}{$\begin{array}{l}\text { Maria Santíssima/ } \\
\text { Manoel de/ }\end{array}$} & Maria Santissima Mystica Cidade de Deos & 1 \\
\hline & Lisboa. 1741. $4^{\circ}$. & \\
\hline & $\begin{array}{l}\text { Marie, ou les Hollandoises } \\
\text { Paris. } 1815.8^{\circ} \text {. }\end{array}$ & 3 \\
\hline & $\begin{array}{l}\text { Marilia de Dirceo } \\
\text { Lisboa. } 1803.8^{\circ}\end{array}$ & 1 \\
\hline Marmontel & $\begin{array}{l}\text { Belisaire } \\
\text { Paris. 1810. } 8^{\circ} .\end{array}$ & 1 \\
\hline Marmontel & $\begin{array}{l}\text { Cuentos Morales } \\
\text { Valência. 1813. } 12 .\end{array}$ & 1 \\
\hline Marsollier/ Mr. de/ & $\begin{array}{l}\text { Vida de São Francisco de Sales. Traduzida do Francez } \\
\text { Coimbra. } 1792.8^{\circ} .\end{array}$ & 2 \\
\hline Marsollier/ Mr. de/ & $\begin{array}{l}\text { Vida de São Francisco de Sales. Traduzida do Francez } \\
\text { Coimbra. } 1792.8^{\circ} .\end{array}$ & $\begin{array}{c}1 \\
\text { Tomo } 1\end{array}$ \\
\hline Marti/ Jayme Creus y/ & $\begin{array}{l}\text { Sermon que en la Solemne Accion de Gracias } \\
\text { [Celebradas por la Universidad de Juardos Generales } \\
\text { de la Isla y Particulares de Ciudadela el Domingo } 13 \text { de } \\
\text { Octubro de } 1816 \text { con] Motivo de los Enlaces del Señor } \\
\text { Don Fernando VII [Rey de las Españas y su Serenisimo } \\
\text { Hermano Don Carlos Maria, con las Serenisimas } \\
\text { Infantas de Portugal Doña Maria Izabel Francisca y } \\
\text { Doña Maria Francisca de Asis] } \\
\text { Barcelona. 1816. } 4^{\circ} \text {. }\end{array}$ & 1 \\
\hline $\begin{array}{l}\text { Mártires/ Frei } \\
\text { Bartolomeu dos/ }\end{array}$ & $\begin{array}{l}\text { Banquete Espiritual } \\
\text { Lisboa. } 1761.8^{\circ} .\end{array}$ & 1 \\
\hline $\begin{array}{l}\text { Masdeu/ D. Juan } \\
\text { Francisco de/ }\end{array}$ & $\begin{array}{l}\text { Historia Critica de España, y de la Cultura Espanõla } \\
\text { Madrid. } 1783.4^{\circ} .\end{array}$ & 20 \\
\hline \multirow[t]{2}{*}{$\begin{array}{l}\text { Masdeu/ D. Juan } \\
\text { Francisco de/ }\end{array}$} & $\begin{array}{l}\text { Vida del Beato Josef Oriol } \\
\text { Barcelona. 1807. } 4^{\circ}\end{array}$ & 1 \\
\hline & $\begin{array}{l}\text { Masque /Le/ de Fer, ou les Aventures Admirables du } \\
\text { Père et du Fils } \\
\text { Paris. } 1794.16^{\circ} \text {. }\end{array}$ & 3 \\
\hline \multirow[t]{2}{*}{$\begin{array}{l}\text { Massillon/ Jean- } \\
\text { Baptiste/ }\end{array}$} & $\begin{array}{l}\text { Sermões } \\
\text { Lisboa. } 1774.8^{\circ} .\end{array}$ & 14 \\
\hline & $\begin{array}{l}\text { Matrimonio /II/ per Sussurro } \\
\text { Lisboa. } 1803.8^{\circ} .\end{array}$ & 1 \\
\hline
\end{tabular}




\begin{tabular}{|c|c|c|}
\hline Autor & Título & Vol \\
\hline \multirow{4}{*}{$\begin{array}{l}\text { Mattos/ Padre } \\
\text { Francisco de }\end{array}$} & Vida Chronologica de Santo Ignacio de Loyola & 1 \\
\hline & Lisboa. 1718. Fol. & \\
\hline & $\begin{array}{l}\text { Maximas Recopiladas das Obras de S. Francisco de } \\
\text { Sales, e Distribuidas por todos os dias do Anno } \\
\text { Lisboa. } 1804.8^{\circ} .\end{array}$ & 1 \\
\hline & $\begin{array}{l}\text { Medico, e Boticario /Novo Entremez/ } \\
\text { Lisboa. } 1778.4^{\circ} .\end{array}$ & 1 \\
\hline \multirow[t]{2}{*}{$\begin{array}{l}\text { Freire/ Pascoal José } \\
\text { de Melo/ }\end{array}$} & $\begin{array}{l}\text { Institutionum Juris Criminalis Lusitani Liber Singularis } \\
\text { Lisboa. } 1807.4^{\circ} .\end{array}$ & 6 \\
\hline & $\begin{array}{l}\text { Mémoires de Luis XIV, Écrits par Lui-Même [Composés } \\
\text { pour le Grand Dauphin, Son Fils, et Adressés a ce } \\
\text { Prince, Suivis de Plusieurs Fragmens de Mémoires } \\
\text { Militaires, de I'Instruction Donnée à Philippe V, de } \\
\text { Dix-Sept Lettres Adressées à ce Monarque sur le } \\
\text { Gouvernement de ses Etats, et de Diverses Autres } \\
\text { Pièces Inédites], Mis en Ordre et Publiés par J. L. M. } \\
\text { de Gain-Montagnac } \\
\text { Paris. } 1806.8^{\circ} .\end{array}$ & 2 \\
\hline \multirow[t]{6}{*}{$\begin{array}{l}\text { Guedes/ Luiz Vaz } \\
\text { Pereira Pinto/ }\end{array}$} & $\begin{array}{l}\text { Memoria e Exposição Authentica da Conducta Civil, e } \\
\text { Militar de Luiz Vaz Pereira Pinto Guedes, Visconde de } \\
\text { Monte Alegre, desde } 1821 \text { até } 1823 \\
\text { Lisboa. } 1823.4^{\circ} .\end{array}$ & 1 \\
\hline & $\begin{array}{l}\text { Memoria Justificativa de Manoel Ignacio Martins } \\
\text { Pamplona, e sua Mulher D. Izabel de Roxas e Lemos } \\
\text { Lisboa. } 1821.4^{\circ} .\end{array}$ & 1 \\
\hline & $\begin{array}{l}\text { Memoria de huma Lapa Descoberta no dia } 28 \\
\text { de Maio de } 1822 \\
\text { Lisboa. } 1822.8^{\circ} .\end{array}$ & 2 \\
\hline & $\begin{array}{l}\text { Memoria de huma Lapa Descoberta na Ribeira } \\
\text { de Jamor } \\
\text { Lisboa. } 1822.8^{\circ} .\end{array}$ & 1 \\
\hline & $\begin{array}{l}\text { Memoria do Maior dos Prodigios que Deos Tem Feito } \\
\text { aos Portuguezes por Intervenção de Nossa Senhora } \\
\text { da Conceição da Rocha } \\
\text { Lisboa. } 1823.8^{\circ} .\end{array}$ & 1 \\
\hline & $\begin{array}{l}\text { Memoria del Dos de Mayo } \\
\text { Sem lugar e ano. } 4^{\circ} \text {. }\end{array}$ & 1 \\
\hline
\end{tabular}




\begin{tabular}{|c|c|c|}
\hline Autor & Título & Vol \\
\hline \multirow[t]{6}{*}{$\begin{array}{l}\text { Guedes/ Luiz Vaz } \\
\text { Pereira Pinto/ }\end{array}$} & $\begin{array}{l}\text { Memoria sobre la Necesidad de Contener la } \\
\text { Demaciada y Perjudicial Licencia } \\
\text { de las Mugeres en el Hablar } \\
\text { Buenos Aires. } 1813.4^{\circ} .\end{array}$ & 1 \\
\hline & $\begin{array}{l}\text { Memoria sobre o Procedimento Havido } \\
\text { com Sua Magestade a Rainha } \\
\text { Lisboa. } 1823.4^{\circ} .\end{array}$ & 1 \\
\hline & $\begin{array}{l}\text { Memoria sobre a Utilidade da Inoculação das Bexigas } \\
\text { Vaccinas. Traduzida do Alemão } \\
\text { Lisboa. } 1801.8^{\circ} .\end{array}$ & 1 \\
\hline & $\begin{array}{l}\text { Memorias de Litteratura Portugueza } \\
\text { Lisboa. } 1792.4^{\circ} .\end{array}$ & 1 \\
\hline & $\begin{array}{l}\text { Memorias de Litteratura Portugueza } \\
\text { Lisboa. } 1812.8^{\circ} .\end{array}$ & 1 \\
\hline & $\begin{array}{l}\text { Memorias de Mathematica e Physica da Academia } \\
\text { Real das Sciencias de Lisboa } \\
\text { Lisboa. 1799. Fol. }\end{array}$ & $\begin{array}{c}2 \\
\text { Tomos } 2 \text { e } 3\end{array}$ \\
\hline $\begin{array}{l}\text { Mendonça/ Luiz } \\
\text { Antônio Carlos } \\
\text { Furtado de/ }\end{array}$ & $\begin{array}{l}\text { Oração Funebre Recitada nas Solemnes Exequias de } \\
\text { Dom Frei Caetano Brandão, Arcebispo da Sé de Braga } \\
\text { Lisboa. } 1806.4^{\circ} .\end{array}$ & 1 \\
\hline $\begin{array}{l}\text { Mendonça/ Luiz } \\
\text { Antônio Carlos } \\
\text { Furtado de/ }\end{array}$ & $\begin{array}{l}\text { Oração Gratulatoria Recitada [na Solemne Acção de } \\
\text { Graças que El-Rey Nosso Senhor Fez Celebrar] na } \\
\text { Capella Real do Rio de Janeiro pelos Desposorios do } \\
\text { Serenissimo Principe Real, o Senhor Dom Pedro etc } \\
\text { Rio de Janeiro. } 1818.4^{\circ} \text {. }\end{array}$ & 1 \\
\hline $\begin{array}{l}\text { Menezes/ Frei Diogo } \\
\text { de Mello e/ }\end{array}$ & $\begin{array}{l}\text { Arte Grammatico-Filosofica [para Aprender } \\
\text { a Lingua Latina] } \\
\text { Lisboa. } 1803.8^{\circ} .\end{array}$ & 1 \\
\hline $\begin{array}{l}\text { Menezes/ Francisco } \\
\text { Alpoim de/ }\end{array}$ & $\begin{array}{l}\text { A Ambição. Tragedia } \\
\text { Lisboa. } 1823.8^{\circ} .\end{array}$ & 1 \\
\hline \multirow[t]{3}{*}{$\begin{array}{l}\text { Malte Brun/ } \\
\text { Mentelle/ Edme }\end{array}$} & $\begin{array}{l}\text { Géographie Mathématique, Physique et Politique } \\
\text { de Toutes les Parties du Monde } \\
\text { Paris. } 1803.8^{\circ} \text {. }\end{array}$ & 16 \\
\hline & $\begin{array}{l}\text { Nouveau Mentor de la Jeunesse pour les Deux Sexes } \\
\text { Paris. } 1814.8^{\circ} .\end{array}$ & 1 \\
\hline & $\begin{array}{l}\text { Mérito /Al/ Oda } \\
\text { Cadiz. 1813. } 4^{\circ} .\end{array}$ & 1 \\
\hline
\end{tabular}




\begin{tabular}{|c|c|c|}
\hline Autor & Título & Vol \\
\hline \multirow[t]{4}{*}{$\begin{array}{l}\text { Mesquita/ José } \\
\text { de Loureiro/ }\end{array}$} & $\begin{array}{l}\text { Manifesto de Todos os Acontecimentos e Cauza } \\
\text { da Revolução da Provincia do Maranhão } \\
\text { Lisboa. 1821. Fol. }\end{array}$ & 1 \\
\hline & $\begin{array}{l}\text { Mestre Francez, [ou Novo Methodo para Aprender } \\
\text { com Perfeição] } \\
\text { Lisboa. } 1777.4^{\circ} .\end{array}$ & 1 \\
\hline & $\begin{array}{l}\text { Metodo para Aprender por Principios la Geografia } \\
\text { General y Particular } \\
\text { Madrid. } 1793.8^{\circ} .\end{array}$ & $\begin{array}{c}1 \\
\text { Tomo } 1\end{array}$ \\
\hline & $\begin{array}{l}\text { Metodo para Aprender por Principios la Geografia } \\
\text { General y Particular } \\
\text { Madrid. } 1793.8^{\circ} .\end{array}$ & $\begin{array}{c}1 \\
\text { Tomo } 8\end{array}$ \\
\hline Middleton/ Conyers/ & $\begin{array}{l}\text { Historia de la Vida de Marco Tulio Ciceron. Traducida } \\
\text { por Don Joseph Nicolas de Azara } \\
\text { Madrid. } 1804.8^{\circ} .\end{array}$ & 3 \\
\hline \multirow[t]{2}{*}{ Millot/ Abade } & $\begin{array}{l}\text { Élémens d'Histoire Générale } \\
\text { Paris. } 1808.8^{\circ} .\end{array}$ & 3 \\
\hline & $\begin{array}{l}\text { Minerva Lusitana } \\
\text { Coimbra. } 1808.4^{\circ} .\end{array}$ & 1 \\
\hline \multirow[t]{6}{*}{ Mirabeau/ } & $\begin{array}{l}\text { Lettres Inédites } \\
\text { Paris. } 1808.8^{\circ} .\end{array}$ & 1 \\
\hline & $\begin{array}{l}\text { Missale Romanum ex Decreto Sacrosancti Concilii } \\
\text { Tridentini Restitutum } \\
\text { Paris. } 1660.12^{\circ} .\end{array}$ & 1 \\
\hline & $\begin{array}{l}\text { Missale Romanum [ex Decreto Sacrosancti Concilii } \\
\text { Tridentini Restitutum] } \\
\text { Lisboa. } 1808 . \text { Fol. }\end{array}$ & 1 \\
\hline & $\begin{array}{l}\text { Missale Hoc Secundum Ritum et Consuetudine Alme } \\
\text { Bracharensis Ecclesie } \\
\text { Florença. 1498. Fol. }\end{array}$ & 1 \\
\hline & $\begin{array}{l}\text { Mystica Cidade de Deos, Doctrinas Celestiaes Dadas } \\
\text { pela Virgem Maria } \\
\text { Lisboa. } 1746.4^{\circ} .\end{array}$ & 1 \\
\hline & $\begin{array}{l}\text { Mistica Ciudad de Dios } \\
\text { Antuérpia. 1755. Fol. }\end{array}$ & 3 \\
\hline
\end{tabular}




\begin{tabular}{llc}
\hline Autor & \multicolumn{1}{c}{ Título } & Vol \\
\hline Mirabeau/ & $\begin{array}{l}\text { Modèles des Jeunes Personnes, ou Traits } \\
\text { Remarquables, Actions Vertueuses, Exemples } \\
\text { de Bonnes Conduite, etc } \\
\text { Paris. 1814. 16. }\end{array}$ & 1 \\
\hline
\end{tabular}

Molière

Oeuvres

8

Lyon. 1799. 12.

Montaigne/ Michel/ Essais de Montaigne, avec les Notes de M. Coste 16 Paris. 1801. 16.

Montani/ Luiz

Catharina de Cóluga, ou o Subterraneo. Dansa Tragica 1

Lisboa. 1821. 12.

\begin{tabular}{ll}
\hline Monte Carmelo/ & $\begin{array}{l}\text { Oração Funebre [nas Exéquias do Senhor] } \\
\text { Cypriano Ribeiro Freire } \\
\text { Frei Alexandre do/ }\end{array}$ \\
& Lisboa. $1825.8^{\circ}$.
\end{tabular}

Montengón/ Pedro Eusebio

Madrid. 1786. $8^{\circ}$.

\begin{tabular}{ll}
\hline Colbert / Carlos & Instrucções Geraes em Forma de Catecismo \\
Joaquim & Lisboa. 1770. $8^{\circ}$.
\end{tabular}

\begin{tabular}{ll}
\hline Morales/ D. José & Memoria sobre la Libertad Politica de la Imprenta \\
Isidoro/ & Sevilla. $1809.4^{\circ}$.
\end{tabular}

\begin{tabular}{lll}
\hline Morel/ & Zélomir & 1 \\
& Paris. 1801. $8^{\circ}$. &
\end{tabular}
Moreri/ Mr. Louis/ Le Grand Dictionnaire [Historique, ou le Mélange 10 Curieux] de l'Histoire Sacrée et Profane Paris. 1759. Fol.

Morganti/ Lourenço

Vida de Santa Zita Virgem Luqueza. Traduzida 1 do Idioma Italiano em Portuguez Lisboa. 1735. $4^{\circ}$.

\section{Morte /La/ di Semiramide. Dramma Serio Per Musica} 1

Lisboa. 1801. $8^{\circ}$.
Moura/ José Vicente
Carmina in [Fautissimam] Acclamationem [Joannis VI]
Gomes
Atque [in Auspicatissimas] Nuptias Petri et Leopoldinae
Coimbra. $1819.8^{\circ}$.
Moura/ José Vicente Noticia [Succinta] dos Monumentos da Lingua Latina, e Gomes dos Subsidios Necessarios para o Estudo da Mesma Coimbra. 1823. $4^{\circ}$.




\begin{tabular}{lll}
\hline Autor & \multicolumn{1}{c}{ Título } & Vol \\
\hline Moura/ José Vicente & $\begin{array}{l}\text { Noticia Succinta dos Monumentos da Lingua Latina, e } \\
\text { dos Subsidios Necessarios para o Estudo da Mesma } \\
\text { Coimbra. 1823. } 4^{\circ} .\end{array}$ \\
\hline Mourão/ Monsenhor & $\begin{array}{l}\text { Oração Funebre [que nas Solemnes Exequias que Fez } \\
\text { Celebrar] na Igreja Parochial de São Julião [pela Mui } \\
\text { Alta e Muito Poderosa Rainha] a Senhora D. Maria I } \\
\text { Lisboa. 1817. 4. }\end{array}$ \\
\hline
\end{tabular}

La Muerte de Abel, ó el Fratricidio: Poema en Prosa

Madrid. $1803.8^{\circ}$.

Museum Wecho's, Printed by H. Reynell

Sem ano e local. $12^{\circ}$.

Nacion /La/ Restablecimiento de Sus Principios

Sociales, etc

Cadiz. 1811. $4^{\circ}$.

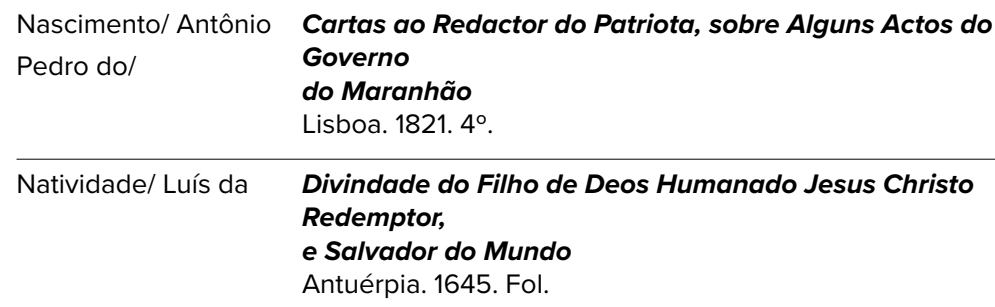




\begin{tabular}{ll}
\hline Autor & \multicolumn{1}{c}{ Título } \\
\hline $\begin{array}{l}\text { Neves/ José Acúrsio } \\
\text { das }\end{array}$ & $\begin{array}{l}\text { Nova Continuação das Cartas de hum Portuguez } \\
\text { aos Seus Concidadãos } \\
\text { Lisboa. 1823. } 4^{\circ} .\end{array}$ \\
\hline $\begin{array}{l}\text { Neves/ José Acúrsio } \\
\text { das }\end{array}$ & $\begin{array}{l}\text { Petição Documentada a El Rei Nosso Senhor } \\
\text { Lisboa. 1823. } 4^{\circ} .\end{array}$ \\
\hline $\begin{array}{l}\text { Noailles/ Louis } \\
\text { Antoine de/ }\end{array}$ & $\begin{array}{l}\text { Oeuvres } \\
\text { Paris. 1800. } 8^{\circ} .\end{array}$ \\
\hline $\begin{array}{l}\text { Bolaños y Novoa/ } \\
\text { Pascual/ }\end{array}$ & $\begin{array}{l}\text { Disertación Histórico-Politico-Legal, sobre la Sucesion } \\
\text { á la Corona de España } \\
\text { Cadiz. 1811. Fol. }\end{array}$ \\
\hline
\end{tabular}

Nogueira/ Frei Manoel Sermão de Acção de Graças pela Restauração,

Joaquim/

Pregado,

na Matriz da Villa do Alandroal

Lisboa. 1823. $4^{\circ}$.

Noronha/ Frei José

Maria de Santa

Oração Funebre Pregada nas Exequias da Senhora

Anna/

Dona Maria I

Lisboa. 1816. $8^{\circ}$.

Noronha/ Frei José

Maria de Santa

Sermão Analytico Pregado nas Exequias do Santo

Anna/

Padre Pio VII

na Santa Igreja Patriarchal

Lisboa1823. $4^{\circ}$.

Noronha/ Frei José

Maria de Santa Anna/

\section{Sermão Historico em Acção de Graças pelo}

Restabelecimento

de Sua Magestade ao Augusto Throno de seus Maiores

Lisboa. 1823. $4^{\circ}$.

Notas para la Inteligencia de los Articulos que Presentó

el Excmo Sr. Ministro de Gracia y Justicia á las Cortes, sobre Reforma

de Regulares

Cadiz. 1812. $4^{\circ}$.

\section{Notice Historique sur le Testament de Louis XVI}

Paris. $4^{\circ}$.

Noticia de las Demostraciones Públicas con que

el Cuerpo Militar y Político de la Real Armada del

Departamento y Esquadra de Cadiz han Celebrado en

la Ciudad de San Fernando la Feliz Restitución a Su

Trono del Senhor Don Fernando VII

Cadiz. 1814. $4^{\circ}$. 


\begin{tabular}{|c|c|c|}
\hline Autor & Título & Vol \\
\hline & $\begin{array}{l}\text { Noticia do Incendio Acontecido em Jerusalem no } \\
\text { Templo do Santissimo Sepulcro do Nosso Senhor Jesus } \\
\text { Christo em } 12 \text { de Outubro de } 1808 \\
\text { Rio de Janeiro. } 1808 \text {. Fol. }\end{array}$ & \\
\hline \multirow[t]{3}{*}{$\begin{array}{l}\text { Noronha/ Frei José } \\
\text { Maria de Santa Anna/ }\end{array}$} & $\begin{array}{l}\text { Noticia Breve de los Obsequios Tributados por la } \\
\text { Ciudad de Córdoba a la Reina Nuestra Señora Doña } \\
\text { María Isabel Francisca de Braganza, y a la Serenísima } \\
\text { Señora Doña María Francisca de Braganza, Infanta de } \\
\text { España, etc } \\
\text { Córdoba. } 1816.4^{\circ} .\end{array}$ & \\
\hline & $\begin{array}{l}\text { Noticia del Origen y Sucesos del Batallon de Artilleros } \\
\text { Voluntarios Gallegos etc } \\
\text { Cadiz. } 1812.4^{\circ} .\end{array}$ & \\
\hline & $\begin{array}{l}\text { Beautés de l'Histoire d'Espagne et de Portugal } \\
\text { Paris. } 1814.8^{\circ} \text {. }\end{array}$ & \\
\hline \multirow{9}{*}{$\begin{array}{l}\text { Nougaret/ Pierre } \\
\text { Jean Baptiste/ }\end{array}$} & $\begin{array}{l}\text { Novena de Santo Agostinho } \\
\text { Lisboa. } 1782.8^{\circ}\end{array}$ & \\
\hline & $\begin{array}{l}\text { Novena de São Camillo de Lellis } \\
\text { Lisboa. } 1789.8^{\circ} .\end{array}$ & \\
\hline & 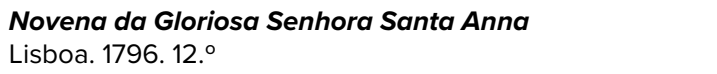 & 1 \\
\hline & $\begin{array}{l}\text { Novena, e Outras Devoções em Desaggravo } \\
\text { do Santissimo Sacramento } \\
\text { Lisboa. } 1788.8^{\circ} .\end{array}$ & 1 \\
\hline & $\begin{array}{l}\text { Novena ou Exercicio Devoto a São João Nepomuceno } \\
\text { Lisboa. } 1790.8^{\circ} .\end{array}$ & 1 \\
\hline & 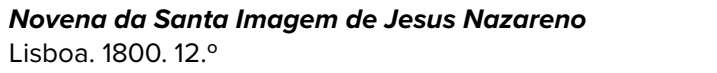 & 1 \\
\hline & $\begin{array}{l}\text { Novena da Immaculada Conceição de Maria } \\
\text { Sem lugar e ano. } 8^{\circ} \text {. }\end{array}$ & 1 \\
\hline & $\begin{array}{l}\text { Novena de São Pedro de Alcantara, com Hum Resumo } \\
\text { da Sua Vida } \\
\text { Lisboa. } 1799.8^{\circ} .\end{array}$ & 1 \\
\hline & $\begin{array}{l}\text { Novena de N. Senhora do Monte } \\
\text { Lisboa. } 1822.8^{\circ} .\end{array}$ & 1 \\
\hline
\end{tabular}




\begin{tabular}{|c|c|c|}
\hline Autor & Título & Vol \\
\hline & $\begin{array}{l}\text { Novena de Santa Teresa de Jesus } \\
\text { Lisboa. } 1795.8^{\circ} .\end{array}$ & 1 \\
\hline & 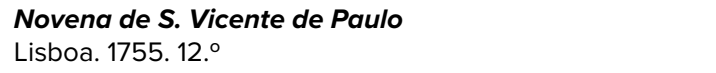 & 1 \\
\hline \multirow[t]{11}{*}{$\begin{array}{l}\text { Nougaret/ Pierre } \\
\text { Jean Baptiste/ }\end{array}$} & $\begin{array}{l}\text { Obsequio Devido aos Sagrados Templos. Traduzido } \\
\text { pelo Padre Frei Carlos de Santo Antonio } \\
\text { Lisboa. } 1739.4^{\circ} .\end{array}$ & 1 \\
\hline & $\begin{array}{l}\text { Obsequios que la Real Maestranza de Caballeria de } \\
\text { Valencia Tributó [á Nuestro Amado Monarca] el Señor } \\
\text { Don Fernando VIl etc } \\
\text { Valência. 1814. Fol. }\end{array}$ & 1 \\
\hline & $\begin{array}{l}\text { Observações sobre as Doenças, Feridas, e Outras } \\
\text { Imperfeições das Arvores Fructiferas e Sylvestres. Etc. } \\
\text { Traduzidas do Inglez } \\
\text { Coimbra. } 1802.4^{\circ} .\end{array}$ & 1 \\
\hline & $\begin{array}{l}\text { Observador / El/ Americano. Periodico } \\
\text { Buenos Aires. } 1816.4^{\circ} .\end{array}$ & 1 \\
\hline & $\begin{array}{l}\text { Ode Saphica } \\
\text { Sem lugar e ano. } 4^{\circ} \text {. }\end{array}$ & 1 \\
\hline & $\begin{array}{l}\text { Office /L'/ de la Sainte Vierge, sans Renvois, en Latin et } \\
\text { en Français } \\
\text { Paris. } 1810.16 .{ }^{\circ}\end{array}$ & 1 \\
\hline & $\begin{array}{l}\text { Officium Beatae Mariae Virginis, Septem Psalmi } \\
\text { Poenitentiales et Aliae Orationes } \\
\text { Sem lugar e ano. } 8^{\circ} .\end{array}$ & 1 \\
\hline & $\begin{array}{l}\text { Officium Proprium in Festo Sancti Sebastiani Martyris } \\
\text { Rio de Janeiro. } 1819.4^{\circ} .\end{array}$ & 1 \\
\hline & $\begin{array}{l}\text { Oficio de la Semana Santa: Segun el Missal y Breviario } \\
\text { Romano } \\
\text { Antuérpia. } 1725.8^{\circ} .\end{array}$ & 1 \\
\hline & $\begin{array}{l}\text { Oficio de la Semana Santa: Segun el Missal y Breviario } \\
\text { Romano } \\
\text { Antuérpia. } 1745.8^{\circ} .\end{array}$ & 3 \\
\hline & $\begin{array}{l}\text { Oitavas: Recitadas em o Dia dos Annos da Senhora } \\
\text { Dona Carlota Josquina, Princeza do Brazil } \\
\text { Lisboa. } 1803.4^{\circ} .\end{array}$ & 1 \\
\hline
\end{tabular}




\begin{tabular}{|c|c|c|}
\hline Autor & Título & Vol \\
\hline \multirow[t]{2}{*}{ Opie/ Amelia } & $\begin{array}{l}\text { Adelina Mowbray. Traduit de l'Anglais } \\
\text { Paris. } 1806.8^{\circ} .\end{array}$ & 3 \\
\hline & $\begin{array}{l}\text { Oração Funebre que se Recitou na Capella Pontificia } \\
\text { nas Exequias Celebradas pela Senhora Rainha } \\
\text { Dona Maria I } \\
\text { Lisboa. } 1824.4^{\circ} .\end{array}$ & 1 \\
\hline \multirow[t]{6}{*}{ Opie/ Amelia } & $\begin{array}{l}\text { Oração Funebre nas Exequias da Excellentissima } \\
\text { Senhora Condessa de Rio Maior } \\
\text { Lisboa. } 1812.4^{\circ} .\end{array}$ & 1 \\
\hline & $\begin{array}{l}\text { Orações /Varias/ Approvadas pela Igreja, de que } \\
\text { Devem Usar Todos os Catholicos, e Devotos } \\
\text { Lisboa. } 1804.8^{\circ} .\end{array}$ & 1 \\
\hline & $\begin{array}{l}\text { Orações / Varias/ a Santa Barbara } \\
\text { Lisboa. } 1804.8^{\circ} .\end{array}$ & 1 \\
\hline & $\begin{array}{l}\text { Ordenanzas Generales de la Armada Naval } \\
\text { Madrid. 1793. fol. }\end{array}$ & 2 \\
\hline & $\begin{array}{l}\text { Ordenanzas de S. M. para el Regimen, Disciplina, } \\
\text { Subordinacion y Servicio de sus Exercitos } \\
\text { Cadiz. } 1810.8^{\circ} .\end{array}$ & 1 \\
\hline & $\begin{array}{l}\text { Ordenanzas de la llustre Universidad, y Casa de } \\
\text { Contratacion de la M. N. y M. L. Villa de Bilbao } \\
\text { Biscaia. 1760. Fol. }\end{array}$ & 1 \\
\hline Orense/ Obispo de/ & $\begin{array}{l}\text { Carta Circular del Excmo. Sr. Obispo de Orense, } \\
\text { Remitiendo á los Párrocos y Fieles de Su diócesis } \\
\text { Exemplares de su Representacion } \\
\text { Cadiz. } 1812.4^{\circ} .\end{array}$ & 1 \\
\hline $\begin{array}{l}\text { Orléans/ } \\
\text { Pierre-Joseph d'/ }\end{array}$ & $\begin{array}{l}\text { Histoire des Révolutions d'Angleterre [depuis le } \\
\text { Commencement de la Monarchie] } \\
\text { Paris. } 1794.8^{\circ} .\end{array}$ & 6 \\
\hline \multirow[t]{3}{*}{$\begin{array}{l}\text { Orléans/ } \\
\text { Pierre-Joseph d'/ } \\
\text { Turpin/ }\end{array}$} & $\begin{array}{l}\text { Histoire des Révolutions d'Angleterre [depuis le } \\
\text { Commencement de la Monarchie] } \\
\text { Avignon. } 1810.8^{\circ} .\end{array}$ & 6 \\
\hline & $\begin{array}{l}\text { Oro /L'/ non Compra Amore. Dramma } \\
\text { Rio de Janeiro. } 1811.8^{\circ} .\end{array}$ & 1 \\
\hline & $\begin{array}{l}\text { Ortografía de la Lengua Castellana } \\
\text { Madrid. 1789. } 8^{\circ} .\end{array}$ & 1 \\
\hline
\end{tabular}




\begin{tabular}{|c|c|c|}
\hline Autor & Título & Vol \\
\hline $\begin{array}{l}\text { Ostolaza/ } \\
\text { Don Blas de/ }\end{array}$ & $\begin{array}{l}\text { El Alma al Pie de la Cruz, Meditando las Siete Palabras } \\
\text { que en ella Dixo el Salvador del Mundo } \\
\text { llha de León. 1811. } 4^{\circ} \text {. }\end{array}$ & Exemplar 2 \\
\hline $\begin{array}{l}\text { Ostolaza/ } \\
\text { Don Blas de/ }\end{array}$ & $\begin{array}{l}\text { Respuesta al Apologista de todos los Juramentados } \\
\text { Etc. } \\
\text { Cadiz. } 1812.4^{\circ} .\end{array}$ & 1 \\
\hline Ottoni/ José Elói/ & $\begin{array}{l}\text { Poezias Feitas ao Consorcio de Dom Pedro Carlos com } \\
\text { a Senhora Princeza da Beira } \\
\text { Rio de Janeiro. } 1811.8^{\circ} .\end{array}$ & 1 \\
\hline Ovídio/ & $\begin{array}{l}\text { Les Métamorphoses, Traduction Nouvelle, avec des } \\
\text { Notes, par [J. Ch. Louis] Malfilatre } \\
\text { Paris. } 1799.8^{\circ} .\end{array}$ & 3 \\
\hline $\begin{array}{l}\text { Ovídio/ } \\
\text { Rego/ José Antonio } \\
\text { da Silva }\end{array}$ & $\begin{array}{l}\text { Compendio das Metamorphoses [de Ovidio, com huma } \\
\text { Sucinta e Methodica Explicaçam a cada Fabula para } \\
\text { Instrucçam dos Meninos da Escola]. Traduzidas por } \\
\text { Joze Antonio da Silva Rego } \\
\text { Lisboa. } 1772.8^{\circ} \text {. }\end{array}$ & 1 \\
\hline Ovídio & $\begin{array}{l}\text { [Ovidii Nasonis] Operum Interpretatione et Notis } \\
\text { Illustravit Daniel Crispinus Helveticus } \\
\text { Bassani. } 1792.4^{\circ} .\end{array}$ & 4 \\
\hline Owenson/ Mis & $\begin{array}{l}\text { Saint-Clair, ou l'Héritière de Desmond } \\
\text { Paris. } 1813.8^{\circ} .\end{array}$ & Tomo 1 \\
\hline $\begin{array}{l}\text { Padilla/ Salvador } \\
\text { Ximenez de Enciso } \\
\text { y Cobos/ }\end{array}$ & $\begin{array}{l}\text { Panegirico Predicado el Dia del Glorioso Martir Español } \\
\text { Señor San Lorenzo, en su Iglesia Parroquial de la } \\
\text { Ciudad de Cadiz } \\
\text { Cadiz. } 1812.4^{\circ} .\end{array}$ & 1 \\
\hline $\begin{array}{l}\text { Padrón/ Antonio } \\
\text { José Ruiz de/ }\end{array}$ & $\begin{array}{l}\text { Apéndice al Dictamen [sobre el Tribunal de la } \\
\text { Inquisicón] } \\
\text { Cadiz. } 1813.8^{\circ} .\end{array}$ & 1 \\
\hline $\begin{array}{l}\text { Padrón/ Antonio } \\
\text { José Ruiz de/ }\end{array}$ & $\begin{array}{l}\text { Dictamen [del Doctor D. Antonio José Ruiz de Padron, } \\
\text { etc, sobre el Tribunal de Ia Inquisicion] } \\
\text { Cadiz. } 1813.4^{\circ} .\end{array}$ & 1 \\
\hline $\begin{array}{l}\text { Padrón/ Antonio } \\
\text { José Ruiz de/ }\end{array}$ & $\begin{array}{l}\text { Dictamen, que se Leyó en la Sesión Pública de } 12 \text { de } \\
\text { Octubre contra el Voto de San-Tiago } \\
\text { Cadiz. } 1812.4^{\circ} .\end{array}$ & 1 \\
\hline
\end{tabular}




\begin{tabular}{|c|c|c|}
\hline Autor & Título & Vol \\
\hline $\begin{array}{l}\text { Padrón/ Antonio } \\
\text { José Ruiz de/ }\end{array}$ & $\begin{array}{l}\text { Dictámen, [de Don Antonio José Ruiz de Padrón, } \\
\text { Diputado por Canarias], Proponiendo para Regenta del } \\
\text { Reyno á la Serenísima Señora D. Carlota Joaquina de } \\
\text { Borbón, [Princesa del Brasil y Infanta de las Españas] } \\
\text { Madrid. } 1814.4^{\circ} .\end{array}$ & 1 \\
\hline $\begin{array}{l}\text { Padrón/ Antonio } \\
\text { José Ruiz de/ }\end{array}$ & $\begin{array}{l}\text { Dictamen sobre el Tribunal de Ia Inquisición } \\
\text { Cadiz. } 1813.4^{\circ} .\end{array}$ & 1 \\
\hline $\begin{array}{l}\text { Padrón/ Antonio } \\
\text { José Ruiz de/ }\end{array}$ & $\begin{array}{l}\text { Monumento de Gratitud al Pueblo de Cadiz, con Motivo } \\
\text { de Disolverse las Cortes Generales y Extraordianarias } \\
\text { Cadiz. } 1813.4^{\circ} .\end{array}$ & 1 \\
\hline $\begin{array}{l}\text { Paio/ Frei Francisco } \\
\text { de São/ }\end{array}$ & $\begin{array}{l}\text { Oração Funebre Recitada no Convento de Santo } \\
\text { Antonio nas Exequias do Reverendissimo Senhor Dom } \\
\text { Lourenço Caleppi } \\
\text { Rio de Janeiro. } 1817.4^{\circ} .\end{array}$ & 1 \\
\hline $\begin{array}{l}\text { Paiva/ Manuel Joaquim } \\
\text { Henriques de }\end{array}$ & $\begin{array}{l}\text { Preservativo das Bexigas, e dos Seus Terriveis Estragos, } \\
\text { ou Historia da Origem e Descobrimento da Vaccina } \\
\text { Lisboa. } 1801.8^{\circ} .\end{array}$ & 1 \\
\hline Palmer/ John/ & $\begin{array}{l}\text { Le Tombeau Mistérieux, ou les Familles de Hénarès et } \\
\text { d'Almanza. [Roman Espagnol] Traduit de l'Anglais par } \\
\text { R. J. Durdent } \\
\text { Paris. } 1810.8^{\circ} \text {. }\end{array}$ & 2 \\
\hline $\begin{array}{l}\text { Portugal/ Marco } \\
\text { Antônio/ }\end{array}$ & $\begin{array}{l}\text { Le Donne Cambiate /Farça/ } \\
\text { Lisboa. } 1806.8^{\circ} .\end{array}$ & 1 \\
\hline \multirow[t]{5}{*}{ Pampilio/ Bernardo/ } & $\begin{array}{l}\text { Representación que Hace a S. M. sobre los Perjuicios } \\
\text { [que le Han Causado los procedimientos] del General } \\
\text { Elío, etc } \\
\text { Cadiz. } 1813.4^{\circ} .\end{array}$ & 1 \\
\hline & $\begin{array}{l}\text { Pappamosca /Li Fratelli/ Dramma } \\
\text { Lisboa. } 1786.8^{\circ} .\end{array}$ & 1 \\
\hline & $\begin{array}{l}\text { Parabens aos Portuguezes, Offerecidos ao Senhor } \\
\text { Infante Dom Miguel } \\
\text { Coimbra. } 1823.8^{\circ} .\end{array}$ & 1 \\
\hline & $\begin{array}{l}\text { Parabien Poético al Rey Nuestro Señor en ocasion } \\
\text { de los Reales Enlaces de S. M. y A } \\
\text { Cadiz. Sem Ano. } 4^{\circ} \text {. }\end{array}$ & 1 \\
\hline & $\begin{array}{l}\text { Parc /Le/ de Mansfield, ou les Trois Cousines. } \\
\text { Traduit de l'Anglais } \\
\text { Paris. } 1816.8^{\circ} .\end{array}$ & 4 \\
\hline
\end{tabular}




\begin{tabular}{|c|c|c|}
\hline Autor & Título & Vol \\
\hline & $\begin{array}{l}\text { Parecer de la Comision Nombrada para Examinar el } \\
\text { Discurso del Deputado D. Andres Angel de la Vega, } \\
\text { sobre la necesidad de Mejorar el sistema de Gobierno } \\
\text { Cadiz. } 1811.4^{\circ} .\end{array}$ & 1 \\
\hline & $\begin{array}{l}\text { Parte Essencial do Processo, com a Sentença, que } \\
\text { Restabeleceo a Memoria Phostuma do Benemerito } \\
\text { Portuguez, o Doutor Jose Ignacio da Rocha Peniz } \\
\text { Lisboa. } 1813.4^{\circ} \text {. }\end{array}$ & 1 \\
\hline Pascal/ & $\begin{array}{l}\text { Penseés de Pascal, avec les Notes de Mr. Voltaire } \\
\text { Londres. 1785. } 12 .^{\circ}\end{array}$ & 2 \\
\hline \multirow[t]{4}{*}{ Pascal/ } & $\begin{array}{l}\text { Paseo por Madrid, ó Guia del Forastero en la Corte } \\
\text { Madrid. 1815. 12. }\end{array}$ & 1 \\
\hline & $\begin{array}{l}\text { Pasienza /Cii Vuol/ Farsa } \\
\text { Lisboa. } 1806.8^{\circ} .\end{array}$ & 1 \\
\hline & $\begin{array}{l}\text { Passeios Instructivos ou Lições Elementares } \\
\text { de Mineralogia, Botanica, e Chymica } \\
\text { Lisboa. } 1803.8^{\circ} .\end{array}$ & 2 \\
\hline & $\begin{array}{l}\text { Passeios Instructivos ou Lições Elementares } \\
\text { de Mineralogia, Botanica, e Chymica } \\
\text { Lisboa. } 1803.8^{\circ} .\end{array}$ & 1 \\
\hline $\begin{array}{l}\text { Porto Moniz/ Nuno } \\
\text { Alvares Pereira/ }\end{array}$ & $\begin{array}{l}\text { Refutação Analytica do Folheto que Escreveo o } \\
\text { Reverendo Padre Jose Agostinho de Macedo } \\
\text { Lisboa. } 1810.8^{\circ} .\end{array}$ & 1 \\
\hline \multirow[t]{3}{*}{ Patrício/ Amador } & $\begin{array}{l}\text { Historia das Antiguidades de Evora } \\
\text { Evora. } 1739.4^{\circ} .\end{array}$ & 1 \\
\hline & $\begin{array}{l}\text { O Patriota Jornal Litterario, Politico, Mercantil. } \\
\text { Os Números 10, 40, 50, e } 60 \text { do } 1 .^{\circ} \text { Semestre de } 1813 . \\
\text { Números } 1,2,4,5 \text { e } 6 \text { do } 2 .^{\circ} \text { Semestre. } \\
\text { Números 2, 3, } 5 \text { e } 6 \text { de } 1814 \\
\text { Rio de Janeiro. } 1813.8^{\circ} .\end{array}$ & 12 \\
\hline & $\begin{array}{l}\text { Paulo e Virginia, Historia Fundada em Factos. } \\
\text { Traduzida do Francez } \\
\text { Lisboa. } 1806.8^{\circ} .\end{array}$ & 1 \\
\hline Pedro/ Frei João & Vida de São Jeronymo Patriarca & 1 \\
\hline de São/ & Lisboa. 1743. Fol. & Tomo 1 \\
\hline $\begin{array}{l}\text { Pellicer/ } \\
\text { Juan Antonio/ }\end{array}$ & $\begin{array}{l}\text { Vida de Miguel de Cervantes Saavedra } \\
\text { Madrid. } 1800,18^{\circ} .\end{array}$ & 8 \\
\hline
\end{tabular}




\begin{tabular}{|c|c|c|}
\hline Autor & Título & Vol \\
\hline \multirow[t]{4}{*}{ Penalva/ Marquês de } & $\begin{array}{l}\text { Novena da Senhora das Misericordias } \\
\text { Lisboa. } 1804.12^{\circ} \text {. }\end{array}$ & 1 \\
\hline & $\begin{array}{l}\text { Peninsula /A/ das Hespanhas Conhecendo-se } \\
\text { a si Mesma } \\
\text { Lisboa. } 1810.8^{\circ} .\end{array}$ & 1 \\
\hline & $\begin{array}{l}\text { Pensamientos Militares de un Paisano } \\
\text { Sevilha. } 1809.8^{\circ} .\end{array}$ & 1 \\
\hline & $\begin{array}{l}\text { Penssées Chrétiennes pour tous les Jours do Mois } \\
\text { Paris. } 12^{\circ} .\end{array}$ & 1 \\
\hline \multicolumn{2}{|c|}{ Péréfixe de Beaumont/ Histoire du Roi Henri le Grand } & 1 \\
\hline Hardouin de & Paris. 1807. $8^{\circ}$. & \\
\hline Pereira/ Benedito/ & $\begin{array}{l}\text { Prosodia in Vocabolarium Bilingue, Latinum, } \\
\text { et Lusitanum } \\
\text { Évora. 1741. Fol. }\end{array}$ & 1 \\
\hline $\begin{array}{l}\text { Pereira/ José Maria } \\
\text { Dantas/ }\end{array}$ & $\begin{array}{l}\text { Cursos de Estudos para uso do Commercio, } \\
\text { e da Fazenda } \\
\text { Lisboa. } 1798.4^{\circ} .\end{array}$ & 1 \\
\hline $\begin{array}{l}\text { Pereira/ José Maria } \\
\text { Dantas/ }\end{array}$ & $\begin{array}{l}\text { Ephemerides Nauticas [de } 1795 \text { a 1806] } \\
\text { Lisboa. } 1795.4^{\circ} .\end{array}$ & 7 \\
\hline $\begin{array}{l}\text { Pereira/ José Maria } \\
\text { Dantas/ }\end{array}$ & $\begin{array}{l}\text { Escritos Maritimos. Etc } \\
\text { Rio de Janeiro. } 1816.4^{\circ} \text {. }\end{array}$ & $\begin{array}{c}1 \\
\text { Tomo } 1\end{array}$ \\
\hline \multirow[t]{2}{*}{ Périn/ Abade/ } & $\begin{array}{l}\text { Abrégé de l'Histoire de Russie Depuis son Origine } \\
\text { jusqu'à nos Jours } \\
\text { Paris. } 1808.8^{\circ} .\end{array}$ & 2 \\
\hline & $\begin{array}{l}\text { Personas que Deben Componer la Regencia de las } \\
\text { Españas, y Razones Por qué } \\
\text { Cadiz. } 1813.4^{\circ} .\end{array}$ & 1 \\
\hline \multirow[t]{3}{*}{ Peyton/ V. J./ } & $\begin{array}{l}\text { Les Éléments de la Langue Anglaise } \\
\text { Londres. } 1800.8^{\circ} .\end{array}$ & 1 \\
\hline & $\begin{array}{l}\text { Pièces Intéressantes et peu Connues pour Servir a } \\
\text { l'Histoire e a la Littérature } \\
\text { Bruxelas. } 1785.8^{\circ} \text {. }\end{array}$ & 8 \\
\hline & $\begin{array}{l}\text { Pièces Judiciaires, et Historiques Relatives au Procès } \\
\text { du Duc d'Enghien, avec le Journal de ce Prince depuis } \\
\text { I'Instant de Son Arrestation } \\
\text { Paris. } 1823.8^{\circ} \text {. }\end{array}$ & 1 \\
\hline
\end{tabular}




\begin{tabular}{|c|c|c|}
\hline Autor & Título & Vol \\
\hline & $\begin{array}{l}\text { Pieza Alegórica, [que con Motivo de Ia Felicidad } \\
\text { que Promete a España] el Venturoso Enlace de Don } \\
\text { Fernando VII [con Doña María Isabel Francisca, Infanta } \\
\text { de Portugal, y el de Su Augusto Hermano]. Etc } \\
\text { Cadiz. } 1816.4^{\circ} .\end{array}$ & 1 \\
\hline Pinamonte/ Pedro & $\begin{array}{l}\text { Compendio Doutrinal [muito Util e Necessario para } \\
\text { Explicar e Saber a Doutrina Cristã, Composto pelo } \\
\text { Italiano, Também Missionário da Companhia, Padre } \\
\text { João Pedro Pinamonti,] e Augmentado pelo Padre } \\
\text { Pedro de Calatayud. } \\
\text { Lisboa. } 1753.12^{\circ} \text {. }\end{array}$ & 1 \\
\hline $\begin{array}{l}\text { Pina/ Antônio } \\
\text { Procópio Sousa/ }\end{array}$ & $\begin{array}{l}\text { Oração aos Serenissimos Principes do Brazil o Senhor } \\
\text { Dom João e a Senhora Dona Carlota no Faustissimo } \\
\text { Dia dos Annos da Serenissima Senhora Dona Maria } \\
\text { Theresa, Princeza da Beira sua Filha } \\
\text { Lisboa. } 1794.8^{\circ} .\end{array}$ & 1 \\
\hline Pino/ Pedro Baptista/ & $\begin{array}{l}\text { Exposicion Sucinta y Sencilla de Ia Provincia del Nuevo } \\
\text { Mexico } \\
\text { Cadiz. } 1812.4^{\circ} .\end{array}$ & 1 \\
\hline $\begin{array}{l}\text { Pinto/ Anônio J } \\
\text { oaquim de Gouvea/ }\end{array}$ & $\begin{array}{l}\text { Compilação das Providencias, que a bem da Criação } \\
\text { e Educação dos Expostos ou Engeitados se Tem } \\
\text { Publicado } \\
\text { Lisboa. } 1820.4^{\circ} .\end{array}$ & 1 \\
\hline $\begin{array}{l}\text { Pinto/ Antônio José } \\
\text { de Sousa/ }\end{array}$ & $\begin{array}{l}\text { Direcções sobre o Uso da Agua d'Inglaterra } \\
\text { Lisboa. } 1809.8^{\circ} .\end{array}$ & 1 \\
\hline \multirow[t]{2}{*}{$\begin{array}{l}\text { Pinto/ Antônio José } \\
\text { de Sousa/ }\end{array}$} & $\begin{array}{l}\text { Elementos de Pharmacia, Chymica, e Botanica } \\
\text { Lisboa. } 1805.4^{\circ} .\end{array}$ & 1 \\
\hline & $\begin{array}{l}\text { Pirro re di Epiro /Dramma/ } \\
\text { Lisboa. } 1806.8^{\circ} .\end{array}$ & 1 \\
\hline \multirow[t]{2}{*}{$\begin{array}{l}\text { De la Place/ } \\
\text { Fielding/ Henry/ }\end{array}$} & $\begin{array}{l}\text { Tom Jones, ou l'Enfant Trouvé. [Imité de Fielding par } \\
\text { M. de La Place] } \\
\text { Londres. } 1801.8^{\circ} .\end{array}$ & 4 \\
\hline & $\begin{array}{l}\text { Plano do Real Collegio de Nossa Senhora e } \\
\text { São Caetano } \\
\text { Rio de Janeiro. } 1816.4^{\circ} .\end{array}$ & 1 \\
\hline
\end{tabular}




\begin{tabular}{llc}
\hline Autor & \multicolumn{1}{c}{ Título } & Vol \\
\hline & Plans /Les/ et les Statuts des Différents Etablissements & 2 \\
& Ordonnés par Sa Majesté Imperiale Catherine II pour & \\
l'Éducation de la Jeunesse etc. Traduits en Langue \\
Françoise d'après les Originaux par M. Clerc \\
Amsterdam. 1775. $8^{\circ}$.
\end{tabular}

Plutarco /O/ Revolucionario, que Descreve a Vida

e Caracter das Personagens, que mais se Tem

Distinguindo de Bonaparte e de Outros nos Annos

da Republica Franceza

Lisboa. 1809. $8^{\circ}$.

Podestà /II/ di Chioggia. Dramma

Lisboa. 1804. $8^{\circ}$.

De la Place/
Fielding/ Henry/
Poesias Distribuidas no Theatro da Rua dos Condes no dia 15 de Setembro de 1821

Lisboa. 1821. Fol.

\begin{tabular}{|c|c|c|}
\hline & $\begin{array}{l}\text { Poesias Distribuidas no Theatro da Rua dos Condes } \\
\text { no dia } 3 \text { de Julho de } 1823 \\
\text { Lisboa. } 1823 . \text { Fol. }\end{array}$ & 1 \\
\hline & $\begin{array}{l}\text { Poesias a Diversos Assumptos [Relativas á Presente } \\
\text { Época, por Hum Anonymo] } \\
\text { Lisboa. Sem ano. } 8^{\circ} .\end{array}$ & 1 \\
\hline & $\begin{array}{l}\text { Poesias ao Feliz Anniversario do Regresso de Sua } \\
\text { Magestade á Antiga Séde da Monarchia } \\
\text { Lisboa. 1823. Fol. }\end{array}$ & 1 \\
\hline & $\begin{array}{l}\text { Poesias al Excmo Señor Lord Wellington quando Tomó } \\
\text { el Mando de General en Jefe de las Tropas Españolas } \\
\text { Ciudad Rodrigo. } 1813.4^{\circ} .\end{array}$ & 1 \\
\hline & $\begin{array}{l}\text { Poesias á Virgem Senhora do Cabo, Offerecidas pelos } \\
\text { Seos Devotos da Freguezia d'Ajuda } \\
\text { Lisboa. } 1821.8^{\circ} .\end{array}$ & 1 \\
\hline Pope/ Alexandre/ & $\begin{array}{l}\text { Ensaios Moraes [de Alexandre Pope: em Quatro } \\
\text { Epistolas a Diversas Pessoas]. Traduzidos em } \\
\text { Portuguez pelo Conde de Aguiar } \\
\text { Rio de Janeiro. } 1811.4^{\circ} .\end{array}$ & 1 \\
\hline Pope/ Alexandre/ & $\begin{array}{l}\text { Oeuvres Diverses, Traduites de l'Anglois } \\
\text { Amsterdam. } 1763.8^{\circ} \text {. }\end{array}$ & 7 \\
\hline Portilla/ Miguel de la/ & $\begin{array}{l}\text { Vida, y Milagros de San Francisco de Sales } \\
\text { Madrid. } 1695.4^{\circ} .\end{array}$ & 1 \\
\hline
\end{tabular}




\begin{tabular}{|c|c|c|}
\hline Autor & Título & Vol \\
\hline \multirow[t]{2}{*}{$\begin{array}{l}\text { Portilho/ João } \\
\text { Anástacio de Sousa } \\
\text { Pereira da Silva/ }\end{array}$} & $\begin{array}{l}\text { Collecção de Principios Geraes para o Estabelecimento, } \\
\text { Conservação, e Augmento de Qualquer Imperio } \\
\text { Rio de Janeiro. } 1817.4^{\circ} .\end{array}$ & 1 \\
\hline & $\begin{array}{l}\text { Portuguez /Hum/ aos Portuguezes } \\
\text { Lisboa. } 1810.4^{\circ} .\end{array}$ & 1 \\
\hline \multirow[t]{2}{*}{ Prazeres/ João dos } & $\begin{array}{l}\text { [O principe dos patriarcas S. Bento. Primeiro Tomo. } \\
\text { De sua] Vida Discursada em Emprezas Politicas e } \\
\text { Predicaveis } \\
\text { Lisboa. } 1682 . \text { Fol. }\end{array}$ & 2 \\
\hline & $\begin{array}{l}\text { Prelecções Philosophicas } \\
\text { Sem lugar e Ano. } 4^{\circ} \text {. }\end{array}$ & 10 \\
\hline \multirow[t]{2}{*}{ Presas/ José de/ } & $\begin{array}{l}\text { Representacion [que Eleva] al Rey [Nuestro Señor] } \\
\text { D. Fernando VII, [Don José de Presas] } \\
\text { Córdoba. } 1815.4^{\circ} \text {. }\end{array}$ & 1 \\
\hline & $\begin{array}{l}\text { Preservativo contra la Irreligion } \\
\text { Cadiz. } 1812.4^{\circ} .\end{array}$ & 1 \\
\hline $\begin{array}{l}\text { Preto/ Marcos Pinto } \\
\text { Soares Vaz/ }\end{array}$ & $\begin{array}{l}\text { Sermão no Anniversario do Regresso do Senhor } \\
\text { Dom João VI } \\
\text { Lisboa. } 1822.4^{\circ} .\end{array}$ & 1 \\
\hline \multirow[t]{6}{*}{ Prévost/ } & $\begin{array}{l}\text { Oeuvres Choisies de Prévost } \\
\text { Paris. } 1810.8^{\circ} .\end{array}$ & 39 \\
\hline & $\begin{array}{l}\text { Principes /Os/ da Armenia. Novella Persiana Traduzida } \\
\text { do Francez por Francisco de Paula e Oliveira } \\
\text { Lisboa. } 1804.8^{\circ} .\end{array}$ & 1 \\
\hline & $\begin{array}{l}\text { Procès du Maréchal Ney } \\
\text { Paris. 1815. } 8^{\circ} \text {. }\end{array}$ & 1 \\
\hline & $\begin{array}{l}\text { Procès de Sir Robert Wilson, Sir Hutchinson, Sir Michel } \\
\text { Bruce, et Autres Accusés Concernant l'Évasion de } \\
\text { M. de Lavalette } \\
\text { Paris. } 1816.8^{\circ} .\end{array}$ & 1 \\
\hline & $\begin{array}{l}\text { Proclama del Excelentisimo Cabildo de Buenos Ayres, } \\
\text { à Sus Habitantes } \\
\text { Buenos Aires. } 1808.4^{\circ} .\end{array}$ & 1 \\
\hline & $\begin{array}{l}\text { Proclamação do Governo Supremo do Reino aos } \\
\text { Portuguezes, e mais Papeis. Etc } \\
\text { Lisboa. 1820. Fol. }\end{array}$ & 1 \\
\hline
\end{tabular}




\begin{tabular}{|c|c|c|}
\hline Autor & Título & Vol \\
\hline & $\begin{array}{l}\text { Profecia Politica Relativa al Nombramiento de Nuevos } \\
\text { Regentes } \\
\text { Cadiz. } 1813.4^{\circ} .\end{array}$ & 1 \\
\hline \multirow[t]{2}{*}{ Prola/ José Maria/ } & $\begin{array}{l}\text { Novena do Glorioso Patriarca S. Joseph } \\
\text { Lisboa. } 1791.8^{\circ} .\end{array}$ & 1 \\
\hline & $\begin{array}{l}\text { Proposiciones que se Hacen al Señor Comandante } \\
\text { General del Exercito Sitiador de Esta Plaza de } \\
\text { Montevideo [Don Carlos Albear para Su Entrega } \\
\text { por los Diputados que Suscriben Autorizados Legal } \\
\text { y Plenamente por el Sr. Capitan General de Estas } \\
\text { Provincias D. Gaspar Vigodet para el Efecto] } \\
\text { Rio de Janeiro. 1814. Fol. }\end{array}$ & 1 \\
\hline \multirow[t]{3}{*}{ Prola/ José Maria/ } & $\begin{array}{l}\text { Proyecto de Constitucion Politica de la Monarquia } \\
\text { Española } \\
\text { Cadiz. } 1811.4^{\circ} .\end{array}$ & 1 \\
\hline & $\begin{array}{l}\text { Psyché et Cupidon; Tableaux-Tentures en Papier Peint } \\
1815.8^{\circ} .\end{array}$ & 1 \\
\hline & $\begin{array}{l}\text { Que Han Hecho los Frayles que Merezca Su Extincion? } \\
\text { Sem lugar, nem ano. } 4^{\circ} .\end{array}$ & 1 \\
\hline $\begin{array}{l}\text { Villegas/ Francisco } \\
\text { de Quevedo/ }\end{array}$ & $\begin{array}{l}\text { Historia y Vida del Gran Tacaño } \\
\text { Madrid. } 1793.8^{\circ} .\end{array}$ & 1 \\
\hline $\begin{array}{l}\text { Villegas/ Francisco } \\
\text { de Quevedo/ }\end{array}$ & $\begin{array}{l}\text { Juguetes de la Niñez y Travesuras del Ingenio } \\
\text { Madrid. } 1794.8^{\circ} .\end{array}$ & 1 \\
\hline $\begin{array}{l}\text { Quintana/ Domingo } \\
\text { Garcia/ }\end{array}$ & $\begin{array}{l}\text { Manifiesto que Hace a la Nacion Española en General y } \\
\text { al Reyno de Galicia en Particular el Diputado en Cortes } \\
\text { por la Provincia de Lugo D. Domingo García Quintana } \\
\text { Coruña. } 1811.4^{\circ} \text {. }\end{array}$ & 1 \\
\hline Quinte-Curce/ & $\begin{array}{l}\text { De la vie et des Actions d'Alexandre le Grande, en Latin } \\
\text { et en François, de la Traduction de Mr. de Vaugelas } \\
\text { Lyon. } 1705.8^{\circ} .\end{array}$ & 2 \\
\hline Ramiro/ José & Resumo dos Proverbios de Salomão & 1 \\
\hline \multirow[t]{2}{*}{ Gonçalves/ } & Lisboa. $1825.8^{\circ}$ & \\
\hline & $\begin{array}{l}\text { Ratificação do Juramento de Fedilidade, e Vassallagem } \\
\text { Offerecida ao Fidelissimo Senhor Dom João VI. [Rey } \\
\text { do Reino Unido de Portugal, Brazil, e Algarves no } \\
\text { Dia da Sua Fautissima Acclamação]. Em Nome do } \\
\text { Excellentisimo, [e Reverendissimo] Bispo do Pará } \\
\text { [Dom Manuel de Almeida Carvalho] } \\
\text { Rio de Janeiro. 1817. } 4^{\circ}\end{array}$ & 1 \\
\hline
\end{tabular}




\begin{tabular}{|c|c|c|}
\hline Autor & Título & Vol \\
\hline \multirow[t]{4}{*}{ Saint Real/ Mr. de / } & $\begin{array}{l}\text { Discurso sobre la Belleza de las Mugeres. Traducido } \\
\text { al Castellano por D. Gaspar de Allo } \\
\text { Salamanca. Sem ano. } 8^{\circ} \text {. }\end{array}$ & 1 \\
\hline & $\begin{array}{l}\text { Recopilacion / Novísima/ de las Leyes de España } \\
\text { Madrid. 1805. Fol. }\end{array}$ & 5 \\
\hline & $\begin{array}{l}\text { Recopilacion de Leyes de los Reynos de las Indias } \\
\text { Madrid. 1756. Fol. }\end{array}$ & 4 \\
\hline & $\begin{array}{l}\text { Recuerdo de Algunos Medios, Poderosos sin Duda, } \\
\text { para que por fin Triunfe Cataluña } \\
\text { Mallorca. } 1811.4^{\circ} .\end{array}$ & 1 \\
\hline \multirow[t]{4}{*}{ Saint Real/ Mr. de / } & $\begin{array}{l}\text { Recurso /Ultimo/ de la Nacion Española para Conservar } \\
\text { Su Existencia Politica } \\
\text { Cadiz. } 1813.8^{\circ} .\end{array}$ & 1 \\
\hline & $\begin{array}{l}\text { Reflexiones Imparciales de un Español } \\
\text { Madrid. 1823. Fol. }\end{array}$ & 1 \\
\hline & $\begin{array}{l}\text { Refutação Methodica das [Chamadas] Bazes da } \\
\text { Constituição Politica da Monarquia Portugueza } \\
\text { Lisboa. } 1824.4^{\circ} .\end{array}$ & 1 \\
\hline & $\begin{array}{l}\text { La Regencia de las Españas } \\
\text { Cadiz. } 1813.8^{\circ}\end{array}$ & 1 \\
\hline Regnault/ Abade & $\begin{array}{l}\text { Instructions pour la Confirmation } \\
\text { Paris. } 1810.12^{\circ} .\end{array}$ & 1 \\
\hline \multirow[t]{5}{*}{$\begin{array}{l}\text { Regnault-Warin/ } \\
\text { Jean-Joseph }\end{array}$} & $\begin{array}{l}\text { Le Cimetière de la Madeleine } \\
\text { Paris. } 12 .^{\circ}\end{array}$ & 3 \\
\hline & $\begin{array}{l}\text { Regra Santissima do Principe dos Patriarchas S. Bento, } \\
\text { Pai de Todos os Monges } \\
\text { Porto. } 1805.32^{\circ} \text {. }\end{array}$ & 1 \\
\hline & $\begin{array}{l}\text { Regulação para as Requisições dos Transportes de Mar, } \\
\text { e Terra para os Exercitos Portuguez, e Inglez } \\
\text { Lisboa. } 1811.8^{\circ} \text {. }\end{array}$ & 1 \\
\hline & $\begin{array}{l}\text { Relação dos Alumnos Matriculados, e Voluntarios que } \\
\text { Frequentão as Aulas da Academia Real da Marinha no } \\
\text { Anno Lectivo de } 1818 \text { para } 1819 \\
\text { Rio de Janeiro. } 1819 . \text { Fol. }\end{array}$ & 1 \\
\hline & $\begin{array}{l}\text { Relação Exacta do Arrebatamento do Santo Padre o } \\
\text { Papa Pio VII } \\
\text { Lisboa. } 1815.8^{\circ} .\end{array}$ & 1 \\
\hline
\end{tabular}




\begin{tabular}{|c|c|c|}
\hline Autor & Título & Vol \\
\hline & $\begin{array}{l}\text { Relação Circunstanciada da Solemne e Fúnebre } \\
\text { Pompa, com que [Quarta-Feira } 17 \text { de Fevereiro de } 1802 \\
\text { Foi Encontrado à Porta Flaminia], e Levado à Basilica } \\
\text { Vaticana o Corpo de Pio VI } \\
\text { Lisboa. } 18028^{\circ} .\end{array}$ & 1 \\
\hline & $\begin{array}{l}\text { Relação das Exequias Celebradas na Real Basilica } \\
\text { do SS. Coração de Jesus no Falecimento da [Sempre } \\
\text { Augusta e Fidelissima] Senhora Dona Maria I } \\
\text { Lisboa. 1816. Fol. }\end{array}$ & 1 \\
\hline \multirow[t]{8}{*}{$\begin{array}{l}\text { Regnault-Warin/ } \\
\text { Jean-Joseph }\end{array}$} & $\begin{array}{l}\text { Relação, e Indice Alphabetico dos Estudantes } \\
\text { Matriculados na Universidade Coimbra nos Annos } \\
\text { Lectivos de } 1823 \text { até } 1826 \\
\text { Coimbra. 1823. Fol. }\end{array}$ & 3 \\
\hline & $\begin{array}{l}\text { Relação dos Factos Praticados pela Commissão dos } \\
\text { Commerciantes de Vinhos em Londres } \\
\text { Lisboa. } 1813.8^{\circ} .\end{array}$ & 1 \\
\hline & $\begin{array}{l}\text { Relacion de los Exercicios Literarios Grados, Meritos y } \\
\text { Servicios del Doctor Don Miguel Nuñez Duarez } \\
\text { Madrid. 1813. Fol. }\end{array}$ & 1 \\
\hline & $\begin{array}{l}\text { Relacion de las Fiestas que Hizo la Ciudad de Cadiz } \\
\text { a la llegada de las S.S. Infantas de Portugal D. Maria } \\
\text { Izabel Francisca, y D. Maria Francisca de Asis } \\
\text { Cadiz. 1816. Fol. }\end{array}$ & 1 \\
\hline & $\begin{array}{l}\text { Relacion de los Singulares Servicios Hechos al Estado } \\
\text { por Don Juan Bautista Aralisson Etc } \\
\text { Madrid. 1820. Fol. }\end{array}$ & 1 \\
\hline & $\begin{array}{l}\text { Relation de la Guérison de la Soeur Sainte-Clotilde } \\
\text { Toulouse. } 1822.8^{\circ} .\end{array}$ & 1 \\
\hline & $\begin{array}{l}\text { Relation de Deux Guérisons Extraordinaires Opéreés à } \\
\text { Metz } \\
\text { Paris. Sem ano. } 8^{\circ} .\end{array}$ & 1 \\
\hline & $\begin{array}{l}\text { Remèdes contre le Péché et les Tentations } \\
\text { Langres. Sem ano. } 12^{\circ} .\end{array}$ & 1 \\
\hline \multirow[t]{2}{*}{$\begin{array}{l}\text { Renneville/ Madame } \\
\text { de/ }\end{array}$} & $\begin{array}{l}\text { La Mère Gouvernante, ou Principes de Politesse Fondés } \\
\text { sur les Qualités du Coeur } \\
1812.8^{\circ} .\end{array}$ & 1 \\
\hline & $\begin{array}{l}\text { Representación del Excmo Sr. Obispo de Orense, } \\
\text { Dirigida al Supremo Consejo de Regencia } \\
\text { Cadiz. } 1812.4^{\circ} .\end{array}$ & 1 \\
\hline
\end{tabular}




\begin{tabular}{|c|c|c|}
\hline Autor & Título & Vol \\
\hline & $\begin{array}{l}\text { Representacion que Eleva al Rey Nuestro Señor Don } \\
\text { Fernando VII, Don Jozé de Presas } \\
\text { Córdova. } 1815.4^{\circ} .\end{array}$ & $\begin{array}{c}1 \\
\text { Exemplar } 4\end{array}$ \\
\hline & $\begin{array}{l}\text { Representación Hecha a [S.A.S.] la Regencia del } \\
\text { Reyno, por el Ayuntamiento de L.M.N. y M.L. Ciudad } \\
\text { de Burgo Solicitando la Más Pronta Reposición del } \\
\text { Santo Tribunal de la Inquisición [al Estado que teni en } \\
\text { Principios del año 1820] } \\
\text { Madrid. 1823. } 8^{\circ} \text {. }\end{array}$ & 1 \\
\hline \multirow[t]{7}{*}{$\begin{array}{l}\text { Renneville/ Madame } \\
\text { de/ }\end{array}$} & $\begin{array}{l}\text { Representacion y Manifiesto que Algunos Diputados á } \\
\text { las Cortes Ordinarias Firmaron [en los Mayores Apuros } \\
\text { du Su Opresion en Madrid] } \\
\text { Madrid. } 1814.4^{\circ} .\end{array}$ & 1 \\
\hline & $\begin{array}{l}\text { Representacion y Manifiesto que Algunos Diputados á } \\
\text { las Cortes Ordinarias Firmaron [en los Mayores Apuros } \\
\text { du Su Opresion en Madrid] } \\
\text { Madrid. 1814. Fol. }\end{array}$ & 1 \\
\hline & $\begin{array}{l}\text { Respuesta al Papel Intitulado Vallesteros } \\
\text { Cadiz. } 1812.4^{\circ} .\end{array}$ & 1 \\
\hline & $\begin{array}{l}\text { Resultado das Observações Feitas no Hospital Real } \\
\text { da Inoculação das Bexigas nos Annos de 1796, 1797, } \\
\text { e } 1798 \\
\text { Lisboa. } 1799.8^{\circ} .\end{array}$ & 1 \\
\hline & $\begin{array}{l}\text { Retratos, e Bustos dos Varões e Donas, que Illustraram } \\
\text { a Nação Portugueza, [em Virtudes, Letras, Armas, e } \\
\text { Artes, assim Nacionais como Estranhos, assim Antigos } \\
\text { como Modernos na Europa, Africa e America] } \\
\text { Lisboa. } 1806.4^{\circ} \text {. }\end{array}$ & 1 \\
\hline & $\begin{array}{l}\text { Revolução e Estado Actual da França } \\
\text { Lisboa. 1793. } 8^{\circ} .\end{array}$ & 7 \\
\hline & $\begin{array}{l}\text { Rhétorique Française a l'Usage des Lycées } \\
\text { Dijon. 1820. } 12 .^{\circ}\end{array}$ & 1 \\
\hline $\begin{array}{l}\text { Ribadeneira/ Padre } \\
\text { Pedro de/ }\end{array}$ & $\begin{array}{l}\text { Tratado de la Religion y Virtudes que Debe Tener el } \\
\text { Principe Christiano, para Gobernar y Conservar sus } \\
\text { Estados } \\
\text { Madrid. } 1788.4^{\circ}\end{array}$ & 1 \\
\hline Ribeiro/Inácio/ & 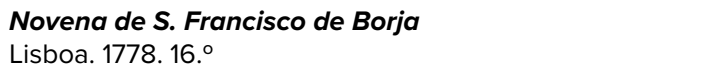 & 1 \\
\hline
\end{tabular}




\begin{tabular}{|c|c|c|}
\hline Autor & Título & Vol \\
\hline Ribeiro/ João Pedro/ & $\begin{array}{l}\text { Indice Chronologico [Remissivo da Legis/ação } \\
\text { Portuguesa Posterior á Publicacção do Codigo } \\
\text { Filippino] } \\
\text { Lisboa. } 1820.4^{\circ} .\end{array}$ & 1 \\
\hline Ribeiro/ João Pedro/ & $\begin{array}{l}\text { Indice Chronologico [Remissivo] da Legislação } \\
\text { Portugueza [Posterior á Publicacão do Codigo Filippino] } \\
\text { Lisboa. } 1805.4^{\circ} .\end{array}$ & $\begin{array}{l}3 \\
\text { Parte } 1^{\mathrm{a}}, 2^{\mathrm{a}} \\
\mathrm{e} 6^{\mathrm{a}}\end{array}$ \\
\hline $\begin{array}{l}\text { Ribeiro/ José } \\
\text { Anastácio de } \\
\text { Figueiredo/ }\end{array}$ & $\begin{array}{l}\text { Historia da Ordem do Hospital, Hoje de Malta, [e dos } \\
\text { Senhores Grão-Priores dela em Portugal] } \\
\text { Lisboa. } 1793.4^{\circ} .\end{array}$ & 1 \\
\hline $\begin{array}{l}\text { Ribeiro/ Padre } \\
\text { Matheus/ }\end{array}$ & $\begin{array}{l}\text { Alivio de Tristes, e Consolação de Queixosos } \\
\text { Lisboa. } 1764.4^{\circ} .\end{array}$ & 1 \\
\hline Richardson/ Samuel/ & $\begin{array}{l}\text { Pamella Andrew ou a Virtude Recompensada. [Novella } \\
\text { de Richardson], Traduzida [Livremente] do Inglez, } \\
\text { [Resumida e Acomodada à Linguagem Porutueza] por } \\
\text { D. Felix Moreno de Monroy y Ros } \\
\text { Lisboa. } 1799.8^{\circ} \text {. }\end{array}$ & 2 \\
\hline \multirow[t]{2}{*}{ Richer/ Mr./ } & $\begin{array}{l}\text { Théatre du Monde } \\
\text { Paris. } 1775.8^{\circ} \text {. }\end{array}$ & 2 \\
\hline & $\begin{array}{l}\text { Robinson /Le/ de la Jeunesse. Traduction par Mr. Feutry } \\
\text { Liège. } 18098^{\circ} .\end{array}$ & 2 \\
\hline \multirow[t]{2}{*}{$\begin{array}{l}\text { Rocha/ Padre Manoel } \\
\text { Ribeiro/ }\end{array}$} & $\begin{array}{l}\text { Socorro dos Fieis aos Clamores das Almas Santas } \\
\text { Lisboa. } 1758.4^{\circ} .\end{array}$ & 1 \\
\hline & $\begin{array}{l}\text { Romance Endecasilabo a la Inmortal Infanta de Castilla } \\
\text { la Señora Doña Maria Francisca de Asis } \\
\text { Sevilha. } 1823.4^{\circ}\end{array}$ & 1 \\
\hline $\begin{array}{l}\text { Rosa y Bazan/ José } \\
\text { Felix de la/ }\end{array}$ & $\begin{array}{l}\text { Panegirico Funeral [que] en las [Solemnes] Exequias } \\
\text { [que Santa Metropolitana Iglesia de Granada en los } \\
\text { dias } 9 \text { y } 10 \text { de Marzo de } 1818 \text { Celebró á la Memoria } \\
\text { Gloriosa] de Doña Maria Luisa de Borbon, Reyna } \\
\text { Madre del Sr. D. Fernando VII } \\
\text { Granada. 1819. } 4^{\circ} \text {. }\end{array}$ & 1 \\
\hline $\begin{array}{l}\text { Rosario/ } \\
\text { Frei Diogo do/ }\end{array}$ & $\begin{array}{l}\text { Flos Sanctorum, 8ou Historia das Vidas de Christo } \\
\text { Nosso Senhor, de sua Santissima May e dos Santos } \\
\text { e suas Festas] } \\
\text { Lisboa. 1767. Fol. }\end{array}$ & 2 \\
\hline Roselli/ Mr./ & $\begin{array}{l}\text { O Desgraçado Napolitano } \\
\text { Lisboa. } 1793.8^{\circ} .\end{array}$ & 1 \\
\hline
\end{tabular}




\begin{tabular}{|c|c|c|}
\hline Autor & Título & Vol \\
\hline $\begin{array}{l}\text { Rosseau/ } \\
\text { Jean-Jacques/ }\end{array}$ & $\begin{array}{l}\text { [Del] Contrato Social, ó Principios del Derecho Politico } \\
\text { Buenos Aires. } 1810.4^{\circ} .\end{array}$ & 1 \\
\hline Rossi/ Domingos & $\begin{array}{l}\text { Semiramis /Baile/ } \\
\text { Lisboa. } 1803.8^{\circ}\end{array}$ & 1 \\
\hline Rossi/ Domingos & $\begin{array}{l}\text { Programma do Novo Baile Heroico Pantomimo } \\
\text { Intitulado A Victoria dos Horacios contra os Curiacios } \\
\text { Lisboa. } 1802.8^{\circ} .\end{array}$ & 1 \\
\hline Rouvière/ Henrietta/ & $\begin{array}{l}\text { L'Abbaye de Lussington } \\
\text { Paris. } 1807.8^{\circ} \text {. }\end{array}$ & 3 \\
\hline \multirow[t]{2}{*}{ Rubio/ Narciso/ } & $\begin{array}{l}\text { Contesta al Autor del Anonimo Publicado con el titulo } \\
\text { de La Ley, Clamor a las Cortes, etc } \\
\text { Cadiz. } 1812.4^{\circ} .\end{array}$ & 1 \\
\hline & $\begin{array}{l}\text { Ruina Escandalosa [Intentada por la Regencia de } \\
\text { las Españas] contra Don Ricardo Meade } \\
\text { Cadiz. } 1812.4^{\circ} .\end{array}$ & 1 \\
\hline $\begin{array}{l}\text { Sá/ José Anastácio } \\
\text { da Costa e/ }\end{array}$ & $\begin{array}{l}\text { Tagidias, ou Festas do Tejo na [Gloriosa] Acclamação } \\
\text { do Senhor Rei D. João IV } \\
\text { Lisboa. 1803. } 4^{\circ}\end{array}$ & 1 \\
\hline $\begin{array}{l}\text { Saavedra/ Miguel } \\
\text { de Cervantes/ }\end{array}$ & $\begin{array}{l}\text { O Engenhoso Fidalgo Dom Quixote de la Mancha } \\
\text { Lisboa. } 1794.8^{\circ} .\end{array}$ & 6 \\
\hline $\begin{array}{l}\text { Saavedra/ Miguel } \\
\text { de Cervantes/ }\end{array}$ & $\begin{array}{l}\text { El Ingenioso Hidalgo Don Quixote de la Mancha } \\
\text { llha de Leão. 1810. } 8^{\circ} .\end{array}$ & 4 \\
\hline $\begin{array}{l}\text { Saavedra Fajardo/ } \\
\text { Diego de/ }\end{array}$ & $\begin{array}{l}\text { Idea de un Principe Politico Christiano, Representada } \\
\text { en Cien Empresas } \\
\text { Antuérpia. } 1655.4^{\circ} .\end{array}$ & 1 \\
\hline Sáez/ Víctor Dámian/ & $\begin{array}{l}\text { Oracion Fúnebre [que en las Solemnes y Reales } \\
\text { Honras, Celebradas de Orden de S.M. el Señor D. } \\
\text { Fernando VII, Rey de España y de las Indias, por el } \\
\text { Alma de su Augusta Madre] la Señora Doña María } \\
\text { Luisa de Borbon } \\
\text { Madrid. } 1819.4^{\circ}\end{array}$ & 1 \\
\hline Sage/ Mr. Le/ & $\begin{array}{l}\text { Aventuras de Gil Blas de Santillana, Traducidas al } \\
\text { Castellano por el Padre José Isla } \\
\text { Madrid. } 1807.8^{\circ} .\end{array}$ & 4 \\
\hline Sage/Mr. Le/ & $\begin{array}{l}\text { Le Diable Boiteux } \\
\text { Amsterdam. 1775. } 8^{\circ} .\end{array}$ & 2 \\
\hline
\end{tabular}




\begin{tabular}{|c|c|c|}
\hline Autor & Título & Vol \\
\hline $\begin{array}{l}\text { Sage/ Mr. Le/ } \\
\text { [Guevara/ Luiz Vélez } \\
\text { de] }\end{array}$ & $\begin{array}{l}\text { El Diablo Cojuelo, Verdades Soñadas, y Novelas de } \\
\text { la Otra Vida. Traducidas [a estar] por Luiz Velez de } \\
\text { Guevara } \\
\text { Madrid. } 1798.8^{\circ} .\end{array}$ & 1 \\
\hline Sage/Mr. Le/ & $\begin{array}{l}\text { O Diabo Coxo } \\
\text { Rio de Janeiro. } 1810.8^{\circ} .\end{array}$ & 2 \\
\hline Sage/ Mr. Le/ & $\begin{array}{l}\text { Oeuvres Choisies [de Le Sage] } \\
\text { Paris. } 1810.8^{\circ} .\end{array}$ & 16 \\
\hline $\begin{array}{l}\text { Saint-Germain/ P. M. } \\
\text { Gault de/ }\end{array}$ & $\begin{array}{l}\text { Vie de Nicolas Poussin, Considéré comme Chef de } \\
\text { l'École Françoise } \\
\text { Paris. } 1806.4^{\circ} .\end{array}$ & 1 \\
\hline $\begin{array}{l}\text { Saint-Pierre/ Jacques } \\
\text { Bernardin Henri de/ }\end{array}$ & $\begin{array}{l}\text { Paul et Virginie } \\
\text { Paris. } 1789.12^{\circ}\end{array}$ & 1 \\
\hline $\begin{array}{l}\text { Saint-Pierre/ Jacques } \\
\text { Bernardin Henri de/ }\end{array}$ & $\begin{array}{l}\text { Paul et Virginie } \\
\text { Paris. } 1800.8^{\circ}\end{array}$ & 1 \\
\hline $\begin{array}{l}\text { Saint-Pierre/ Jacques } \\
\text { Bernardin Henri de/ }\end{array}$ & $\begin{array}{l}\text { Paul et Virginie } \\
\text { Paris. } 1816.8^{\circ} .\end{array}$ & 1 \\
\hline $\begin{array}{l}\text { Saint-Ursin/ P. J. Marie } \\
\text { de/ }\end{array}$ & $\begin{array}{l}\text { L'Ami des Femmes, ou Lettres d'un Médecin } \\
\text { Paris. } 1805.8^{\circ}\end{array}$ & 1 \\
\hline $\begin{array}{l}\text { Salas/ Francisco } \\
\text { Gregorio de/ }\end{array}$ & $\begin{array}{l}\text { Observatorio Rustico } \\
\text { Madrid. } 1802.8^{\circ} .\end{array}$ & 1 \\
\hline $\begin{array}{l}\text { Salazar/ D. Francisco } \\
\text { Lobon de/ } \\
\text { [Isla/ José Francisco } \\
\text { de/] }\end{array}$ & $\begin{array}{l}\text { Historia del Famoso Predicador Fray Gerundio de } \\
\text { Campazas, alias Zotes } \\
\text { Madrid. } 1804.4^{\circ} .\end{array}$ & 3 \\
\hline $\begin{array}{l}\text { Sales/ São Francisco } \\
\text { de/ }\end{array}$ & $\begin{array}{l}\text { El Estandarte de la Santísima Cruz de Nuestro Redentor } \\
\text { Jesu-Christo. Traducido del Francés al Castellano por } \\
\text { Florian Anison } \\
\text { Madrid. } 1738.4^{\circ} .\end{array}$ & 1 \\
\hline \multirow[t]{2}{*}{$\begin{array}{l}\text { Sales/ São Francisco } \\
\text { de/ }\end{array}$} & $\begin{array}{l}\text { Traité de l'Amour de Dieu } \\
\text { Liège. } 1802.8^{\circ} .\end{array}$ & 1 \\
\hline & $\begin{array}{l}\text { Salubre Consilium et Auxilium, seu Novena \& Decena } \\
\text { Devotio ad Sanctum Franciscum Xaverium } \\
\text { Viena. Sem ano. } 12^{\circ} .\end{array}$ & 1 \\
\hline Salustio Crispo/ Cayo/ & $\begin{array}{l}\text { La Conjuracion de Catilina y la Guerra de Jugurta } \\
\text { Madrid. } 1772 \text {. Fol. }\end{array}$ & 1 \\
\hline
\end{tabular}




\begin{tabular}{|c|c|c|}
\hline Autor & Título & Vol \\
\hline $\begin{array}{l}\text { Sampaio/ Antônio } \\
\text { Marques de/ }\end{array}$ & $\begin{array}{l}\text { Oração em Acção de Graças pela [Feliz] Chegada [de } \\
\text { sua Alteza Real e sua Augusta] Familia [a esta Corte do } \\
\text { Brasil, Recitada na Real Capela do] Rio de Janeiro [em } \\
7 \text { de Março de } 1812 \text { ] } \\
\text { Rio de Janeiro. } 1812.8^{\circ} .\end{array}$ & 1 \\
\hline $\begin{array}{l}\text { Sampaio/ D. Sebastião } \\
\text { de/ }\end{array}$ & $\begin{array}{l}\text { Compendio da Vida do Glorioso Pontifice São Pio V } \\
\text { Roma. } 1728.4^{\circ}\end{array}$ & 1 \\
\hline $\begin{array}{l}\text { Santos/ Padre Luiz } \\
\text { Gonçalves dos }\end{array}$ & $\begin{array}{l}\text { Memorias para Servir á Historia do Reino do Brazil } \\
\text { Lisboa. } 1825.4^{\circ}\end{array}$ & 2 \\
\hline Savary/Mr. / & $\begin{array}{l}\text { Lettres sur l'Égypte } \\
\text { Amsterdam. 1787. } 8^{\circ}\end{array}$ & 3 \\
\hline \multirow[t]{4}{*}{$\begin{array}{l}\text { Saxe/ Marechal de/ } \\
\text { [Maurice de Saxe] }\end{array}$} & $\begin{array}{l}\text { Lettres et Mémoires Choisis parmi les Papiers Originaux } \\
\text { [du Maréchal de Saxe] } \\
\text { Paris. } 1794.8^{\circ} .\end{array}$ & 5 \\
\hline & $\begin{array}{l}\text { Scènes et Tableaux Tirés d'Atala } \\
\text { Paris. 1814. Fol. }\end{array}$ & 1 \\
\hline & $\begin{array}{l}\text { Sciencia dos Costumes, ou Etica Resumida } \\
\text { Lisboa. } 1813.8^{\circ}\end{array}$ & 1 \\
\hline & $\begin{array}{l}\text { Sedicente /II/ Filosofo: Farça, Giocosa [per Musica, } \\
\text { da Rappresentarsi nel Teatro Carcano, il Carnovale } \\
\text { dell'anno 1807] } \\
\text { Lisboa. } 1804.8^{\circ} .\end{array}$ & 1 \\
\hline $\begin{array}{l}\text { Seixas/ Romualdo } \\
\text { Antonio de/ }\end{array}$ & $\begin{array}{l}\text { Sermão de Acção de Graças [que no Dia } 13 \text { de Maio } \\
\text { Celebrou o Senado da Câmara do Pará] pela [Feliz] } \\
\text { Aclamação do [Muito Alto e Poderoso] Senhor D. João } \\
\text { VI [, Rei do Reino Unido de Portugal, Brasil e Algarves] } \\
\text { Rio de Janeiro. 1818. } 4^{\circ} \text {. }\end{array}$ & 1 \\
\hline Sejournant/ Mr.de/ & $\begin{array}{l}\text { Nouveau Dictionnaire Espagnol, François et Latin } \\
\text { Paris. } 1789.4^{\circ} .\end{array}$ & 2 \\
\hline $\begin{array}{l}\text { Semedo/ Belchior } \\
\text { Manuel Curvo/ }\end{array}$ & $\begin{array}{l}\text { Composições Poeticas } \\
\text { Lisboa. } 1803.8^{\circ}\end{array}$ & 2 \\
\hline \multirow[t]{2}{*}{ Señeri/ Padre Pablo/ } & $\begin{array}{l}\text { EI Devoto de la Virgen Maria, Instruido en los Motivos, } \\
\text { y en los Medios, que le Conducen a Servila bien } \\
\text { Barcelona. } 1723.4^{\circ} .\end{array}$ & 1 \\
\hline & $\begin{array}{l}\text { Sentença de Absolvição Proferida a favor do Conde } \\
\text { da Ega } \\
\text { Lisboa. } 1823.4^{\circ} .\end{array}$ & 1 \\
\hline
\end{tabular}




\begin{tabular}{|c|c|c|}
\hline Autor & Título & Vol \\
\hline & $\begin{array}{l}\text { Sentença a favor de Alvaro Xavier Botelho } \\
\text { Lisboa. 1821. Fol. }\end{array}$ & 1 \\
\hline & $\begin{array}{l}\text { Sentença a favor do Dezembargador Inspector dos } \\
\text { Transportes Motivada pela Arguição que se lhe Fez em } \\
\text { Cortes na Sessão de } 4 \text { de Junho de } 1821 \\
\text { Lisboa. 1821. Fol. }\end{array}$ & 1 \\
\hline & $\begin{array}{l}\text { Sentença Proferida contra os Réos Comprehendidos } \\
\text { na Devassa da Alçada, que Sua Magestade Foi Servido } \\
\text { Mandar á llha da Madeira } \\
\text { Funchal. } 1823.4^{\circ}\end{array}$ & 1 \\
\hline \multirow[t]{5}{*}{ Señeri/ Padre Pablo/ } & $\begin{array}{l}\text { Sentença dos Réos Sentenciados a pena Ultima no } \\
\text { Anno de } 1811 \\
\text { Lisboa. } 1811 . \text { Fol. }\end{array}$ & 1 \\
\hline & $\begin{array}{l}\text { Sentença dos Réos Sentenciados em } 1817 \\
\text { Fol. }\end{array}$ & 1 \\
\hline & $\begin{array}{l}\text { Sentença a favor do Dezembargador João Jozé } \\
\text { Mascarenhas de Azevedo e Silva. Etc } \\
\text { Lisboa. } 1814.4^{\circ} .\end{array}$ & 1 \\
\hline & $\begin{array}{l}\text { Sentimientos de Jesu-Christo Señor Nuestro Clavado } \\
\text { en la Cruz, Convenciendo al Hombre por su Ingratitud } \\
\text { Madrid. } 1786.8^{\circ} \text {. }\end{array}$ & 1 \\
\hline & $\begin{array}{l}\text { Sepulveda Patenteado, ou Voz Publica, e Solemne. Etc } \\
\text { Londres. 1813. Fol. }\end{array}$ & 1 \\
\hline \multirow{4}{*}{$\begin{array}{l}\text { Sequeira/ Domingos } \\
\text { Antonio de/ }\end{array}$} & Explicação de Hum Painel & 1 \\
\hline & Lisboa. 1810. $4^{\circ}$. & \\
\hline & $\begin{array}{l}\text { Sermão nas Exequias da Senhora Dona Maria I } \\
\text { Lisboa. } 1816.4^{\circ}\end{array}$ & 1 \\
\hline & $\begin{array}{l}\text { Serpentão /O/ Periodico } \\
\text { Lisboa. 1823. Fol. }\end{array}$ & 1 \\
\hline Serra/ Joze & Collecção de Livros Ineditos de Historia Portugueza & 1 \\
\hline Correia da/ & Lisboa. 1793. Fol. & Tomo 3 \\
\hline $\begin{array}{l}\text { Sevigné/ La Marquise } \\
\text { de/ } \\
\text { Grignan/ la Comtesse } \\
\text { de/ }\end{array}$ & $\begin{array}{l}\text { Recueil de Lettres } \\
\text { Rouen. } 1784.8^{\circ} .\end{array}$ & 10 \\
\hline
\end{tabular}




\begin{tabular}{lcc}
\hline Autor & Título & Vol \\
\hline $\begin{array}{l}\text { Sevigné/ Madame de/ } \\
\text { aintenon/ Madame de/ Paris. } 1805.8^{\circ} .\end{array}$ & & 1
\end{tabular}

Sevilla y su Iglesia a su Rey libre

Sevilla. 1823. $4^{\circ}$

Siècles /Les/ Chrétiens, ou Histoire du Christianisme

Paris. $1775.8^{\circ}$

\begin{tabular}{ll}
\hline Silva/ Joaquim da & Demonstração do que [o Conselheiro Joaquim da Costa \\
Costa e/ & e Silva] Praticou, como Inspector que Foi da Obra do \\
& Palacio d'Ajuda \\
& Lisboa. 1821. $4^{\circ}$.
\end{tabular}

Silva/ Joaquim da Resposta Comprovada que [o Conselheiro Joaquim da

Costa e/ Costa e Silva] Apresenta para Mostrar e Convencer a Falsidade do que Escreveo António Francisco Roza Lisboa. 1822. Fol.

Silva/ Joaquim José

Ventura da Regras Methodicas para se Aprender a Escrever 1 - Caracter da Letra Ingleza Lisboa. 1803. $8^{\circ}$.

Silva/ José Joaquim
Mendes e/
Silva/ Frei José
Leonardo da/

Silva/ José Maria da

Costa e/

Obras Poéticas

Lisboa. 1823. $4^{\circ}$

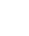




\begin{tabular}{|c|c|c|}
\hline Autor & Título & Vol \\
\hline Smith/ Charlote/ & $\begin{array}{l}\text { Les Loisirs de l'Enfance et de la jeunesse. Traduit de } \\
\text { I'Anglais par Bertin } \\
\text { Paris. } 1811.8^{\circ} .\end{array}$ & 4 \\
\hline Soares/ José Maria/ & $\begin{array}{l}\text { Memorias para a Historia da Medicina Lusitana } \\
\text { Lisboa. } 1821.4^{\circ} .\end{array}$ & $\begin{array}{c}1 \\
\text { Exemplar } 2\end{array}$ \\
\hline \multirow[t]{3}{*}{ Soares/ José Maria/ } & $\begin{array}{l}\text { Memorias para a Historia da Medicina Lusitana } \\
\text { Lisboa. } 1821.4^{\circ} .\end{array}$ & 1 \\
\hline & $\begin{array}{l}\text { Soireés /Les/ de l'Enfance, ou Conversations entre un } \\
\text { Père et ses Enfants. Traduction d'Anglois par T.P. Bertin } \\
\text { Paris. 1811. 12. }\end{array}$ & 4 \\
\hline & $\begin{array}{l}\text { Sol /EI/ de Cadiz } \\
\text { Cadiz. } 1813.4^{\circ}\end{array}$ & 1 \\
\hline \multirow[t]{2}{*}{$\begin{array}{l}\text { Soledade/ Antônio } \\
\text { Vieira da/ }\end{array}$} & $\begin{array}{l}\text { Oração Funebre [que] nas Exequias do [Serenissimo] } \\
\text { Senhor Infante [de Hespanha] Dom Pedro Carlos [de } \\
\text { Bourbon e Bragança, Almirante General da Marinha } \\
\text { Portugueza, junto á Real Pessoa, Recitou na Igreja de } \\
\text { S. Rita desta Corte no dia } 8 \text { de Julho do Anno de 1812] } \\
\text { Rio de Janeiro. 1812. } 8^{\circ} \text {. }\end{array}$ & 1 \\
\hline & $\begin{array}{l}\text { Soliloquios ao Senhor Menino Jesus dos Atribulados } \\
\text { Lisboa. } 1819.16^{\circ} .\end{array}$ & 1 \\
\hline Solís/ D. Antônio de/ & $\begin{array}{l}\text { Historia de la Conquista de Mexico } \\
\text { Barcelona. } 1771.8^{\circ} .\end{array}$ & 2 \\
\hline Solís/ D. Antonio de/ & $\begin{array}{l}\text { Historia de la Conquista de Mexico } \\
\text { Madrid. 1791. } 8^{\circ} .\end{array}$ & 3 \\
\hline \multirow[t]{2}{*}{$\begin{array}{l}\text { Someruelos/ Marqués } \\
\text { de/ }\end{array}$} & $\begin{array}{l}\text { Proclama: Habitantes de la Isla de Cuba, [Hijos Dignos } \\
\text { de la Generosa Nacion Española] } \\
\text { Havana. } 1808.4^{\circ} .\end{array}$ & 1 \\
\hline & $\begin{array}{l}\text { Sonetos Offerecidos a EI Rei o Senhor Dom João VI } \\
\text { Porto. 1823. } 4^{\circ} \text {. }\end{array}$ & 1 \\
\hline Sonnerat/ M./ & $\begin{array}{l}\text { Voyage aux Index Orientales et à la Chine, Fait par } \\
\text { Ordre de Louis XVI depuis } 1774 \text { jusqu'en } 1781 \\
\text { Paris. } 1806.8^{\circ} .\end{array}$ & 1 \\
\hline Sosa/ Francisco & Breve Noticia del Paraguay & 2 \\
\hline Antonio de/ & Sem ano. $4^{\circ}$. & \\
\hline
\end{tabular}




\begin{tabular}{|c|c|c|}
\hline Autor & Título & Vol \\
\hline & $\begin{array}{l}\text { Souvenirs d' un Homme de Cour, ou Mémoires d'un } \\
\text { Ancien Page } \\
\text { Paris. } 1805.8^{\circ} .\end{array}$ & 2 \\
\hline & $\begin{array}{l}\text { Souvenirs de ma vie depuis } 1774 \text { jusqu'en } 1814 \\
\text { Paris. } 1815.8^{\circ}\end{array}$ & 1 \\
\hline $\begin{array}{l}\text { Souza/ Bernardo } \\
\text { Avellino Ferreira e/ }\end{array}$ & $\begin{array}{l}\text { Relação dos Festejos, [que] á Feliz Acclamação do } \\
\text { [Muito Alto, Muito Poderoso, e Fidelissimo] Senhor } \\
\text { Dom João VI, [Rei do Reino Unido de Portugal, Brasil, } \\
\text { e Algarves, na Noite do Indelevel, e Fautissimo dia } 6 \\
\text { de Fevereiro, e nas duas Subsequentes, com tanta } \\
\text { Cordialidade, como Respeito Votarão os Habitantes } \\
\text { do Rio de Janeiro: Seguidas das Poesias Dedicadas ao } \\
\text { Mesmo Venerado Objecto] } \\
\text { Rio de Janeiro. } 1818\end{array}$ & 1 \\
\hline $\begin{array}{l}\text { Souza/ Frei Joé } \\
\text { Guedes Pinto de } \\
\text { Carvalho/ }\end{array}$ & $\begin{array}{l}\text { Requerimento Feito a S. Magestade } \\
\text { Lisboa. } 1825 . \text { Fol. }\end{array}$ & 1 \\
\hline Sousa/ José Roberto/ & $\begin{array}{l}\text { Remissoens das Leys Novissimas, Decretos, Avisos, } \\
\text { e mais Disposiçoens, que se Promulgarão não Só no } \\
\text { Reinado d'El Rey D. Joze I como tambem no de Dona } \\
\text { Maria I } \\
\text { Lisboa. } 1778.4^{\circ} .\end{array}$ & 2 \\
\hline Soyé/ Luís Rafael/ & $\begin{array}{l}\text { Noites Jozephinas de Mirtilo } \\
\text { Lisboa. } 1790.8^{\circ} .\end{array}$ & 1 \\
\hline $\begin{array}{l}\text { Stockler/ Francisco de } \\
\text { Borja Garção/ }\end{array}$ & $\begin{array}{l}\text { Compendio da Theorica dos Limites, ou Introducção } \\
\text { ao Methodo das Fluxões } \\
\text { Lisboa. } 1794.8^{\circ} .\end{array}$ & 1 \\
\hline Stockler/ Francisco de & Obras & 1 \\
\hline Borja Garção/ & Lisboa. 1805. $8^{\circ}$. & Tomo 1 \\
\hline Suleau/ Elysée de & $\begin{array}{l}\text { Récit des Opérations de l'Armée Royale du Midi } \\
\text { Paris. } 1815.8^{\circ} .\end{array}$ & 1 \\
\hline \multirow[t]{2}{*}{ Scudéry/ } & $\begin{array}{l}\text { L'Artamene, [overo Ciro il Grande]. Portato dal Francese } \\
\text { dal Sig. Marchese Majolino Bisaccioni } \\
\text { Veneza. } 1740.8^{\circ} .\end{array}$ & 10 \\
\hline & $\begin{array}{l}\text { Systema de Signaes [para a Communicação dos Navios } \\
\text { entre si, e com a Terra: : em qualquer Occasião, Logar, } \\
\text { e Tempo: e Seja qual for a Ordem Naval Adoptada] } \\
\text { Rio de Janeiro. } 1817.4^{\circ} \text {. }\end{array}$ & 2 \\
\hline
\end{tabular}




\begin{tabular}{|c|c|c|}
\hline Autor & Título & Vol \\
\hline & Systema, [ou Collecção] dos Regimentos Reaes & 1 \\
\hline & Lisboa. 1789. Fol. & Tomo 5 \\
\hline & $\begin{array}{l}\text { Tableau de l'Histoire de France, depuis le } \\
\text { Commencement de la Monarchie jusqu'au 1.er Août } 1815 \\
\text { Paris. } 1815.8^{\circ} .\end{array}$ & 2 \\
\hline & Tableau de Paris & 12 \\
\hline & Amsterdam. 1788. $8^{\circ}$. & \\
\hline & $\begin{array}{l}\text { Tableaux de la Suisse, ou Voyage Pittoresque Fait dans } \\
\text { les XIII Cantons du Corps Helvétique etc } \\
\text { Paris. } 1784.4^{\circ} .\end{array}$ & 8 \\
\hline & $\begin{array}{l}\text { Taboas Auxiliares nos Uzos das Ephemerides Nauticas } \\
\text { e Astronomicas } \\
\text { Lisboa. } 1800.4^{\circ} \text {. }\end{array}$ & 1 \\
\hline Scudéry/ & $\begin{array}{l}\text { Taboas que Contem os Logarithmos dos Numeros } \\
\text { Naturaes } \\
\text { Lisboa. } 1804.8^{\circ} .\end{array}$ & 1 \\
\hline Talassi/ Angelo/ & $\begin{array}{l}\text { L'Olmo Abbatuto. Poema } \\
\text { Lisboa. 1795. } 8^{\circ} \text {. }\end{array}$ & 1 \\
\hline Talavera/ Gabriel de/ & $\begin{array}{l}\text { Historia de Nuestra Señora de Guadalupe } \\
\text { Toledo. } 1579.4^{\circ} .\end{array}$ & 1 \\
\hline Tasso/ Torquato/ & $\begin{array}{l}\text { La Gerusalemme Liberata } \\
\text { Paris. } 1792.8^{\circ} .\end{array}$ & 1 \\
\hline Tavares/ Francisco/ & $\begin{array}{l}\text { Observationes, et Epicrisis de Corticis Peruviani } \\
\text { Salutari et Proficuo usu in Podagra } \\
\text { Lisboa. } 1802.8^{\circ} .\end{array}$ & 1 \\
\hline Thomas/ Mr./ & $\begin{array}{l}\text { Oeuvres } \\
\text { Paris. } 1792.8^{\circ} .\end{array}$ & 4 \\
\hline Thomson/ James/ & $\begin{array}{l}\text { Les Saisons. Traduites en vers Français par J. Poulin } \\
\text { Paris. } 1802.8^{\circ} .\end{array}$ & 1 \\
\hline & $\begin{array}{l}\text { Tio /EI/ Tremenda ó los Críticos de Malecon } \\
\text { Sevilla. } 1823.8^{\circ} .\end{array}$ & $\begin{array}{l}\text { Números } \\
1 \text { a } 14\end{array}$ \\
\hline $\begin{array}{l}\text { Tolentino de Almeida/ } \\
\text { Nicolau/ }\end{array}$ & $\begin{array}{l}\text { Obras Poéticas } \\
\text { Lisboa. } 1801.8^{\circ} .\end{array}$ & 2 \\
\hline Tomkins/ Thomas/ & $\begin{array}{l}\text { New Large Text, and Dutch Striking Alphabets } \\
\text { London. } 1785.4^{\circ} \text {. }\end{array}$ & 1 \\
\hline
\end{tabular}




\begin{tabular}{|c|c|c|}
\hline Autor & Título & Vol \\
\hline $\begin{array}{l}\text { Torre/ D. Francisco } \\
\text { de la/ }\end{array}$ & $\begin{array}{l}\text { El Peregrino At/ante S. Francisco Xavier etc. Epítome } \\
\text { Historico y Panegyrico de su vida y Prodigios } \\
\text { Lisboa. } 1674.4^{\circ} .\end{array}$ & 1 \\
\hline $\begin{array}{l}\text { Torres/ João Carlos } \\
\text { Feo Cardoso de } \\
\text { Castello Branco e/ }\end{array}$ & $\begin{array}{l}\text { Memorias Contendo a Biographia do Vice Almirante } \\
\text { Luiz da Motta Feo e Torres } \\
\text { Paris. } 1825.8^{\circ} .\end{array}$ & 1 \\
\hline \multirow[t]{2}{*}{$\begin{array}{l}\text { Torres/ Manuel } \\
\text { Agostinho Madeira/ }\end{array}$} & $\begin{array}{l}\text { Sermão de Acção de Graças pelos Ultimos Gloriosos } \\
\text { Triunfos da Campanha de } 1813 \\
\text { Lisboa. } 1816.8^{\circ} .\end{array}$ & 1 \\
\hline & $\begin{array}{l}\text { Tradução das Letras em que Clemente XIV Concedeo } \\
\text { Indulgencias Plenarias a Sua Magestade e Real Familia } \\
\text { Lisboa. } 1774.4^{\circ} .\end{array}$ & 1 \\
\hline \multirow[t]{5}{*}{$\begin{array}{l}\text { Torres/ Manuel } \\
\text { Agostinho Madeira/ }\end{array}$} & $\begin{array}{l}\text { Traité de Paix entre le Roi et les Puissances Alliées, } \\
\text { Conclu à Paris, le } 30 \text { Mai } 1814 \\
\text { Paris. } 1815.8^{\circ} .\end{array}$ & 1 \\
\hline & $\begin{array}{l}\text { Traslado a toda la Nación Española } \\
\text { Cadiz. } 1812.4^{\circ} .\end{array}$ & 1 \\
\hline & $\begin{array}{l}\text { Tratado de Abolição do Trafico da Escravatura da } \\
\text { Costa de Africa } \\
\text { Rio de Janeiro. 1815. Fol. }\end{array}$ & 1 \\
\hline & $\begin{array}{l}\text { Tratado de Amizade, e Aliança entre o Principe Regente } \\
\text { de Portugal, e EIRey da Gram Bretanha } \\
\text { Rio de Janeiro. 1810. Fol. }\end{array}$ & 1 \\
\hline & $\begin{array}{l}\text { Tratado de Amizade, e Aliança entre o Principe Regente } \\
\text { de Portugal, e EIRey da Gram Bretanha } \\
\text { Lisboa. } 1810.4^{\circ} \text {. }\end{array}$ & 1 \\
\hline $\begin{array}{l}\text { Trindade/ Frei Bento } \\
\text { da/ }\end{array}$ & $\begin{array}{l}\text { Sermão de Acção de Graças pela Vinda do Principe } \\
\text { Regente para os Estados do Brazil Pregado em a Igreja } \\
\text { do Sacramento em Pernanbuco } \\
\text { Rio de Janeiro. } 1809.8^{\circ} .\end{array}$ & 1 \\
\hline \multirow[t]{3}{*}{$\begin{array}{l}\text { Trindade/ D. Frei José } \\
\text { da Santíssima/ }\end{array}$} & $\begin{array}{l}\text { Carta Pastoral } \\
\text { Bahia. } 1820.4^{\circ}\end{array}$ & 1 \\
\hline & $\begin{array}{l}\text { Tripa por huma vez } \\
\text { Lisboa. } 1823.4^{\circ} .\end{array}$ & 1 \\
\hline & $\begin{array}{l}\text { Tripa /A/ Virada. Periodico Semanal } \\
\text { Lisboa. } 1823 .\end{array}$ & $\begin{array}{l}\text { Números } \\
1 \text { e } 2\end{array}$ \\
\hline
\end{tabular}




\begin{tabular}{|c|c|c|}
\hline Autor & Título & Vol \\
\hline & $\begin{array}{l}\text { Triunfo da Virtude, ou as Aventuras da Religiosa Dona } \\
\text { Olimpia. Traduzido do Francez por João Carlos Marão } \\
\text { Pinheiro } \\
\text { Lisboa.1799. Em } 8^{\circ} \text {. }\end{array}$ & 1 \\
\hline & $\begin{array}{l}\text { Trovas de Bandarra } \\
\text { Barcelona. } 1809.8^{\circ} .\end{array}$ & 1 \\
\hline & $\begin{array}{l}\text { Trovas Patrioticas, ou Lembranças Constitucionaes } \\
\text { Rio de Janeiro. } 1821.8^{\circ} .\end{array}$ & 1 \\
\hline & $\begin{array}{l}\text { Uffizio della } B \text {. Vergine Maria etc } \\
\text { Roma. } 1755.8^{\circ} .\end{array}$ & 1 \\
\hline $\begin{array}{l}\text { Uribe/ D. Miguel de } \\
\text { Lardizabal y }\end{array}$ & $\begin{array}{l}\text { Manifiesto que Presenta á la Nacion } \\
\text { Alicante. } 1811.4^{\circ} .\end{array}$ & 1 \\
\hline $\begin{array}{l}\text { Valdecebro/ Frei } \\
\text { André Ferrer de }\end{array}$ & $\begin{array}{l}\text { O Porque de todas as Couzas ou Endelechia da } \\
\text { Filosofia Natural, e Moral } \\
\text { Lisboa. } 1818.8^{\circ} .\end{array}$ & 1 \\
\hline $\begin{array}{l}\text { Valente/ Antônio } \\
\text { Diniz de Couto/ }\end{array}$ & $\begin{array}{l}\text { Ephemerides Nauticas para o Anno de } 1822 \\
\text { Lisboa. } 1821.4^{\circ} .\end{array}$ & 1 \\
\hline $\begin{array}{l}\text { Valenzuela/ D. Gabriel } \\
\text { Maria/ }\end{array}$ & $\begin{array}{l}\text { Vita di Maria Vergine Esposta in Novena } \\
\text { Roma. } 1722.8^{\circ} .\end{array}$ & 1 \\
\hline \multirow[t]{4}{*}{ Vallesteros/ Francisco/ } & $\begin{array}{l}\text { Contextacion [de D. Francisco Vallesteros] al Oficio que } \\
\text { Recebió de la Exôneracion de su Mando } \\
\text { Cadiz. } 1812.4^{\circ} .\end{array}$ & 1 \\
\hline & $\begin{array}{l}\text { Vallesteros: el Impugnador Impugnado } \\
\text { Cadiz. } 1812.4^{\circ} .\end{array}$ & 1 \\
\hline & $\begin{array}{l}\text { Ballesteros. Monologo } \\
\text { Cadiz. } 1813.4^{\circ} .\end{array}$ & 1 \\
\hline & $\begin{array}{l}\text { Ballesteros } \\
\text { Sevilla. Sem ano. } 4^{\circ} \text {. }\end{array}$ & 1 \\
\hline \multirow[t]{2}{*}{ Vallesteros/ Francisco/ } & $\begin{array}{l}\text { Respetuosos Descargos [que el Teniente General Don } \\
\text { Francisco Vallesteros Ofrece] a la generosa Nacion } \\
\text { Española } \\
\text { Algeciras. } 1813.4^{\circ} .\end{array}$ & 1 \\
\hline & $\begin{array}{l}\text { Valmont /Le Comte de/, ou les Égarements de la Raison } \\
\text { Paris. 1784. } 4^{\circ} .\end{array}$ & $\begin{array}{c}1 \\
\text { Tomo } 2\end{array}$ \\
\hline
\end{tabular}




\begin{tabular}{|c|c|c|}
\hline Autor & Título & Vol \\
\hline $\begin{array}{l}\text { Valsecchi/ Frei } \\
\text { Antonino/ }\end{array}$ & $\begin{array}{l}\text { La Religion Vincitrice } \\
\text { Gênova. } 1776.4^{\circ} .\end{array}$ & 1 \\
\hline $\begin{array}{l}\text { Varanda/ D. Bernardo } \\
\text { Sainz de/ }\end{array}$ & $\begin{array}{l}\text { El Rey Nuestro Señor Don Fernando Séptimo, } \\
\text { Comparado con el Gobierno de las Cortes Intruzas de } \\
\text { España } \\
\text { Madrid. } 1823.4^{\circ} .\end{array}$ & 1 \\
\hline $\begin{array}{l}\text { Varela/ D. Manuel } \\
\text { Fernandez/ }\end{array}$ & $\begin{array}{l}\text { Oracion Fúnebre por la Reina [Nuestra Señora] Doña } \\
\text { María Isabel Francisca de Braganza } \\
\text { Madrid. 1819. Fol. }\end{array}$ & 1 \\
\hline $\begin{array}{l}\text { Vasconcelos/ Paulino } \\
\text { Ferreira da Costa e/ }\end{array}$ & $\begin{array}{l}\text { Paz Literaria em Forma de Soliloquios, ou Sabonete } \\
\text { aos Soliloquios do R. P. J. A. M. } \\
\text { Lisboa. } 1811.8^{\circ} \text {. }\end{array}$ & 1 \\
\hline \multirow[t]{2}{*}{$\begin{array}{l}\text { Vasconcelos/ Paulino } \\
\text { Ferreira da Costa e/ }\end{array}$} & $\begin{array}{l}\text { Vassalagem /A/ Cantata [a três vozes. A Lealdade, a } \\
\text { Formosura, a Constância. Dedicada ao Felicissimo dia } \\
\text { Natalicio de Sua Alteza Real] o Principe Regente Nosso } \\
\text { Senhor } \\
\text { Lisboa. } 1801.4^{\circ} .\end{array}$ & 1 \\
\hline & $\begin{array}{l}\text { Vassalagem /A/ Cantata [a três vozes. A Lealdade, a } \\
\text { Formosura, a Constância. Dedicada ao Felicissimo dia } \\
\text { Natalicio de Sua Alteza Real] o Principe Regente Nosso } \\
\text { Senhor } \\
\text { Lisboa. } 1801.4^{\circ} .\end{array}$ & 1 \\
\hline Vaz/ Antônio José/ & $\begin{array}{l}\text { Epicedio á Sentida Morte do Serenissimo Senhor } \\
\text { Infante Dom Pedro Carlos de Bourbon e Bragança } \\
\text { Rio de Janeiro. } 1812.8^{\circ} .\end{array}$ & 1 \\
\hline Vazquez/ Francisco/ & $\begin{array}{l}\text { Atlas Elementar. Metodo Nuevo, Breve [y Demostrativo] } \\
\text { Facil para Aprender la Geografía etc } \\
\text { Madrid. } 1795.4^{\circ} .\end{array}$ & 1 \\
\hline $\begin{array}{l}\text { Vega/ Inca Garcilaso } \\
\text { de la/ }\end{array}$ & $\begin{array}{l}\text { Historia General del Perú } \\
\text { Madrid. } 1800.12^{\circ}\end{array}$ & 17 \\
\hline $\begin{array}{l}\text { Vega/ Inca Garcilaso } \\
\text { de la/ }\end{array}$ & $\begin{array}{l}\text { Obras } \\
\text { Madrid. 1796. } 12 .\end{array}$ & 1 \\
\hline \multirow[t]{2}{*}{ Vergara/ D. Miguel de/ } & $\begin{array}{l}\text { Vida [Interior del Ilustrissimo, Excelentissimo, y } \\
\text { Venerable Señor] D. Juan de Palafox y Mendoza } \\
\text { Sevilha. } 1691.4^{\circ} .\end{array}$ & 1 \\
\hline & $\begin{array}{l}\text { Vergini /Le/ del Sole. Drama } \\
\text { Lisboa. } 1802.8^{\circ} .\end{array}$ & 1 \\
\hline
\end{tabular}




\begin{tabular}{|c|c|c|}
\hline Autor & Título & Vol \\
\hline & $\begin{array}{l}\text { Vergini /Le/ del Sole. Drama } \\
\text { Lisboa. } 1802.8^{\circ} .\end{array}$ & 1 \\
\hline & $\begin{array}{l}\text { Verídico /EI/ Español } \\
\text { Lisboa. } 1812.4^{\circ} .\end{array}$ & 1 \\
\hline & $\begin{array}{l}\text { Versos que no Faustissimo Aniversario de Sua Alteza } \\
\text { Real O Principe Regente destes Reinos Additou na } \\
\text { Praça do Rocio Joze Pedro da Silva } \\
\text { Lisboa. } 1814.8^{\circ} \text {. }\end{array}$ & 1 \\
\hline & $\begin{array}{l}\text { EI Viage: Dialogo Critico, Verídico, Burlesco entre la } \\
\text { Tristeza y Pocapena } \\
\text { Madrid. } 1823.4^{\circ} .\end{array}$ & 1 \\
\hline Vergara/ D. Miguel de/ & $\begin{array}{l}\text { Viagens de Gulliver a varios Paises Remotos } \\
\text { Lisboa. } 1807.8^{\circ} .\end{array}$ & 3 \\
\hline \multirow[t]{8}{*}{ Viale/ Antônio/ } & $\begin{array}{l}\text { David Triunfante } \\
\text { Lisboa. } 1819.4^{\circ} .\end{array}$ & 1 \\
\hline & $\begin{array}{l}\text { [La Dichosa Peregrina] Santa Brigida de Suecia, } \\
\text { Princesa de Nericia. Traduzida del Idioma Italiano por } \\
\text { el Padre Gaspar de San Antonio } \\
\text { Lisboa. } 1714.4^{\circ} .\end{array}$ & 1 \\
\hline & $\begin{array}{l}\text { Vida de Deziderio Estok, ou a Força de huma Amizade } \\
\text { Lisboa. } 1807.8^{\circ} .\end{array}$ & 1 \\
\hline & $\begin{array}{l}\text { Vida /Compendio da Prodigiosa/ de São Gonçalo } \\
\text { de Lagos } \\
\text { Lisboa. } 1778.8^{\circ} .\end{array}$ & 1 \\
\hline & $\begin{array}{l}\text { Vida de São José Calasans. Traduzida em Portuguez } \\
\text { Lisboa. } 1794.8^{\circ} .\end{array}$ & 1 \\
\hline & $\begin{array}{l}\text { Vida e Opusculos de São Martinho Bracarense, } \\
\text { Impressos [pela Primeira vez, neste Reino], por } \\
\text { Cuidado, e Ordem do Excelentissimo e Reverendissimo } \\
\text { Senhor Dom Frei Caetano Brandão Arcebispo Primaz } \\
\text { Lisboa. 1803. Fol. }\end{array}$ & 1 \\
\hline & $\begin{array}{l}\text { Vida e Regras Relegiosas de São Frutuoso Bracarense } \\
\text { Lisboa. } 1805 . \text { Fol. }\end{array}$ & 1 \\
\hline & $\begin{array}{l}\text { Vida de S. Vicente de Paula. Traduzida em Portuguez } \\
\text { por Dom José Barboza } \\
\text { Lisboa. 1738. Fol. }\end{array}$ & 1 \\
\hline
\end{tabular}




\begin{tabular}{|c|c|c|}
\hline Autor & Título & Vol \\
\hline Transtagano/ Antônio & Diccionario Inglez e Portuguez & 1 \\
\hline Vieira/ & Londres. 1782. $8^{\circ}$. & \\
\hline Transtagano/ Antônio & [A] Dictionary of the Portuguese and English Languages & 2 \\
\hline Vieira/ & Londres. $1805.4^{\circ}$ & \\
\hline Villa Flor/ Conde de/ & $\begin{array}{l}\text { Manifesto que Faz ao Publico sobre o Processo, } \\
\text { e Condemnação de Manoel da Costa } \\
\text { Lisboa. } 1822.4^{\circ} \text {. }\end{array}$ & 1 \\
\hline Virgílio & $\begin{array}{l}\text { Oeuvres [de Virgile]. Traduites en François par } M . \\
\text { L'Abbé des Fontaines } \\
\text { Lyon. } 1801.8^{\circ} .\end{array}$ & 2 \\
\hline Virgílio & $\begin{array}{l}\text { [Tradução Livre ou Imitação das] Georgicas [de Virgilio } \\
\text { em verso solto], e outras mais Composições Poeticas } \\
\text { por Antonio José Ozorio de Pina Leitão } \\
\text { Lisboa. } 1794.8^{\circ} .\end{array}$ & 1 \\
\hline $\begin{array}{l}\text { Viterbo/ Frei Joaquim } \\
\text { de Santa Rosa de/ }\end{array}$ & $\begin{array}{l}\text { Elucidario das Palavras, Termos, e Frazes, que em } \\
\text { Portugal Antiguamente se Usarão, etc } \\
\text { Lisboa. } 1798.8^{\circ} .\end{array}$ & 2 \\
\hline \multirow[t]{5}{*}{ Vosgien } & $\begin{array}{l}\text { Nouveau Dictionnaire Géographique, ou Description } \\
\text { de toutes les Parties du Monde. Enrichie de sept Cartes } \\
\text { Géographiques par M. Beaumont } \\
\text { Paris. } 1817.8^{\circ} .\end{array}$ & 1 \\
\hline & $\begin{array}{l}\text { Voto del Señor Don Gregorio Laguna, Mariscal } \\
\text { de Campo [de los Reales Exércitos], Diputado } \\
\text { en Cortes etc } \\
\text { llha de Leão. } 1811.4^{\circ} .\end{array}$ & 1 \\
\hline & $\begin{array}{l}\text { Votos a Deos Feitos por Sua Magestade, Sendo } \\
\text { Offerecida no Templo a Princeza da Beira, [á } \\
\text { Semelhança dos do Rei David por seu Filho Salomão no } \\
\text { Salmo 71]. Parafrazeado em Verso Portuguez por José } \\
\text { Bernardes de Castro } \\
\text { Rio de Janeiro. } 1819.4^{\circ} .\end{array}$ & 1 \\
\hline & $\begin{array}{l}\text { Voyages d'Antenor en Grèce et en Asie. Traduit par E. } \\
\text { T. Lantier } \\
\text { Paris. } 1800.12^{\circ} .\end{array}$ & 5 \\
\hline & $\begin{array}{l}\text { Voyages Imaginaires, [Romanesques, Merveilleux, } \\
\text { Allégoriques, Amusans, Comiques et Critiques. Suivis } \\
\text { des] Songes et Visions, et des Romans Cabalistiques } \\
\text { Amsterdam. } 1787.8^{\circ} \text {. }\end{array}$ & 39 \\
\hline
\end{tabular}




\begin{tabular}{|c|c|c|}
\hline Autor & Título & Vol \\
\hline & $\begin{array}{l}\text { Voz /A/ da Natureza sobre a Origem dos Governos. } \\
\text { Traduzido [da Segunda Edição] Franceza } \\
\text { Lisboa. } 1814.4^{\circ} .\end{array}$ & 2 \\
\hline & $\begin{array}{l}\text { Vozes dos Leaes Portuguezes ou Fiel Echo das suas } \\
\text { Novas Acclamações á Religião, a EIRey, e as Cortes } \\
\text { destes Reinos } \\
\text { Lisboa. } 1820.4^{\circ} .\end{array}$ & 2 \\
\hline Wandelaincourt/ M. & $\begin{array}{l}\text { L'École de la Vertu et de la Politesse } \\
\text { Paris. } 1808.12^{\circ} .\end{array}$ & 1 \\
\hline $\begin{array}{l}\text { Wanton/ Henrique/ } \\
\text { [Seriman/ Zaccaria] }\end{array}$ & $\begin{array}{l}\text { Viagens [de Henrique Wanton ás Terras Incógnitas, } \\
\text { Austraes, e] ao Paiz das Monas } \\
\text { Lisboa. } 1799.8^{\circ} .\end{array}$ & $\begin{array}{c}4 \\
\text { Tomos }^{\circ}, \\
2^{\circ}, 3^{\circ} \mathrm{e} \\
5^{\circ}\end{array}$ \\
\hline $\begin{array}{l}\text { Wanton/ Henrique/ } \\
\text { [Seriman/ Zaccaria] }\end{array}$ & $\begin{array}{l}\text { Viagens [de Henrique Wanton] ás Terras Incógnitas, } \\
\text { Austraes, e ao Paiz das Monas } \\
\text { Lisboa. } 1799.8^{\circ} .\end{array}$ & 5 \\
\hline Weber/ Joseph/ & $\begin{array}{l}\text { Mémoires Concernant Marie Antoinette, [Archiduchesse } \\
\text { d'Autriche,] Reine de France, [et ] sur [plusiers époques } \\
\text { importantes de] la Révolution Françoise [,depuis son } \\
\text { origine jusqu'au } 16 \text { octobre 1793, jour du Martyre de Sa } \\
\text { Majesté } \\
\text { Londres. } 1804.4^{\circ} \text {. }\end{array}$ & 3 \\
\hline \multirow[t]{3}{*}{ Yríarte/ Tomas de/ } & $\begin{array}{l}\text { La Música. Poema } \\
\text { Madrid. 1779. } 4^{\circ} .\end{array}$ & 1 \\
\hline & $\begin{array}{l}\text { Zélé /Le/ Serviteur de Jésus-Christ, ou l'Adorateur du } \\
\text { Verbe Éternel } \\
\text { Paris. } 1810.8^{\circ} .\end{array}$ & 1 \\
\hline & $\begin{array}{l}\text { Zélie dans le Désert } \\
\text { Genebra. 1795. } 8^{\circ} .\end{array}$ & 4 \\
\hline
\end{tabular}




\section{Manuscriptos}

\begin{tabular}{|c|c|c|c|}
\hline Autor & Título & Vol & $\begin{array}{c}\text { Localização - Acervo } \\
\text { Biblioteca da Ajuda }\end{array}$ \\
\hline Aboim/ Joaquim da & Vida de São Carlos Borromêo & & \\
\hline \multirow[t]{2}{*}{ Nóbrega Cão de/ } & Sem lugar. $1801.4^{\circ}$ & 1 & $54-V-15$ \\
\hline & $\begin{array}{l}\text { Alfabetos /Três/ para se Aprender a } \\
\text { Escrever } \\
12 .^{\circ}\end{array}$ & 1 & \\
\hline \multirow[t]{2}{*}{$\begin{array}{l}\text { Beja/ João Bernardo } \\
\text { Freire de Andrade/ }\end{array}$} & $\begin{array}{l}\text { Hidrodynamica Politica, ou } \\
\text { Considerações sobre a Constituição } \\
\text { Portugueza } \\
\text { Sem lugar, nem ano. Fol. }\end{array}$ & 1 & $51-X I I-100$ \\
\hline & $\begin{array}{l}\text { Ceremonias, y Etiquetas que Deben } \\
\text { Observarse en la entrada de S. M. Ia } \\
\text { Reina N. Sra. Y de la Serenissima Sra. } \\
\text { Infanta D. Maria Francisca de Assis, en } \\
\text { Madrid } \\
4^{\circ} .\end{array}$ & 1 & $51-X-35 N^{\circ} 2$ \\
\hline Costa/ Francisca de & Epistola & & \\
\hline Paula Possollo da/ & Fol. & 1 & $54-X-12 N^{\circ} 49$ \\
\hline $\begin{array}{l}\text { Costa/ José Joaqquim } \\
\text { Carneiro de Miranda e }\end{array}$ & $\begin{array}{l}\text { Novella Familiar Instructiva com } \\
\text { / Explicação de todas as Virtudes } \\
\text { Moraes } \\
\text { Sem lugar, nem ano. } 4^{\circ} .\end{array}$ & 1 & $50-1-57$ \\
\hline $\begin{array}{l}\text { Costa/ Paulo Francisco } \\
\text { Gomes da/ }\end{array}$ & $\begin{array}{l}\text { Discurso em que se Mostra que o } \\
\text { dia } 3 \text { de Julho de } 1821 \text { he de todas } \\
\text { as Venturas, e Maravilhas para os } \\
\text { Portuguezes } \\
\text { Lisboa. } 1823.4^{\circ} \text {. }\end{array}$ & 1 & $49-I I I-39 N^{\circ} 11$ \\
\hline \multirow[t]{3}{*}{ Caetano da Silva/ } & $\begin{array}{l}\text { Pastoral } \\
\text { Rio de Janeiro. 1811. Fol. }\end{array}$ & 1 & $54-X I I I-4 N^{\circ} 39$ \\
\hline & $\begin{array}{l}\text { Dedicatoria em Verso Offerecida a Sua } \\
\text { Magestade sobre o Preparar huma } \\
\text { Nova Galea } \\
\text { Sem lugar, nem ano. } 4^{\circ} \text {. }\end{array}$ & 1 & \\
\hline & $\begin{array}{l}\text { Descripção da Illuminação que Fez } \\
\text { Antonio José da Silva Braga pela } \\
\text { Acclamação do Senhor Dom João VI } \\
\text { Fol. }\end{array}$ & 1 & $54-\mathrm{XI}-23 \mathrm{~N}^{\circ} 171$ \\
\hline
\end{tabular}




\begin{tabular}{ll} 
Autor & \multicolumn{1}{c}{ Título } \\
\hline $\begin{array}{l}\text { Coutinho/ José } \\
\text { Caetano da Silva/ }\end{array}$ & $\begin{array}{l}\text { Descripção da Illuminação que Fez } \\
\text { Antonio José da Silva Braga pelo } \\
\text { Nascimento do Serenissimo Principe } \\
4^{\circ} .\end{array}$ \\
& $\begin{array}{l}\text { Despezas Pertencentes a Rainha Nossa } \\
\text { Senhora nos Annos 1822 e 1824 } \\
\text { Fol. }\end{array}$
\end{tabular}

Vol

Localização - Acervo Biblioteca da Ajuda

\begin{tabular}{|c|c|c|c|}
\hline & $\begin{array}{l}\text { Dia /Ao Festivo/ dos Annos de Sua } \\
\text { Magestade Imperial, e Real a Rainha } \\
\text { Nossa Senhora no Anno de } 1826 \\
4^{\circ} \text {. }\end{array}$ & 1 & \\
\hline & $\begin{array}{l}\text { Discurso para se Recitar por hum dos } \\
\text { Membros da Camara da Villa de Mafra } \\
4^{\circ} .\end{array}$ & 1 & \\
\hline & $\begin{array}{l}\text { Disertacion sobre los derechos } \\
\text { eventuales al trono de España de la } \\
\text { Señora Infanta Carlota Juaquina de } \\
\text { Borbón } \\
\text { Cádis. } 1811.4^{\circ} .\end{array}$ & 1 & $54-\mathrm{VI}-14 \mathrm{~N}^{\circ} 46$ \\
\hline & $\begin{array}{l}\text { Diversas Poesias } \\
8^{\circ} \text {. }\end{array}$ & 1 & \\
\hline & $\begin{array}{l}\text { Estillo /Novo/ de Cantar os Reis } \\
\text { Rio de Janeiro. } 1818.4^{\circ} \text {. }\end{array}$ & 1 & $54-\mathrm{XI}-18 \mathrm{~N}^{\circ} 71$ \\
\hline $\begin{array}{l}\text { Estremera/ Juan } \\
\text { Lopes/ }\end{array}$ & $\begin{array}{l}\text { Accion Comica Alegorica en un Acto } \\
\text { Titulada La Féliz Alianza } \\
\text { Sem lugar, nem ano. } 8^{\circ} .\end{array}$ & 1 & $49-I-42 N^{\circ} 23$ \\
\hline
\end{tabular}

Fabulas /As/ que leva o Toucador,

Divididas pelas suas Respectivas Peças

Sem lugar, nem ano. $8^{\circ}$.

Factura de los Acopios que D. ${ }^{n}$ S. ${ }^{n} B{ }^{\text {ta }}$

Ardisson ha hecho en Paris para la Guarda Ropa de S. M. Ia Reyna N. S., y

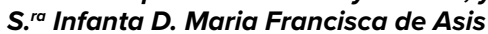

Paris. 1816. $4^{\circ}$. 


\begin{tabular}{|c|c|c|c|}
\hline Autor & Título & Vol & $\begin{array}{l}\text { Localização - Acervo } \\
\text { Biblioteca da Ajuda }\end{array}$ \\
\hline $\begin{array}{l}\text { Estremera/ Juan } \\
\text { Lopes/ }\end{array}$ & $\begin{array}{l}\text { Fausto /II/ e Félice Arrivo al Rio de } \\
\text { Janeiro di S. A. I. e R. [L'Arciduchessa } \\
\text { d'Austria] Carolina Giuseppa } \\
\text { Leopoldina etc } \\
4^{\circ} .\end{array}$ & 1 & $54-X-11 N^{\circ} 25$ \\
\hline $\begin{array}{l}\text { Figueredo/ José Pedro } \\
\text { de/ }\end{array}$ & $\begin{array}{l}\text { Decimas } \\
\text { Fol. }\end{array}$ & 1 & $54-X I-18 N^{0} 75$ \\
\hline $\begin{array}{l}\text { Freitas/ José Antônio } \\
\text { de/ }\end{array}$ & $\begin{array}{l}\text { As Delicias do Campo } \\
\text { Rio de Janeiro. } 1817.4^{\circ} \text {. }\end{array}$ & 1 & 50-I-59 \\
\hline $\begin{array}{l}\text { Freitas/ José Antônio } \\
\text { de/ }\end{array}$ & $\begin{array}{l}\text { Oração em Acção de Graças pela } \\
\text { Chegada de Sua Alteza Real a Capital } \\
\text { do Rio de Janeiro } \\
\text { Rio de Janeiro. } 1815.4^{\circ} .\end{array}$ & 1 & $49-111-39$ No 19 \\
\hline $\begin{array}{l}\text { Freitas/ José Antônio } \\
\text { de/ }\end{array}$ & $\begin{array}{l}\text { Tristissimo Quadro, ou Imagem de } \\
\text { huma Verdadeira Dor no Falecimento } \\
\text { da Senhora Dona Maria I } \\
\text { Rio de Janeiro. } 1816.4^{\circ} .\end{array}$ & 1 & $49-I I I-39 N^{\circ} 4$ \\
\hline Gardner/ Daniel/ & $\begin{array}{l}\text { Primeiro dia de Curso sobre Chymica, } \\
\text { Feita na Pressença de Sua Alteza Real } \\
\text { o Principe Regente Nosso Senhor } \\
4^{\circ} \text {. }\end{array}$ & 1 & \\
\hline \multirow[t]{3}{*}{$\begin{array}{l}\text { Guarany/ El Marques } \\
\text { del/ }\end{array}$} & $\begin{array}{l}\text { Demonstracion a cerca del juramento } \\
\text { exigido por las Cortes á la Reyna de } \\
\text { Portugal, Doña Carlota Joaquina de } \\
\text { Borbón, a que con tanto heroismo } \\
\text { resistio } \\
\text { Lisboa. } 1822.4^{\circ} .\end{array}$ & 1 & $54-X I-16$ No 120 \\
\hline & $\begin{array}{l}\text { Historia da Vida de Maria do Bom- } \\
\text { Successo, natural da Villa de Santarem } \\
\text { Fol. }\end{array}$ & 2 & $49-I V-41 N^{\circ} 42$ \\
\hline & $\begin{array}{l}\text { Incintivos para Aforvorar Coraçõens na } \\
\text { Devoção de Maria Santissima Nossa } \\
\text { Senhora } \\
\text { Sem lugar, nem ano. } 8^{\circ} .\end{array}$ & 1 & \\
\hline $\begin{array}{l}\text { Jardim/ Joaquim } \\
\text { Veríssimo/ }\end{array}$ & $\begin{array}{l}\text { Ode aos Annos da Rainha Nossa } \\
\text { Senhora Dona Carlota Joaquina de } \\
\text { Borbon } \\
4^{\circ} \text {. }\end{array}$ & 1 & \\
\hline
\end{tabular}




\begin{tabular}{ll} 
Autor & \multicolumn{1}{c}{ Título } \\
\hline Jesus Maria/ & $\begin{array}{l}\text { Sonetos A Rainha Nossa Senhora por } \\
\text { não Jurar as Bazes da Constituição }\end{array}$
\end{tabular}

Sem lugar, nem ano. $4^{\circ}$.

Localização - Acervo

Biblioteca da Ajuda

Frei Bento de/

Ode Pindarica

Leitão/ Antônio José

Osório de Pina/

$4^{\circ}$.

1

$50-I-25 N^{\circ} 282$

Lemos/ José

Coelho de/

Ad Serenissimum Lisio Infantem.

Epigramma

Fol.

$1 \quad 54-\mathrm{XI}-18 \mathrm{~N}^{\circ} 69$

Loayza/ José

Martinez de/

Oracion Pronunciada el dia 20 Octubre

de 1812, en la [Parroquia de San

Sebastian]

$1 \quad 54-\mathrm{XI}-18$

$4^{\circ}$.

Lobo/ Roque Ferreira/ Oração Panegyrica a Rainha Nossa

Senhora na sua Nova Exaltação

$4^{\circ}$.

Lopez/ Juan Yglesias/ La Noche. Canto en verso Suelto a la Memoria de la Serenisima Ynfanta

Doña Maria de Braganza

$1 \quad 49-I-58$ NN$^{0} 16$

Sem lugar, nem ano. $8^{\circ}$.

Marrocos/ Luís

As Manhãs da Primavera

Joaquim dos Santos/ Lisboa. 1803. $4^{\circ}$.

$1 \quad 49-I I I-53 N^{\circ} 64$ a 66

Morato/ Frei Francisco Ode Offerecida ao Tenente Coronel

de Santa Ana/

Raimundo Joze Pinheiro Commandante

e Governador do Castello de São João

da Foz do Porto

$1 \quad 49-I I I-53 N^{\circ} 37$

Sem lugar, nem ano. $4^{\circ}$.

Ode a firmeza de caracter da Rainha

a Senhora D. Carlota Joaquina de

Borbon

$1 \quad 54-X-13 N^{\circ} 125$

Fol.

Oliver/ D. José Frego Viage /Al/ á Bayona del Rey Nuestro

de/ Señor Don Fernando VII

Sem lugar, nem ano. $4^{\circ}$.

$1 \quad 54-X-11 N^{\circ} 19$

Papeis Pertencentes a Conducta

de Jose Xavier Mozinho da Silveira

na Occasião da Retirada de Sua

Magestade para Villa Franca

Fol. 


\begin{tabular}{ll} 
Autor & \multicolumn{1}{c}{ Título } \\
\hline $\begin{array}{l}\text { Oliver/ D. José Frego } \\
\text { de/ }\end{array}$ & $\begin{array}{l}\text { Pastoral do Bispo do Rio de Janeiro } \\
\text { Fol. }\end{array}$
\end{tabular}

Vol

Localização - Acervo

Biblioteca da Ajuda

de/

Fol.

1

54-XIII-4

Peças Justificativas, Sentenças,

e mais Papeis Pertencentes ao

Processo Formado por Ordem das

Chamadas Cortes de 1820, contra

- Dezembargador Manoel Gomes

de Mello, Procurador da Real Caza,

e Estado das Senhoras Rainhas de

Portugal

$4^{\circ}$.

Portugal/ José de

Paula de Moraes

Louro de/

\section{Ode a Restauração do Porto}

$4^{\circ}$.

$1 \quad 54-X-12 N^{\circ} 56$

Prôemio ou Dissertação Preliminar

á Historia do Gloriozo São Carlos

Barromêo

1

54-V-16

Sem lugar. 1801. $4^{\circ}$.

\section{Quadras}

$4^{\circ}$.

1

Quadras

Fol.

Quadras para se Cantar por Muzica

$8^{\circ}$.

Reglas Communes de las Hygas de

la Caridad, Syervas de los Pobres

Enfermos

2

Sem lugar, nem local. Fol

Relatorio do Estado da Saude de Sua

Magestade Dona Carlota Joaquina de

Borbon, e Copia das Receitas que se

Aplicarão no Rio de Janeiro

$54-X-28 N^{\circ} 29$

$4^{\circ}$.

\section{Representação Feita a Suas}

Magestades e Altezas por Dom

Christovão Thomas Mascarenhas

Vellasques Sarmento, o Alarcão

$4^{\circ}$. 
Autor

Título

Vol

Localização - Acervo

Biblioteca da Ajuda

Portugal/ José de

Paula de Moraes

Louro de/
Representação Feita a Sua Magestade

a Rainha Nossa Senhora por varios

Officiaes, e mais Pessoas da Cidade

do Porto, depois da Queda da Infame

Constituição de 1820, e Copia do

Relatório Apresentado a EIRei o Senhor

Dom João VI pelo Bispo do Porto, e

outros, na Mesma Epoca

Porto. 1823. $4^{\circ}$.

\section{Requerimento das Fidalgas da Corte}

de Lisboa a Sua Magestade em que

Pedem se Digne ser Fundadoras das

Irmãas da Caridade

Fol.

Ditto Feito por Joaquim Honorio

Henriques de Oliveira á Sua Magestade

com os Documentos Juntos

$4^{\circ}$.

Sá/ Manuel José Maria da Costa e/
Huma Voz sobre a Entrada dos

Regimentos Portuguezes em Lisboa no

Anno de 1814

$8^{\circ}$.

\begin{tabular}{lll}
\hline $\begin{array}{l}\text { Santos/ Antônio Pio } \\
\text { dos/ }\end{array}$ & $\begin{array}{l}\text { Hymno } \\
\text { Fol. }\end{array}$ & 1
\end{tabular}

Sequeira/ João

Henriques de/

Sequeira/ João

Henriques de/

Sequeira/ João

Henriques de/
Banco de Emprestimo sobre Penhores

Sem lugar, nem ano. $4^{\circ}$.
$1 \quad 54-\mathrm{V}-42 \mathrm{~N}^{\circ} 104$

Tratado Geral de Commercio com hum 2

Diccionario Economico de todas as

Fazendas

$1^{\mathrm{a}}, 5^{\mathrm{a}}$

parte

$49-1-48$

\section{1}

Sem lugar, nem ano. $4^{\circ}$.

\section{Sobscripção Voluntaria, para Elevar}

huma Estatua de Bronze, A Sua Alteza

Real, o Principe Nosso Senhor

$1 \quad 54-X-6 N^{\circ} 28$

$4^{\circ}$.

\section{Soneto aos Annos de Sua Alteza Real o}

Senhor Infante $D$. Miguel

$1 \quad 54-X-13 N^{\circ} 73$

Fol.

Spence/ Maria do Livramento/
Deolinda, e Deonel /Novella/

Sem lugar, nem ano. $4^{\circ}$.
1

$50-1-61$

\section{Suplemento ao Diario de Mafra}

$4^{\circ}$. 


\begin{tabular}{|c|c|c|c|}
\hline Autor & Título & Vol & $\begin{array}{l}\text { Localização - Acervo } \\
\text { Biblioteca da Ajuda }\end{array}$ \\
\hline $\begin{array}{l}\text { Vasconcelos/ Antônio } \\
\text { Bandeira Subagoa/ }\end{array}$ & $\begin{array}{l}\text { Ode, ás Chagas de Nosso Redemtor; } \\
\text { Armas de Portugal } \\
4^{\circ} .\end{array}$ & 1 & $54-\mathrm{XI}-17 \mathrm{~N}^{\circ} 132$ \\
\hline $\begin{array}{l}\text { Vieira/ Francisco de } \\
\text { São Dâmaso de Abreu/ }\end{array}$ & $\begin{array}{l}\text { Pastoral } \\
\text { Bahia. 1814. } 4^{\circ} .\end{array}$ & 1 & $54-I V-34 N^{\circ} 10$ \\
\hline $\begin{array}{l}\text { Villas Boas/ José } \\
\text { Joaquim de Oliveira/ }\end{array}$ & $\begin{array}{l}\text { Reprezentação Feita a Sua Alteza Real } \\
\text { A Princeza Nossa Senhora } \\
4^{\circ} .\end{array}$ & 1 & \\
\hline
\end{tabular}

\section{Referências}

ANASTÁCIO, Vanda. Bibliotecas particulares e problemas concretos. In:

ANASTÁCIO, Vanda (org.). Tratar, estudar, disponibilizar: um futuro para as bibliotecas particulares. Lisboa: Banco Espírito Santo, 2013, p. 47-58.

AZEVEDO, Francisca L. Nogueira. Carlota Joaquina: cartas inéditas. Rio de Janeiro: Casa da Palavra, 2008.

BENASSAR, Bartolomé. A cama, o poder e a morte: rainhas e princesas da Europa do Renascimento ao lluminismo. Trad. Maria Dias Correia. Lisboa: Círculo de Leitores, 2009.

CASTRO, Zília Osório de. Bibliotecas femininas (1769-1770) In: A.A. V.V., Congresso O Marquês de Pombal e a sua Época. Atas, Oeiras, Câmara Municipal de Oeiras, 2001, p. 477-484.

Catalogo que foi de S. Mag.de a Imperatriz Rainha e Senhora D. Carlota Joaquina de Bourbon. Lisboa: Biblioteca da Ajuda, 1831.

COSTA, Cristina Maria de Castro Correia Cardoso da. As bibliotecas particulares femininas nos espaços de educação no século XVIII em Portugal: um contributo para o estudo do género. Dissertação de Mestrado, FLUL, Lisboa, 2010.

LISBOA, Luís João; MIRANDA, Tiago dos Reis. A cultura escrita nos espaços privados. In: MATTOSO, José (Org.). História da Vida Privada em Portugal: A Idade Moderna. Lisboa: Círculo de Leitores, 2011, p. 334-394.

. A leitura em Portugal: os finais do Antigo Regime. In: COSTA, Fernando Marques da; DOMINGOS, Francisco Contente; MONTEIRO, Nuno Gonçalo (orgs.). Do Antigo Regime ao Liberalismo 1750-1850. Lisboa: Veja, 1993. 
LOURENÇO, Maria Paula Marçal. Rainhas no Portugal moderno: casa, corte e patrimônio. Lisboa: Edições Colibri, 2012.

MORETTI, Franco. Atlas do romance europeu 1800-1900. São Paulo: Boitempo Editorial, 2003.

NEVES, Lúcia Maria Bastos P. "A biblioteca de Daniel Pedro Müller e as luzes luso-brasileiras". In: XXIV Reunião da Sociedade Brasileira de Pesquisa Histórica, Curitiba, 2004.

PEREIRA, Ana Cristina Duarte Pereira. Princesas e Infantas de Portugal. Lisboa: Edições. Colibri, 2008.

PEREIRA, Sara Marques. D. Carlota Joaquina rainha de Portugal. Lisboa: Livros Horizonte, 2008.

SANTOS, Mariana Machado. Alexandre Herculano e a Biblioteca da Ajuda. Coimbra: Coimbra Editora, 1965.

\section{Notas}

1 A historiadora Sara Marques Pereira, em D. Carlota Joaquina e os espelhos de Clio, foi talvez a primeira pessoa a chamar atenção para a existência de uma livraria particular em posse da rainha Carlota Joaquina. Ainda assim, fez isso de modo bastante sucinto, destacando na ocasião a necessidade de se realizar um estudo sobre o catálogo dessa biblioteca. Desde a década de 1990, quando essa observação foi feita, até hoje, tal estudo ainda não foi realizado.

$2 \mathrm{~A}$ posse de livros por princesas, além de certificar a educação que recebiam, podia ter a finalidade de validálas socialmente, conferindo-Ihes prestígio e reconhecimento, bens simbólicos que Ihes garantiam ocupar lugares de destaque no seio da corte, especialmente durante uma etapa específica da vida: o casamento, possível via de acesso para atingir o posto de rainha, em geral resultado de acordos que se inscreviam "no quadro mais amplo das relações internacionais pautadas pelas uniões dinásticas” (LOURENÇO, 2012, p. 11). Nesse sentido, a biblioteca (corolário da formação da princesa) poderia, a par de conveniências políticas, influir na celebração de uma aliança entre duas monarquias. Com efeito, esse tipo de acervo caracterizavase pela reunião de um patrimônio que promovia estudo, e acima de tudo servia como reflexo do valor das princesas. A formação era pensada, nesses termos, como um dote, que agiria como "um atrativo, um autêntico elemento de sedução" (BENNASSAR, 2009, p. 218).

3 D. Carlota Joaquina foi educada até aos 10 anos de idade na corte do seu avô, o rei Carlos III, símbolo da monarquia ilustrada espanhola. Nesse ambiente, onde reinava o fausto de uma das monarquias mais importantes da Europa à época, recebeu uma instrução primorosa. Ela teve como mestre o padre Felipe Scio, destacado intelectual ilustrado da corte de Carlos III, o que "reforça a diretriz de uma instrução 'ilustrada"' (AZEVEDO, 2008, p 28). Em 1785, ano em que foi enviada para Portugal para se casar com o príncipe D. João, levou consigo o seu preceptor, que continuou a instruíla na corte portuguesa. Mesmo depois de ter concluído o período de formação, manteve ao longo da vida práticas diárias de estudo e leitura, que, "a par das ocupações políticas, a mantinham longas horas ocupada em seu gabinete" (PEREIRA, 2008, p. 31).

4 A possiblidade de o Catálogo da livraria que foi de Sua Majestade a Imperatriz Rainha a Senhora Dona Carlota Joaquina de Bourbon ter sido produzido na Biblioteca da Ajuda não descarta a hipótese de ele ter sido apenas recolhido por essa instituição numa altura em que já estivesse acabado. Quanto à destinação das obras registradas nele, é possível assegurar que parte delas integra atualmente o acervo da Biblioteca 
da Ajuda, conforme apurei durante a realização do projeto de pesquisa de pós-doutorado "Os romances que D. Maria Francisca Benedita (1746-1829) e D. Carlota Joaquina (1775-1830) liam”, ocasião em que localizei nesse acervo livros que apresentavam as mesmas características descritas nesse catálogo e com marcas de posse da rainha D. Carlota Joaquina, como ex-libris e super-libris. A parcela de livros que não foi localizada, considerando a hipótese de ela também ter sido integrada aos fundos da Ajuda, pode ter sofrido algum tipo de extravio, ocorrência que verifiquei na edição de El Ingeniozo Hidalgo Don Quixote de la Mancha (1810), obra que consta no catálogo e é descrita como sendo composta por quatro volumes. Entretanto, encontrei apenas dois, o I e o III. Na contracapa do volume III, foi deixada uma anotação a lápis que explica a ausência dos outros dois. Diz a nota: "esta obra faltão-lhe 2 volumes $\left(2^{\circ}\right.$ e $\left.4^{\circ}\right)$ que vieram de menos do quarto dos Senhores Médicos (em abril de 1885) para onde tinham sido emprestados 2 annos antes". Ou seja, os volumes II e IV foram emprestados e não retornaram ao acervo, indicativo de que os livros circulavam fora do espaço da biblioteca e não eram de uso estrito da família real, o que explica, nesse caso, o extravio. Como qualquer outro acervo, a Biblioteca da Ajuda era, e é, um organismo em permanente mudança. Ao longo dos anos, tem sido não apenas destino de sucessivas remessas de livros, mas também alvo de inúmeras subtrações, ocorridas pelos mais variados motivos: transferência do acervo de um lugar para outro, empréstimos não restituídos, permutas e vendas, desgaste natural das obras e incendidos. Em 1843, Alexandre Herculano, seu encarregado à época, realizou a troca e venda de um lote de títulos duplicados. "A primeira venda foi feita em 6 de Junho de 1843, à Real Biblioteca de Munique, que pagou $237 \$ 480$ réis por 278 volumes". [...] Dos mesmos duplicados em língua portuguesa, espanhola e latina, ficou a Biblioteca Real de Berlim, em 8-III-1844 com 130 livros no valor de $118 \$ 640$ réis" (SANTOS, 1965, p. 25-26). Tal ocorrência permite formular mais uma hipótese para a destinação dos livros não encontrados. Em relação às circunstâncias e ao momento em que as obras pertencentes à rainha Carlota Joaquina foram incorporadas à Biblioteca da Ajuda, ainda pairam incertezas. Na condição de biblioteca real, ela poderia servir como local de armazenamento dessas obras antes mesmo da morte de sua proprietária, cabendoIhe depois desse acontecimento a posse dessa coleção, caso não houvesse outra destinação expressa. Por outro lado, há a hipótese de esses livros terem dado entrada posteriormente, por determinação de D. Miguel, que, além de ser rei nesse período, foi designado testamenteiro de sua mãe, cabendo-lhe a autoridade para decidir sobre o destino dos bens deixados por ela. Vale acrescentar que, nessa mesma época, D. Miguel realizava esforços para recompor a Real Biblioteca da Ajuda, buscando dotá-la novamente de meios para atender às necessidades da família real, já que a maior parte do acervo que antes cumpria essa função ficara no Rio de Janeiro em 1821. Nesse contexto, ele ordenou a incorporação compulsória de diversas bibliotecas particulares à Ajuda e determinou, por alvará de 6 de fevereiro de 1832, que para lá fosse enviado um exemplar de todo escrito impresso em Portugal. Desse modo, parece bastante plausível que ele tenha ordenado a entrada dos livros que pertenceram à sua mãe na Real Biblioteca da Ajuda, atitude inteiramente dentro do seu campo de possibilidades e de acordo com seus interesses.

5 João Luís Lisboa e Thiago Miranda (2011) lembram que um inventário de livros pode estar sujeito aos critérios de organização e avaliação de testamenteiros, o que, não raro, resulta na exclusão de obras cujo valor não é considerado digno de registro. Ao cruzar os títulos desse catálogo com listas de livros que D. Carlota Joaquina comprou (disponíveis no Arquivo Histórico do Museu Imperial de Petrópolis - Rio de Janeiro), constatei que nem todas as obras adquiridas foram inventariadas, como é o caso de Les mille et une nuits e Jean Jacques Rousseau de la Jeunesse.

6 Conferir Zília Osório de Castro (2001); Cristina Maria de Castro Correia Cardoso Costa (2010); João Luís Lisboa (2011); e Vanda Anastácio (2013).

7 Os títulos e as datas das obras referem-se aqui às edições tais como aparecem no catálogo, e não necessariamente ao título e à data de publicação originais.

8 Por romance entende-se aqui um conjunto de narrativas em prosa ficcional, em geral de grande ou média extensão, nomeadas no século XVIII e até certa altura do século XIX como novela, história, conto, memórias, cartas, anedota, viagens e romance.

${ }^{9}$ Sobre essa mudança, conferir João Luís Lisboa (1989).

10 Em Portugal, a educação feminina dos grupos privilegiados era composta sistematicamente, segundo Pereira (2008), pelo ensino de princípios religiosos, leitura e escrita, aritmética prática, conhecimentos básicos de farmacopeia e jurisprudência, disciplinas que deveriam ser complementadas por outras matérias 
de estudo, como literatura, história, latim, geografia, filosofia, música, pintura, dança, a par dos trabalhos de costura. Esse programa foi defendido por Claude Fleury, em Traité sur le choix et la méthode des études, e por Fénelon no seu livro dedicado à educação feminina, De l'éducation des filles (1687). A metodologia desse programa preconizava, em primeiro lugar, ler, escrever, coser, bordar e rezar, e depois o estudo da filosofia, geografia, história, línguas, música, dança e pintura. A aprendizagem da leitura tinha por base obras de espiritualidade, que tinham a função de incutir nas princesas os valores necessários para que se tornassem boas mulheres, e textos clássicos greco-latinos, que eram usados para apresentar exemplos da história e o modelo político romano, habitual fonte das monarquias europeias durante o Antigo Regime. Pereira (2008) sublinha que, no caso específico das princesas, a história era uma disciplina central, ao lado da geografia, dos costumes de outras partes do mundo e do ensino de línguas estrangeiras, conhecimentos fundamentais para que elas pudessem se tornar rainhas em outros reinos. Esse programa é ilustrativo da educação recebida pela princesa D. Maria Bárbara de Bragança (1711-1756) e se reflete na constituição de sua biblioteca, composta por 577 obras, entre as quais Pereira (2008) identificou as seguintes categorias: religião (que possui maior peso), história e geografia (com presença expressiva), literatura (fábulas de La Fontaine e de Esopo), teatro, música, línguas, medicina, matemática, direito, economia, além de desenhos e estampas. Apesar de ter nascido em uma geração diferente, D. Carlota Joaquina foi submetida a currículo muito parecido ao aplicado à formação de D. Maria Bárbara de Bragança, o que nos autoriza a tomá-lo como parâmetro de comparação. A julgar pelas avaliações que D. Carlota Joaquina realizou durante o período de formação registradas pela Gazeta de Lisboa, sabe-se que ela estudou estas disciplinas: religião, história (sagrada e profana), geografia, gramática, línguas (latim, castelhano, português e francês).

${ }^{11}$ A extrapolação ao perfil especializado da biblioteca principesca aqui referida também pode ser efeito direto das dimensões da biblioteca da rainha $D$. Carlota Joaquina, que era grande o bastante para não se fixar apenas em um conteúdo padronizado. Em geral, acervos grandes tendem a ser menos canônicos, como nota Franco Moretti (2003).

Moizeis Sobreira de SOUSA. Pós-doutorando do Departamento de Teoria Literária do Instituto de Estudos da Linguagem da Universidade Estadual de Campinas (UNICAMP), Campinas, SP, Brasil.

Declaração de Financiamento. Este trabalho integra o projeto de pesquisa intitulado "A presença de romances em bibliotecas femininas da família real portuguesa", financiado pela FAPESP, 2014/23370-0.

Recebido em: 28/12/2017

Aprovado em: 10/04/2018 